\title{
Fetal lung underdevelopment is rescued by administration of amniotic fluid stem cell extracellular vesicles in rodents
}

Article

Accepted Version

Antounians, L., Catania, V. D., Montalva, L., Liu, B. D., Hou, H., Chan, C., Matie, A. C., Tzabetakis, A., Li, B., Figueira, R.

L., da Costa, K. M., Wong, A. P., Mitchell, R., David, A. L., Patel, K., de Coppi, P., Sbragia, L., Wilson, M. D., Rossant, J. and Zani, A. (2021) Fetal lung underdevelopment is rescued by administration of amniotic fluid stem cell extracellular vesicles in rodents. Science Translational Medicine, 13 (590). eaax5941. ISSN 1946-6234 doi:

https://doi.org/10.1126/scitranslmed.aax5941 Available at https://centaur.reading.ac.uk/93652/

It is advisable to refer to the publisher's version if you intend to cite from the work. See Guidance on citing.

To link to this article DOI: http://dx.doi.org/10.1126/scitransImed.aax5941

Publisher: American Association for the Advancement of Science

All outputs in CentAUR are protected by Intellectual Property Rights law, including copyright law. Copyright and IPR is retained by the creators or other copyright holders. Terms and conditions for use of this material are defined in the End User Agreement. 


\section{www.reading.ac.uk/centaur}

\section{CentAUR}

Central Archive at the University of Reading

Reading's research outputs online 


\section{Fetal lung underdevelopment is rescued}

\section{by amniotic fluid stem cell extracellular vesicles}

Lina Antounians ${ }^{1,2}$, Vincenzo D. Catania ${ }^{1,2}$, Louise Montalva ${ }^{1,2}$, Benjamin D. Liu ${ }^{1,2}$, Huayun $\mathrm{Hou}^{3,4}$, Cadia Chan ${ }^{3,4}$, Andreea C. Matei ${ }^{1,2}$, Areti Tzanetakis ${ }^{1,2}$, Bo Li $i^{2,5}$, Rebeca L. Figueira ${ }^{6}$, Karina M. da Costa ${ }^{6}$, Amy P. Wong ${ }^{1}$, Robert Mitchell ${ }^{7}$, Anna L. David ${ }^{8,9}$, Ketan Patel ${ }^{7,10}$, Paolo De Coppi $^{11,12}$, Lourenço Sbragia ${ }^{6}$, Michael D. Wilson ${ }^{3,4}$, Janet Rossant ${ }^{1,4}$, Augusto Zani ${ }^{1,2, *}$

${ }^{1}$ Developmental and Stem Cell Biology Program, Peter Gilgan Centre for Research and Learning, The Hospital for Sick Children, Toronto, M5G 0A4, Canada.

${ }^{2}$ Division of General and Thoracic Surgery, The Hospital for Sick Children, Toronto, M5G 1X8, Canada.

${ }^{3}$ Genetics and Genome Biology Program, Peter Gilgan Centre for Research and Learning, The Hospital for Sick Children, Toronto, M5G 0A4, Canada.

${ }^{4}$ Department of Molecular Genetics, University of Toronto, Toronto, M5S 1A8, Canada.

${ }^{5}$ Translational Medicine Program, Peter Gilgan Centre for Research and Learning, The Hospital for Sick Children, Toronto, M5G 0A4, Canada.

${ }^{6}$ Laboratory of Experimental Fetal and Neonatal Surgery, Division of Pediatric Surgery, Ribeirão Preto Medical School, University of São Paulo, Ribeirão Preto, São Paolo, 14049-900, Brazil.

${ }^{7}$ School of Biological Sciences, University of Reading, Reading, RG6 6AS, UK.

${ }^{8}$ Institute for Women's Health, University College London, London, WC1E 6HU, UK.

${ }^{9}$ NIHR University College London Hospitals Biomedical Research Centre, London, W1T 7HA, UK

${ }^{10}$ FRIAS Freiburg Institute for Advanced Studies, University of Freiburg, Freiburg, 79104, Germany.

${ }^{11}$ Stem Cell and Regenerative Medicine Section, Great Ormond Street Institute of Child Health, University College of London, London, WC1N 1EH, UK.

${ }^{12}$ NIHR Biomedical Research Centre and Specialist Neonatal and Paediatric Unit, Great Ormond Street Hospital, London, WC1N 1EH, UK.

*To whom correspondence should be addressed: augusto.zani@sickkids.ca

One Sentence Summary: Fetal lung regeneration via administration of extracellular vesicles derived from amniotic fluid stem cells 


\begin{abstract}
Fetal lung underdevelopment, also known as pulmonary hypoplasia, is characterized by decreased lung growth and maturation. The most common birth defect found in babies with pulmonary hypoplasia is congenital diaphragmatic hernia (CDH). Despite research and clinical advances, $\mathrm{CDH}$ babies still have high morbidity and mortality rates, which are directly related to the severity of lung underdevelopment. To date, there is no effective treatment that promotes fetal lung growth and maturation. Herein, we describe a stem cell-based approach that enhances fetal lung development via the administration of extracellular vesicles (EVs) derived from amniotic fluid stem cells (AFSCs). Using fetal rodent models of pulmonary hypoplasia (primary epithelial cells, organoids, explants, and in vivo), we demonstrated that AFSC-EV administration promotes branching morphogenesis and alveolarization, rescues tissue homeostasis, and stimulates epithelial cell and fibroblast differentiation. We confirmed this regenerative ability in human models of lung injury, where human AFSC-EVs obtained following good manufacturing practices restored pulmonary epithelial homeostasis. Investigating EV mechanism of action by tracking AFSC-EV cargo transfer, profiling EV protein and RNA content, and sequencing target lung epithelial cells, we found that AFSC-EV beneficial effects were exerted via the release of RNA cargo. Particularly, miRNAs that regulate the expression of genes involved in lung development, such as the miR17 92 cluster and its paralogues, were highly enriched in AFSCEVs and were increased in AFSC-EV-treated primary lung epithelial cells compared to untreated cells. Our findings suggest that AFSC-EVs hold regenerative ability for underdeveloped fetal lungs, demonstrating potential for therapeutic application in patients with pulmonary hypoplasia.
\end{abstract}




\section{Introduction}

Fetal lung development is a crucial step during embryogenesis, which if disrupted leads to a condition called pulmonary hypoplasia. Hypoplastic lungs have fewer bronchiolar divisions, enlarged airspaces, defective alveolarization, and impaired tissue maturation (1). Pulmonary hypoplasia is idiopathic or secondary to associated malformations, the most common of which is congenital diaphragmatic hernia $(\mathrm{CDH})(1,2) . \mathrm{CDH}$ is a birth defect characterized by an incomplete closure of the diaphragm and herniation of intra-abdominal organs into the chest $(1$, 2). Pulmonary hypoplasia secondary to $\mathrm{CDH}$ has a mortality rate of $40 \%$ with most babies dying within the first days of life (3), and with $60 \%$ of survivors suffering from long-term morbidities $(4,5)$. There is an unmet clinical need for an effective treatment that rescues lung growth and maturation, but none of the therapies tested to date has been successful ( 6 ). As pulmonary hypoplasia can be diagnosed as early as at the anatomy scan (18-20 weeks of gestational age), the paradigm of treatment in the last decades has focused on promoting lung growth and maturation before birth $(6)$.

Lung development is a complex process regulated by a network of signaling molecules. Particularly, some miRNAs control branching morphogenesis and epithelial and mesenchymal differentiation (7-9), and are missing or dysregulated in human and animal hypoplastic lungs (10-13). Correcting the dysregulated network of signaling molecules would be beneficial to promote lung regeneration in fetuses with pulmonary hypoplasia.

A promising strategy to deliver a heterogeneous population of small RNA species is by administering extracellular vesicles (EVs) (14-16). EVs are biological membrane-bound nanoparticles carrying genetic material and bioactive proteins as cargo (17-19). EVs are key mediators of stem cell paracrine signaling and promote tissue maturation and regeneration (20- 
22). Amniotic fluid stem cells (AFSCs) could be the ideal source of EVs to promote lung regeneration as AFSCs integrate and differentiate into epithelial lung lineages (23), reduce lung fibrosis (24), repair damaged alveolar epithelial cells (25), and promote lung growth in a model of pulmonary hypoplasia secondary to $\mathrm{CDH}(26,27)$. AFSCs confer regenerative ability despite low engraftment rates, thus suggesting a paracrine effect (26-28), which could be partly mediated by EVs. Recently, AFSC-EVs have been reported to hold regenerative potential in several animal models, including lung, kidney, and muscle injury (29).

In the present study, we investigated whether AFSC-EV administration to various models of pulmonary hypoplasia could promote growth and maturation of underdeveloped fetal lungs.

\section{Results}

Rat AFSC-EV administration promotes growth and maturation in fetal hypoplastic lungs

The most robust model of pulmonary hypoplasia relies on nitrofen administration to pregnant rats at embryonic day (E) $9.5(30,31)$, which mainly targets retinoic acid synthesis (32). In this model, the whole litter has a degree of lung underdevelopment analogous to that of human fetuses (2, 30-33). In utero nitrofen exposure results in fewer bronchiolar divisions and airspaces compared to lungs from uninjured fetuses (Fig. 1, A to C) (30). Administration of rat AFSC-EVs (rAFSC-EVs, mean size $140 \pm 5 \mathrm{~nm}$ ) to hypoplastic lung explants harvested during the pseudoglandular stage (E14.5) resulted in improved branching morphogenesis (Fig. 1, A to C, fig. S1). Particularly, rAFSC-EV-treated lung explants had increased bud count and surface area compared to untreated hypoplastic lung explants and similar to control. This effect was specifically due to rAFSC-EVs, as administration of rAFSC conditioned medium (CM) or EVdepleted rAFSC-CM did not rescue impaired terminal branching. As larger rAFSC-EVs $(363 \pm 17$ $\mathrm{nm}$ ) did not rescue branching morphogenesis (fig. S1F), in all experiments performed hereafter 
we used small rAFSC-EVs $(140 \pm 5 \mathrm{~nm})$. We also tested whether the effects obtained with rAFSC-EVs could be replicated by another EV source, namely mesenchymal stromal cells (MSCs). There is growing evidence that MSC-EVs ameliorate bronchopulmonary dysplasia (BPD) (34), a neonatal lung condition similar to pulmonary hypoplasia secondary to CDH. However, rMSC-EV administration to hypoplastic lung explants did not rescue branching morphogenesis (Fig. 1, A to C, fig. S1). Moreover, rAFSC-EVs did not affect branching morphogenesis in uninjured control lungs (fig. S2, A and B). Investigating pathways responsible for branching morphogenesis, we observed that compared to control, hypoplastic lungs had lower expression of Fgf10, Vegf $\alpha$ and receptors (Flt1, Kdr), which were increased upon rAFSCEV administration (Fig. 1D) (35, 36).

Along with compromised fetal lung growth, pulmonary hypoplasia is characterized by impaired maturation, a feature replicated with in utero nitrofen exposure $(2,30)$. Hypoplastic lungs have decreased cell proliferation and delayed epithelial cell differentiation, as demonstrated by increased density of distal progenitor cells $\left(\mathrm{SOX}^{+}\right)$and reduced surfactant protein $\mathrm{C}$ (SPC) expression (Fig. 1, E to L, fig. S3, A and B) (32, 37, 38). rAFSC-EV administration rescued cell proliferation and improved epithelial cell differentiation, as evidenced by lower $\mathrm{SOX} 9^{+}$cell density (Fig 1, E and F) and increased SPC expression (Fig. 1, E to L). As reported, hypoplastic lungs had similar degree of apoptosis compared to control, and rAFSC-EV administration did not alter this phenotype (Fig. 1, M and N, fig. S3C) $(33,39)$.

rAFSC-EV administration rescues homeostasis and stimulates differentiation of lung epithelial cells

A hallmark of pulmonary hypoplasia secondary to $\mathrm{CDH}$ is impaired respiratory epithelial homeostasis $(2,40)$. rAFSC-EV administration to primary lung epithelial cells isolated from 
hypoplastic lungs of nitrofen-injured fetuses increased proliferation and reduced cell death back to control (Fig. 2, A and B). We confirmed that these effects were specific to rAFSC-EVs, as they were not reproduced by the administration of either rAFSC-CM, or EV-depleted rAFSCCM. Interestingly, rMSC-EVs improved proliferation of primary lung epithelial cells, but failed to rescue cell death (fig. S3, D and E). We also observed that rAFSC-EV administration to uninjured control cells did not change proliferation or cell death rates (fig. S2, C and D).

To study rAFSC-EV effects on respiratory epithelial cell differentiation, we generated fetal lung organoids from nitrofen-injured and control lungs (Fig. 2C, fig. S3F). rAFSC-EV administration to nitrofen-injured organoids had proliferation rates similar to control organoids and higher than untreated nitrofen-injured organoids (Fig. 2D, fig. S3G). Moreover, rAFSC-EV administration improved respiratory epithelial differentiation, with higher SPC (marker of early distal epithelium and alveolar type II cells) and CC10 (marker of club cells) expression (Fig. 2, E and F, fig. S3, H and I).

rAFSC-EV cargo content and its effect on lung epithelium

rAFSC-EV effects on nitrofen-injured hypoplastic lungs and respiratory epithelium were associated with transfer of EV cargo, detected throughout the lung parenchyma (Movie S1) and primary lung epithelial cells (Fig. 3, A and B; Movie S2, S3). To study the cargo content, we differentially analyzed rAFSC-EV and rMSC-EV protein and RNA, as we had observed different effects between the two EV sources. Proteomics analysis identified 222 differentially expressed proteins, none of which had obvious molecular functions directly related to fetal lung development (fig. S4A). rAFSC-EVs contained proteins involved in EV formation (HSPa and CD63), miRNA stabilization (Annexins and Hnrnps), and EV structure and function (table S1). 
To test whether rAFSC-EV effects were due to their RNA cargo, we treated rAFSC-EVs with RNase-A. We verified that RNase-A was captured by rAFSC-EVs and degraded their RNA cargo (Fig. 3, C to I). RNase-pretreated rAFSC-EVs administered to hypoplastic lung explants or primary epithelial cells derived from hypoplastic lungs did not rescue branching morphogenesis or epithelial homeostasis (Fig. 3, J to M). We confirmed that these effects were not due to carryover of RNase-A to the epithelial cells (fig. S4B). Taken together, these data suggested that the rAFSC-EV RNA was key for their biological effects on fetal lung development. With RNAsequencing we found that both rAFSC-EV and rMSC-EV cargos contained mRNA, tRNA, miRNA, and piRNA (Fig. 3N, fig. S4C). Among all, miRNAs were the RNA species most proportionally different between rAFSC-EV and rMSC-EV cargos. Compared to rMSC-EVs, rAFSC-EVs were enriched for miRNAs critical for lung development, such as the miR17 92 cluster and paralogues (miRs-93, -106, -250, -363; fold enrichment range: $5.1-9.36$; table S2, Fig. 3O). Moreover, rAFSC-EVs contained miRNAs that were reported to be dysregulated in hypoplastic lungs, such as miR-33 and miR-200 (table S3) $(10,12)$.

To identify the regulatory pathways affected by rAFSC-EVs, we used mRNA-sequencing to compare gene expression between primary lung epithelial cells from nitrofen-injured lungs treated with rAFSC-EVs or rMSC-EVs. Nitrofen-injury altered the gene expression profile of primary lung epithelial cells compared to uninjured epithelial cells (fig. S4D). Gene set enrichment analysis showed that $\mathrm{AAFSC}-\mathrm{EV}$ administration to nitrofen-injured primary epithelial cells altered the expression of genes related to epithelial differentiation and homeostasis maintenance, whereas rMSC-EV administration altered the expression of genes involved with cell cycle regulation and nuclear organization (Fig. 4, A and B, fig. S5, A and B). Furthermore, we manually queried these genes and identified those that are critical for lung development (table 
S4). We then asked if the miRNAs identified in the rAFSC-EV cargo were part of predicted regulatory networks with the mRNAs that were down-regulated in the target epithelial cells (Fig. 4C). The network that resulted from this analysis showed that there were genes important for lung development and that were regulated by miR17 92 cluster and paralogues. Small RNAsequencing of nitrofen-injured rAFSC-EV-treated primary epithelial lung cells showed that most miRNAs in the network had higher expression compared to nitrofen-injured untreated cells (Fig. 4C). Lastly, we correlated the miRNA cargo content with the miRNA target cell content, and their validated mRNAs in the target cells (fig. S6). This triple analysis identified miRNAmRNAs pairs that might be responsible for the phenotype observed and provided indirect evidence that the rAFSC-EV miRNA cargo was transferred to the target cells.

\section{Towards clinical translation of AFSC-EVS as treatment for fetal lung regeneration}

To test the effects of rAFSC-EVs in vivo, we used a surgical model of pulmonary hypoplasia secondary to $\mathrm{CDH}$ in fetal rabbits, as it allowed us to topically deliver our treatment (Fig. 5A) (41). To prevent rAFSC-EV egression, we performed tracheal occlusion on rabbit fetuses (Movie S4), a procedure currently used in clinical trials for selected CDH human fetuses (42). rAFSCEV administration improved lung alveolarization by increasing the number of alveoli, decreasing the alveolar wall thickness, and promoting alveolar lipofibroblast maturation (Fig. 5, B to E). Moreover, only rAFSC-EV-treated lungs had improved BMP signaling (BMP2, BMP4, Id1), important for alveolar maturation (Fig. 5F). These effects were not observed in rMSC-EV-treated lungs (fig. S5, C to E).

To investigate whether rAFSC-EV beneficial effects could be translated onto human lung tissue, we obtained human AFSCs (hAFSCs) from donated amniotic fluid following clinically compliant good manufacturing practices (GMP), as reported (22). hAFSC-EV administration 
replicated similar effects on cellular homeostasis observed in rat models on both a validated model of lung injury with nitrofen-injured human alveolar epithelial (A549) cells and on nitrofen-injured primary human pulmonary alveolar epithelial cells (HPAEpiC) isolated from a fetus at 21 weeks of gestation (Fig. 5, G to J). We verified that fluorescently labeled $\mathrm{PKH} 26^{+}$ hAFSC-EVs entered A549 cells and HPAEpiC (Fig. 5, K and L). Administration of human MSC-EVs (hMSC-EVs) to HPAEpiC did not rescue cell homeostasis, despite entering the cells (fig. S7, A to C). Lastly, when we tested hAFSC-EVs on the in vivo rabbit model, we found similar effects on alveolar wall thickness, as found with rAFSC-EV administration (fig. S7, D to F).

\section{Discussion}

In this study, we have shown that AFSC-EV administration to various models of pulmonary hypoplasia promotes fetal lung regeneration. Specifically, AFSC-EVs administered to fetal hypoplastic lungs rescued branching morphogenesis and alveolarization, promoted epithelial and mesenchymal tissue maturation, and re-established cellular homeostasis (Fig. 6). These beneficial effects were obtained through AFSC-EV RNA cargo, including miRNAs that regulate lung development.

EVs are emerging as a successful strategy to promote tissue regeneration in various models. The regenerative potential observed in our models of fetal pulmonary hypoplasia has been reported in other models of tissue regeneration using either AFSC-EVs (29) or EVs from other stem cell sources $(14-16,20,43,44)$. In fact, there is increasing evidence that EVs secreted by stem cells carry cargo that stimulates stem cell-like paracrine functions on target cells such as renewal, differentiation, and maturation (45-47). In this study, we confirmed that rAFSC-EVs have similar effects on hypoplastic lung explants and lung epithelium to that exerted by their parent 
cells, rAFSCs (fig. S8, A to D). For this reason and their immunological innocuity, EVs are an advantageous and safer cell-free alternative to stem cell-based therapies (48-50). Although GMPgrade CM could be therapeutic in humans (51-53), in our study the EV fraction of the CM was more potent than the whole $\mathrm{CM}$ or than the EV-depleted CM fraction, as also observed by others $(54,55)$. This could be due to EVs carrying active molecules that are more concentrated than in parent cells (fig. S8E). This is in line with our previous findings that AFSC-EV concentration is the most important parameter responsible for their regenerative potential (29). Likewise, in the present study, we have shown that rAFSC-EV effects are dependent on the concentration of EVs isolated from CM, as well as on the size of the vesicles that enter target cells (fig. S1, D to G, Movie S2, S3, and S5). How size contributes to biological function of EVs remains unknown (56). Nonetheless, small EVs, also called exosomes (17), have traditionally been considered the EV subpopulation with more potent, protective, and pathological functions than larger vesicles, and therefore with more potential as diagnostic or therapeutic tools (29).

We used MSCs as an alternative EV source, since MSCs are being tested in several clinical trials for BPD treatment (57), the lung condition that is most comparable to pulmonary hypoplasia. In our study, MSC-EV administration to pulmonary hypoplasia models did not have similar beneficial effects as AFSC-EV administration, despite entering primary lung cells (fig. S2, S3, Movie S6). The different effects obtained with the two EV populations may be due to differences in disease pathogenesis, where pulmonary hypoplasia is mainly the result of abnormal and delayed lung development, and BPD is a chronic postnatal lung disease with severe inflammatory response (58). Moreover, our analysis of the EV cargo identified profile differences between the two EV populations, which could explain the outcome differences observed. 
In our models of pulmonary hypoplasia, we identified that rAFSC-EV RNA cargo was key to regenerate hypoplastic fetal lungs. This finding is in line with reports that EV-mediated effects occur through RNA transfer (14-17). When considering the rAFSC-EV specific genes in the context of miRNA cargo enriched in rAFSC-EVs, we found miRNA species important for the phenotypes observed, including branching morphogenesis, alveolarization, cell homeostasis and differentiation (table S2). Specifically, a family of miRNAs that is enriched in rAFSC-EVs compared to rMSC-EVs is the miRNA 17 92 cluster. This cluster is essential for lung branching morphogenesis (59), and when knocked out causes severe fetal pulmonary hypoplasia, making this a candidate mechanism that warrants further investigation (9). Moreover, small RNA sequencing analysis revealed that members of this cluster were up-regulated in rAFSC-EVtreated nitrofen-injured primary lung epithelial cells (fig. S8F).

Improved fetal lung development was observed not just when the same species of AFSC-EVs was administered on the same species of target cells (i.e. rAFSC-EVs on rat lung tissue or hAFSC-EVs on human lung epithelial cells), but also when we tested rAFSC-EVs or hAFSCEVs on the in vivo rabbit model (Fig. 5, A to F, fig. S7, D to F). We speculate that the improvement in alveolarization observed in rabbit fetuses is because some miRNAs and their targets are conserved across species (60). For instance, from the top 50 miRNAs that were enriched in hAFSC-EVs, 13 were evolutionarily conserved between human and rabbit species, including one member of the miR17 92 cluster member (table S5).

Our study provides insights into the potential use of AFSC-EVs as a therapy for fetal pulmonary hypoplasia. Using GMP-grade hAFSC-EVs, we have confirmed similar beneficial effects on damaged epithelial cells derived from a fetal lung at the gestational age when pulmonary hypoplasia and $\mathrm{CDH}$ are typically detected. Further steps are needed for AFSC-EVs to be used 
as a therapy in human fetuses, such as identifying the most effective and safest administration route. In this study, we employed topical administration via intra-tracheal injection in rabbit fetuses. This route could be further explored, also in clinical settings, as it is currently used to occlude the trachea of human fetuses with severe pulmonary hypoplasia secondary to $\mathrm{CDH}$ (42).

We acknowledge that our study has some limitations. Our findings are mainly based on the use of animal models and human lung epithelial cells to study a complex human condition with an unknown etiology. However, obtaining human lung tissues from babies with pulmonary hypoplasia is not considered ethically acceptable nor has it been reported. Moreover, in this study we mainly focused on fetal lung epithelium and mesenchyme, but we did not examine other lung compartments such as pulmonary vasculature, which is known to undergo remodeling in hypoplastic lungs. Nonetheless, we observed improvements in pathways important for lung vascular development, such as VEGF and FGF10 that suggest the opportunity for further studies. Another limitation is that little is known about factors that alter lung development and the mechanisms that are dysregulated in pulmonary hypoplasia. Similarly, it remains unknown how exactly the EV RNA cargo species function. It is hoped that our transcriptomic profiling of both hypoplastic lungs and EVs increases the understanding on the pathogenesis of pulmonary hypoplasia and on EV function. 


\section{Materials and Methods}

\section{Study Design}

This study aimed to evaluate the ability of AFSC-EV administration to promote fetal lung growth and maturation in pulmonary hypoplasia. As obtaining human lung tissues from babies with $\mathrm{CDH}$ is not considered ethically acceptable, part of this study was conducted using animal models that closely resemble the degree of pulmonary hypoplasia observed in human fetuses. To advance towards a translational therapy, we obtained EVs from GMP-grade hAFSCs isolated from donated amniotic fluid during amniocentesis. We tested hAFSC-EVs first on a validated lung injury model using A549 alveolar epithelial cells $(29,61)$. To more closely replicate human fetal pulmonary hypoplasia, we investigated the GMP-grade hAFSC-EV effects on nitrofeninjured human pulmonary alveolar epithelial cells obtained from a healthy fetus at 21-weeks of gestation. Experimental models and sample collections were approved by appropriate regulatory committees at: The Hospital for Sick Children, Toronto (protocol \#39168 and 49892); University College London Hospital, London, UK (UCL/UCLH Joint Committee for the Ethics of Human Research, REC Reference: 08/0304); Ribeirão Preto Medical School, University of São Paulo, Brazil (191/2018+40/2020). Sprague-Dawley rats and New Zealand rabbits were used for animal studies. Samples from all models were randomly assigned to treatment groups. All data including outliers are shown, and all experiments were performed in at least triplicate, with the number of replicates indicated in the figure legends. Analysis of data was conducted by at least two blinded investigators. Additional details on methods used are provided in Supplementary Materials.

\section{Extracellular vesicles}

EVs from rat and human AFSCs or bone-marrow MSCs were isolated by ultracentrifugation from CM of cells treated with exosome-depleted fetal bovine serum for 18 hours, as described 
(29). Based on previous studies, we established that $4 \times 10^{6}$ AFSCs cultured under these conditions secrete approximately $3 \times 10^{9} \pm 1 \times 10^{7} \mathrm{EVs}$, quantified by nanoparticle tracking analysis (29). For all experiments, EV doses are described as $\mathrm{v} / \mathrm{v}$ (EV volume in CM volume). In accordance with the International Society for Extracellular Vesicles guidelines, EVs were characterized for size (nanoparticle tracking analysis), morphology (transmission electron microscopy), and expression of canonical EV-related protein markers (Western blot analysis), as described (29). To track EV migration into primary lung epithelial cells and lung explants, EV cargoes were fluorescently labelled for RNA and protein using Exo-Glow ${ }^{\mathrm{TM}}$ and for lipid membrane using PKH26. To determine the role of RNA in rescuing pulmonary hypoplasia, RNase enzymatic digestion of rAFSC-EV cargo was conducted and confirmed by bioanalyzer and immuno-electron microscopy.

Experimental models of pulmonary hypoplasia

Ex vivo - In fetal rats, pulmonary hypoplasia was induced as described $(30,40)$ with nitrofen administration to dams $(100 \mathrm{mg})$ by oral gavage on E9.5. At E14.5, the dam was euthanized, and fetal lungs were micro-dissected. Lungs were grown on nanofilter membranes, and incubated for $72 \mathrm{~h}$ in culture medium alone, rAFSC-CM, or medium supplemented with rAFSC-EVs or rMSCEVs $(0.5 \% \mathrm{v} / \mathrm{v})$. Fetal lungs from dams that received olive oil (no nitrofen) at E9.5 served as control.

In vitro - 1) For primary epithelial cell experiments in rats, a single cell suspension was obtained at E14.5 from pooled lungs of control or nitrofen-injured rat fetuses by trypsinization. Cells were subjected to serial fibroblast depletions as described $(40,62)$. 2) For organoid studies, cells were seeded in a ratio of 60:40 semi-solid Matrigel to medium, as described (63). Cells from nitrofeninjured fetuses were cultured for 10 days with medium alone or medium supplemented with 
rAFSC-EVs or rMSC-EVs $(1.2 \% \mathrm{v} / \mathrm{v})$. Lung organoids from fetuses whose mothers had not received nitrofen served as control. 3) A549 cells were treated for $24 \mathrm{~h}$ with nitrofen (40 $\mu \mathrm{M})$, and treated with medium alone, or medium supplemented with hAFSC-EVs or hMSC-EVs $(0.5 \% \mathrm{v} / \mathrm{v})$. Uninjured and untreated A549 cells served as control. 4) HPAEpiCs were obtained from the lung of a 21-week-gestation fetus and used at first passage. Cells were injured with 400 $\mu \mathrm{M}$ nitrofen for 24 hours, and treated with medium alone, or medium supplemented with hAFSC-EVs or hMSC-EVs $(0.5 \% \mathrm{v} / \mathrm{v})$.

In vivo - Pulmonary hypoplasia was induced by surgical creation of $\mathrm{CDH}$ at E25 in New Zealand rabbits (41). At E27, tracheal ligation was performed alone or after intra-tracheal administration of a $50 \mu \mathrm{L}$ bolus containing rAFSC-EVs, rMSC-EVs, or hAFSC-EVs (Movie S4). Lungs were harvested at E31 and frozen for RNA extraction or fixed in 4\% paraformaldehyde and embedded in paraffin.

\section{Outcome measures}

For lung morphometry, rat fetal lung explants were imaged by differential interference contrast microscopy and independently assessed by two blinded researchers for terminal bud density and surface area using ImageJ, as described (27). Rabbit fetal lungs were blindly evaluated with histology (hematoxylin/eosin) to assess alveolar density and wall thickness, as described (64, 65). For RNA expression, factors involved in rat or rabbit lung branching morphogenesis were assessed with quantitative polymerase chain reaction (qPCR). To investigate cellular homeostasis on lung explants and organoids, we used 5-ethynyl-2'-deoxyuridine (EdU) incorporation, viability/cytotoxicity staining, terminal deoxynucleotidyl transferase dUTP nick end labeling (TUNEL assay), or $\mathrm{Ki} 7^{+}$immunostaining. To assess epithelial differentiation, lung explants were immunostained and blotted for SOX9 and SPC, and organoids were 
immunostained for SPC and CC10. To study rat EV protein cargo, we used nanoscale liquid chromatography coupled to tandem mass spectrometry and performed differential expression analysis ( $1 \%$ protein and peptide false discovery rate, FDR). For rat EV RNA cargo, we conducted small RNA-sequencing and compared RNA content using Bioconductor DESeq. To study rAFSC-EV RNA effects on target cells, total RNA was isolated from primary lung epithelial cells from each condition and used edgeR for comparative analyses. To study changes in miRNA expression patterns in the same target cells, we further analyzed the Nitrofen and Nitrofen+rAFSC-EVs treated cells using small RNA-sequencing. edgeR was used to determine miRNA expression changes (FDR $<0.1$ ), and Spearman's correlation was used to assess potential gene targets of detected miRNAs in cells. Pathway enrichment analysis was conducted with g:profiler and miRNA-mRNA network analysis was performed with TargetScan, miRTarBase, and Cytoscape.

\section{Statistical Analysis}

Groups were compared using two-tailed Student t-test, Mann-Whitney test, one-way ANOVA (Tukey post-test), or Kruskal-Wallis (post-hoc Dunn's nonparametric comparison) test according to Gaussian distribution assessed by D'Agostino-Pearson omnibus normality test. For correlation studies, a Pearson coefficient was reported as $\mathrm{r}$ (confidence interval). $\mathrm{P}$ value was considered significant when $\mathrm{p}<0.05$. All statistical analyses were produced using GraphPad Prism ${ }^{\circledR}$ software version 6.0. mRNA and miRNA sequencing analyses in lung epithelial cells were performed in R (version 3.6.0). Package "edgeR" (version 3.26.5) was used for differential analyses between two conditions with FDR $<0.1$ considered as significant for both mRNA and small RNA-sequencing. 


\section{Supplementary Materials}

Fig. S1. Characterization of rAFSC-EVs and rMSC-EVs and effects on lung explants based on size and concentration.

Fig. S2. Effects of rAFSC-EVs on control lung explants and primary lung epithelial cells.

Fig. S3. Effects of rMSC-EV administration on in vitro and ex vivo models of pulmonary hypoplasia.

Fig. S4. Analysis of protein and RNA cargo of rAFSC-EV and rMSC-EV.

Fig. S5. Enrichment plots for RNA-seq analysis of rMSC-EV treated primary lung epithelial cells and effects on in vivo model of pulmonary hypoplasia.

Fig. S6. Correlation analysis of miRNA-mRNA sequencing in primary lung epithelial cells.

Fig. S7. Effects of hAFSC-EVs and hMSC-EVs on human fetal lung epithelial cells and in the in vivo model of pulmonary hypoplasia.

Fig. S8. Influence of rAFSCs in co-culture with ex vivo and in vitro models of pulmonary hypoplasia and effects on rAFSC-EV miRNA cargo.

Table S1. Highlighted proteins expressed in rAFSC-EVs and rMSC-EVs.

Table S2. miRNAs related to lung development that are differentially expressed in rAFSC-EVs over rMSC-EVs.

Table S3. miRNAs known to be involved in pulmonary hypoplasia and present in rAFSC-EVs.

Table S4. Genes differentially expressed in nitrofen-injured lung epithelial cells.

Table S5. Inter-species conservation of top enriched miRNA in hAFSC-EVs 
Table S6: Primer sequences used in this study.

Table S7. Details of antibodies used in this study.

Movie S1. rAFSC-EV tracking into lung explant.

Movie S2. Live tracking of rAFSC small EV RNA into lung epithelial cells.

Movie S3. Live tracking of rAFSC small EV Protein into lung epithelial cells.

Movie S4. In vivo administration of AFSC-EVs prior to tracheal ligation in fetal rabbits.

Movie S5. Live tracking of rAFSC medium/large EV RNA into lung epithelial cells.

Movie S6. Live tracking of rMSC small EV RNA into lung epithelial cells.

Data file S1 (Microsoft Excel format). Differential analysis of rAFSC-EV and rMSC-EV protein cargo using proteomic analysis.

Data file S2 (Microsoft Excel format). Quality control table for all RNA-sequencing experiments used in this study.

Data file S3 (Microsoft Excel format). Full list of differentially expressed genes with pair-wise comparisons between Nitrofen vs. Nitrofen+rAFSC-EVs, and Nitrofen vs. Nitrofen+rMSC-EVs.

Data file S4 (Microsoft Excel format). Full list of pathway enrichments for mRNA-sequencing experiments.

Data file S5 (Microsoft Excel format). Data for Western blot experiments. 


\section{References and Notes}

1. A. Hislop, L. Reid. Persistent hypoplasia of the lung after repair of congenital diaphragmatic hernia. Thorax. 31, 450-455 (1976).

2. P. K. Donahoe, M. Longoni, F. A. High. Polygenic causes of congenital diaphragmatic hernia produce common lung pathologies. Am. J. Pathol. 186, 2532-2543 (2016).

3. M. T. Harting, K. P. Lally. The Congenital Diaphragmatic Hernia Study Group registry update. Semin. Fetal Neonatal. Med. 19, 370-375 (2014).

4. M. Spoel, M. H. van der Cammen-van Zijp, W. C. Hop, D. Tibboel, J. C. de Jongste, H. Ijsselstijn. Lung function in young adults with congenital diaphragmatic hernia; a longitudinal evaluation. Pediatr. Pulmonol. 48, 130-137 (2013).

5. L. Montalva, G. Raffler, A. Riccio, G. Lauriti, A. Zani. Neurodevelopmental impairment in children with congenital diaphragmatic hernia: Not an uncommon complication for survivors. J Pediatr Surg. 55, 625-634 (2020).

6. C. Jeanty, S. M. Kunisaki, T. C. MacKenzie. Novel non-surgical prenatal approaches to treating congenital diaphragmatic hernia. Semin. Fetal Neonatal Med. 19, 349-356 (2014).

7. L. Cushing, Z. Jiang, P. Kuang, J. Lü. The roles of microRNAs and protein components of the microRNA pathway in lung development and diseases. Am. J. Respir. Cell Mol. Biol. 52, 397-408 (2015).

8. M. Herriges, E. E. Morrisey. Lung development: orchestrating the generation and regeneration of a complex organ. Development 141, 502-513 (2014). 
9. A. Ventura, A. G. Young, M. M. Winslow, L. Lintault, A. Meissner, S. J. Erkeland, J. Newman, R. T. Bronson, D. Crowley, J. R. Stone, R. Jaenisch, P. A. Sharp, T. Jacks. Targeted deletion reveals essential and overlapping functions of the miR-17 through 92 family of miRNA clusters. Cell 132, 875-886 (2008).

10. S. Zhu, Q. He, R. Zhang, Y. Wang, W. Zhong, H. Xia, J. Yu. Decreased expression of miR-33 in fetal lungs of nitrofen-induced congenital diaphragmatic hernia rat model. $J$. Pediatr. Surg. 51, 1096-100 (2016).

11. T. H. Mahood, D. R. Johar, B. M. Iwasiow, W. Xu, R. Keijzer. The transcriptome of nitrofen-induced pulmonary hypoplasia in the rat model of congenital diaphragmatic hernia. Pediatr. Res. 79, 766-775 (2016).

12. P. Pereira-Terra, J. A. Deprest, R. Kholdebarin, N. Khoshgoo, P. DeKoninck, A. A. Munck, J. Wang, F. Zhu, R. J. Rottier, B. M. Iwasiow, J. Correia-Pinto, D. Tibboel, M. Post, R. Keijzer. Unique tracheal fluid microRNA signature predicts response to FETO in patients with congenital diaphragmatic hernia. Ann. Surg. 262, 1130-1140 (2015).

13. E. L. Sanford, K. W. Choy, P. K. Donahoe, A. A. Tracy, R. Hila, M. Loscertales, M. Longoni. MiR-449a affects epithelial proliferation during the pseudoglandular and canalicular phases of avian and mammal lung development. PLoS One 18, e0149425 (2016).

14. L. Alvarez-Erviti, Y. Seow, H. Yin, C. Betts, S. Lakhal, M. J. Wood. Delivery of siRNA to the mouse brain by systemic injection of targeted exosomes. Nat. Biotechnol. 29, 341345 (2011). 
15. S. Rani, A. E. Ryan, M. D. Griffin, T. Ritter. Mesenchymal stem cell-derived extracellular vesicles: Toward cell-free therapeutic applications. Mol. Ther. 23, 812-823 (2015).

16. B. György, M. E. Hung, X. O. Breakefield, J. N. Leonard. Therapeutic applications of extracellular vesicles: clinical promise and open questions. Annu. Rev. Pharmacol. Toxicol. 5, 439-464 (2015).

17. H. Valadi, K. Ekström, A. Bossios, M. Sjöstrand, J. J. Lee, J. O. Lötvall. Exosomemediated transfer of mRNAs and microRNAs is a novel mechanism of genetic exchange between cells. Nat. Cell Biol. 9, 654-659 (2007).

18. E. van der Pol, A. N. Böing, P. Harrison, A. Sturk, R. Nieuwland. Classification, functions, and clinical relevance of extracellular vesicles. Pharmacol. Rev. 64, 676-705 (2012).

19. A. F. Hill, D. M. Pegtel, U. Lambertz, T. Leonardi, L. O'Driscoll, S. Pluchino, D. TerOvanesyan, E. N. Nolte-'t Hoen. ISEV position paper: Extracellular vesicle RNA analysis and bioinformatics. J. Extracell. Vesicles 2 (2013).

20. S. Sedrakyan, V. Villani, S. Da Sacco, N. Tripuraneni, S. Porta, A. Achena, M. Lavarreda-Pearce, A. Petrosyan, H. Soloyan, R. E. Filippo, B. Bussolati, L. Perin. Amniotic fluid stem cell-derived vesicles protect from VEGF-induced endothelial damage. Sci. Rep. 7, 16875 (2017).

21. M. Riazifar, E. J. Pone, J. Lötvall, W. Zhao. Stem Cell Extracellular Vesicles: Extended Messages of Regeneration. Annu. Rev. Pharmacol. Toxicol. 57, 125-154 (2017). 
22. B. Mellows, R. Mitchell, M. Antonioli, O. Kretz, D. Chambers, M. T. Zeuner, B. Denecke, L. Musante, D. L. Ramachandra, F. Debacq-Chainiaux, H. Holthofer, B. Joch, S. Ray, D. Widera, A. L. David, T. B. Huber, J. Dengjel, P. De Coppi, K. Patel. Protein and molecular characterization of a clinically compliant amniotic fluid stem cell-derived extracellular vesicle fraction capable of accelerating muscle regeneration through enhancement of angiogenesis. Stem Cells Dev. 26, 1316-1333 (2017).

23. G. Carraro, L. Perin, S. Sedrakyan, S. Giuliani, C. Tiozzo, J. Lee, G. Turcatel, S. P. De Langhe, B. Driscoll, S. Bellusci, P. Minoo, A. Atala, R. E. De Filippo, D. Warburton. Human amniotic fluid stem cells can integrate and differentiate into epithelial lung lineages. Stem Cells 26, 2902-2911 (2008).

24. O. Garcia, G. Carraro, G. Turcatel, M. Hall, S. Sedrakyan, T. Roche, S. Buckley, B. Driscoll, L. Perin, D. Warburton. Amniotic fluid stem cells inhibit the progression of bleomycin-induced pulmonary fibrosis via CCL2 modulation in bronchoalveolar lavage. PLoS One 8, e71679 (2013).

25. S. Buckley, W. Shi, G. Carraro, S. Sedrakyan, S. Da Sacco, B. A. Driscoll, L. Perin, R. E. De Filippo, D. Warburton. The milieu of damaged alveolar epithelial type 2 cells stimulates alveolar wound repair by endogenous and exogenous progenitors. Am. J. Respir. Cell Mol. Biol. 45, 1212-1221 (2011).

26. F. Pederiva, M. Ghionzoli, A. Pierro, P. De Coppi, J. A. Tovar. Amniotic fluid stem cells rescue both in vitro and in vivo growth, innervation, and motility in nitrofen-exposed hypoplastic rat lungs through paracrine effects. Cell Transplant. 22, 1683-1694 (2013). 
27. J. Di Bernardo, M. M. Maiden, M. B. Hershenson, S. M. Kunisaki. Amniotic fluid derived mesenchymal stromal cells augment fetal lung growth in a nitrofen explant model. J. Pediatr. Surg. 49, 859-864 (2014).

28. A. Zani, M. Cananzi, F. Fascetti-Leon, G. Lauriti, V. V. Smith, S. Bollini, M. Ghionzoli, A. D'Arrigo, M. Pozzobon, M. Piccoli, A. Hicks, J. Wells, B. Siow, N. J. Sebire, C. Bishop, A. Leon, A. Atala, M. F. Lythgoe, A. Pierro, S. Eaton, P. De Coppi. Amniotic fluid stem cells improve survival and enhance repair of damaged intestine in necrotising enterocolitis via a COX-2 dependent mechanism. Gut 63, 300-309 (2014).

29. L. Antounians, A. Tzanetakis, O. Pellerito, V. D. Catania, A. Sulistyo, L. Montalva, M. J. McVey, A. Zani. The regenerative potential of amniotic fluid stem cell extracellular vesicles: Lessons learned by comparing different isolation techniques. Sci. Rep. 9, 1837 (2019).

30. I. Iritani. Experimental study on embryogenesis of congenital diaphragmatic hernia. Anat. Embryol. (Berl.) 169, 133-139 (1984).

31. L. Antounians, R.L. Figueira, L. Sbragia, A. Zani. Congenital Diaphragmatic Hernia: State of the Art in Translating Experimental Research to the Bedside. Eur. J. Pediatr. Surg. 29, 317-327 (2019).

32. L. Montalva, A. Zani. Assessment of the nitrofen model of congenital diaphragmatic hernia and of the dysregulated factors involved in pulmonary hypoplasia. Pediatr. Surg. Int. 35, 41-61 (2019). 
33. R. Keijzer, J. Liu, J. Deimling, D. Tibboel, M. Post. Dual-hit hypothesis explains pulmonary hypoplasia in the nitrofen model of congenital diaphragmatic hernia. Am. J. Pathol. 156, 1299-1306 (2000).

34. G. R. Willis, A. Fernandez-Gonzalez, J. Anastas, S. H. Vitali, X. Liu, M. Ericsson, A. Kwong, S. A. Mitsialis, S. Kourembanas. Mesenchymal stromal cell exosomes ameliorate experimental bronchopulmonary dysplasia and restore lung function through macrophage immunomodulation. Am. J. Respir. Crit. Care Med. 197, 104-116 (2018).

35. H. Teramoto, A. Yoneda, P. Puri. Gene expression of fibroblast growth factors 10 and 7 is downregulated in the lung of nitrofen-induced diaphragmatic hernia in rats. J. Pediatr. Surg. 38, 1021-1024 (2003).

36. A. F. Schmidt, F. L. Gonçalves, A. C. Regis, R. M. Gallindo, L. Sbragia. Prenatal retinoic acid improves lung vascularization and VEGF expression in CDH rat. Am. J. Obstet. Gynecol. 207, 25-32 (2012).

37. J. Rhodes, D. Saxena, G. Zhang, G. K. Gittes, D. A. Potoka. Defective parasympathetic innervation is associated with airway branching abnormalities in experimental CDH. Am. J. Physiol. Lung Cell. Mol. Physiol. 309, L168-74 (2015).

38. P. E. Cogo, M. Simonato, O. Danhaive, G. Verlato, G. Cobellis, F. Savignoni, D. Peca, A. Baritussio, V. P. Carnielli. Impaired surfactant protein B synthesis in infants with congenital diaphragmatic hernia. Eur. Respir. J. 41, 677-682 (2013).

39. E. C. Jesudason, M. G. Connell, D. G. Fernig, D. A. Lloyd, P. D. Losty. Cell proliferation and apoptosis in experimental lung hypoplasia. J. Pediatr. Surg. 35, 129-133 (2000). 
40. A. Tzanetakis, L. Antounians, A. Belfiore, Q. Ma, M. Stasiewicz, O. Pellerito, A. Zani. Endoplasmic reticulum stress response is activated in pulmonary hypoplasia secondary to congenital diaphragmatic hernia, but is decreased by administration of amniotic fluid stem cells. Pediatr. Surg. Int. 35, 63-69 (2019).

41. R. L. Figueira, K. Costa, A. L. Marsico, T. Milani, W. A. Gonçalves, M. C. Borges, O. Silva, L. Sbragia. Vascular and ventilatory mechanical responses in three different stages of pulmonary development in the rabbit model of congenital diaphragmatic hernia. Acta Cirurg Brasileira. 33, 879-888 (2018).

42. J. Deprest. P. Brady, K. Nicolaides, A. Benachi, C. Berg, J. Vermeesch, G. Gardener, E. Gratacos. Prenatal management of the fetus with isolated congenital diaphragmatic hernia in the era of the TOTAL trial. Semin. Fetal Neonatal Med. 19, 338-348 (2014).

43. M. Pierro, L. Ionescu, T. Montemurro, A. Vadivel, G. Weissmann, G. Oudit, D. Emery, S. Bodiga, F. Eaton, B. Péault, F. Mosca, L. Lazzari, B. Thébaud. Short-term, long-term and paracrine effect of human umbilical cord-derived stem cells in lung injury prevention and repair in experimental bronchopulmonary dysplasia. Thorax 68, 475-484 (2013).

44. L. Barile, V. Lionetti, E. Cervio, M. Matteucci, M. Gherghiceanu, L. M. Popescu, T. Torre, F. Siclari, T. Moccetti, G. Vassalli. Extracellular vesicles from human cardiac progenitor cells inhibit cardiomyocyte apoptosis and improve cardiac function after myocardial infarction. Cardiovasc Res. 103, 530-541 (2014).

45. M. Nawaz, F. Fatima, K. C. Vallabhaneni, P. Penfornis, H. Valadi, K. Ekström, S. Kholia, J. D. Whitt, J. D Fernandes, R. Pochampally, J. A. Squire, G. Camussi. 
Extracellular vesicles: Evolving factors in stem cell biology. Stem Cells Int. 2016, 1073140 (2016).

46. M. Khan, R. Kishore. Stem cell exosomes: Cell-free therapy for organ repair. Methods Mol. Biol. 1553, 315-321 (2017).

47. M. Riazifar, E. J. Pone, J. Lötvall, W. Zhao. Stem cell extracellular vesicles: extended messages of regeneration. Annu. Rev. Pharmacol. Toxicol. 57, 125-154 (2017).

48. S. G. Ong, J. C. Wu. Exosomes as potential alternatives to stem cell therapy in mediating cardiac regeneration. Circ. Res. 117, 7-9 (2015).

49. T. R. Doeppner, M. Bähr, D. M. Hermann, B. Giebel. Concise review: Extracellular vesicles overcoming limitations of cell therapies in ischemic stroke. Stem Cells Transl. Med. 6, 2044-2052 (2017).

50. M. Adamiak, G. Cheng, S. Bobis-Wozowicz, L. Zhao, S. Kedracka-Krok, A. Samanta, E. Karnas, Y. T. Xuan, B. Skupien-Rabian, X. Chen, U. Jankowska, M. Girgis, M. Sekula, A. Davani, S. Lasota, R. J. Vincent, M. Sarna, K. L. Newell, O. L. Wang, N. Dudley, Z. Madeja, B. Dawn, E. K. Zuba-Surma. Induced pluripotent stem cell (iPSCs)-derived extracellular vesicles are safer and more effective for cardiac repair than iPSCs. Circ. Res. 122, 296-309 (2018).

51. S. Y. Kim, J. H. Lee, H. J. Kim, M. K. Park, J. W. Huh, J. Y. Ro, Y. M. Oh, S. D. Lee, Y. S. Lee. Mesenchymal stem cell-conditioned media recovers lung fibroblasts from cigarette smoke-induced damage. Am. J. Physiol. Lung Cell Mol. Physiol. 302, L891-908 (2012). 
52. B. R. Zhou, Y. Xu, S. L. Guo, Y. Xu, Y. Wang, F. Zhu, F. Permatasari, D. Wu, Z. Q. Yin, D. Luo. The effect of conditioned media of adipose-derived stem cells on wound healing after ablative fractional carbon dioxide laser resurfacing. Biomed. Res. Int. 2013, $519126(2013)$.

53. H. Shin, C. H. Won, W. K. Chung, B. S. Park. Up-to-date clinical trials of hair regeneration using conditioned media of adipose-derived stem cells in male and female pattern hair loss. Curr. Stem Cell Res. Ther. 12, 524-530 (2017).

54. M. Monguió-Tortajada, S. Roura, C. Gálvez-Montón, J. M. Pujal, G. Aran, L. Sanjurjo, M. Franquesa, M. R. Sarrias, A. Bayes-Genis, F. E. Borràs. Nanosized UC MSC-derived extracellular vesicles but not conditioned medium exclusively inhibit the inflammatory response of stimulated T cells: implications for nanomedicine. Theranostics 7, 270-284 (2017).

55. S. Sahoo, E. Klychko, T. Thorne, S. Misener, K. M. Schultz, M. Millay, A. Ito, T. Liu, C. Kamide, H. Agrawal, H. Perlman, G. Qin, R. Kishore, D. W. Losordo. Exosomes from human CD34(+) stem cells mediate their proangiogenic paracrine activity. Circ. Res. 109, 724-728 (2011).

56. L. Margolis, Y. Sadovsky. The biology of extracellular vesicles: The known unknowns. PLoS Biol. 17, e3000363 (2019).

57. https://clinicaltrials.gov/ct2/results?cond=Bronchopulmonary+Dysplasia\&term=mesench $\mathrm{ymal}+$ stem + cell $\&$ cntry $=\&$ state $=\&$ city $=\&$ dist $=$ 
58. T. Shahzad, S. Radajewski, C. M. Chao, S. Bellusci, H. Ehrhardt. Pathogenesis of bronchopulmonary dysplasia: when inflammation meets organ development. Mol. Cell Pediatr. 3, 23 (2016).

59. Y. Lu, J. M. Thomson, H. Y. Wong, S. M. Hammond, B. L. Hogan. Transgenic overexpression of the microRNA miR-17-92 cluster promotes proliferation and inhibits differentiation of lung epithelial progenitor cells. Dev. Biol. 310, 442-453 (2007).

60. M. Ha, M. Pang, V. Agarwal, Z. J. Chen. Interspecies regulation of microRNAs and their targets. Biochim. Biophys. Acta. 1779, 735-742 (2008).

61. Q.-S. Tong, L.-D. Zheng, S.-T. Tang, G.-S. Jiang, Q.-L. Ruan, F.-Q. Zeng, J.-H. Dong. Nitrofen suppresses cell proliferation and promotes mitochondria-mediated apoptosis in type II pneumocytes. Acta Pharmacol. Sin. 28, 672-684 (2007).

62. I. Caniggia, I. Tseu, R. N. Han, B. T. Smith, K. Tanswell, M. Post. Spatial and temporal differences in fibroblast behavior in fetal rat lung. Am. J. Physiol. 261, L424-433 (1991).

63. M. Bilodeau, S. Shojaie, C. Ackerley, M. Post, J. Rossant. Identification of a proximal progenitor population from murine fetal lungs with clonogenic and multilineage differentiation potential. Stem Cell Reports 3, 634-649 (2014).

64. J. L. Emery, A. Mithal. The number of alveoli in the terminal respiratory unit of man during late intrauterine life and childhood. Arch. Dis. Child. 35, 544-547 (1960).

65. X. I. Roubliova, J. M. Biard, L. Ophalvens, D. Gallot, J. C. Jani, E. K. Verbeken, C. P. Van De Ven, D. Tibboel, J. A. Deprest. Morphology of the developing fetal lung - the rabbit experimental model. In: Modern Research and Educational Topics in Microscopy, edited by Méndez-Vilas A Díaz J. Badajoz, Spain: Formatex, 2007, p. 417-425. 
66. P. De Coppi, G. Bartsch, Jr., M. M. Siddiqui, T. Xu, C. C. Santos, L. Perin, G. Mostoslavsky, A. C. Serre, E. Y. Snyder, J. J. Yoo, M. E. Furth, S. Soker, A. Atala. Isolation of amniotic stem cell lines with potential for therapy. Nat. Biotechnol. 25, 100106 (2007).

67. R. A. McCloy, S. Rogers, C. E. Caldon, T. Lorca, A. Castro, A. Burgess. Partial inhibition of Cdk1 in G 2 phase overrides the SAC and decouples mitotic events. Cell Cycle 13, 1400-1412 (2014).

68. G. Y. Xiao, C. C. Cheng, Y. S. Chiang, W. T. Cheng, I. H. Liu, S. C. Wu. Exosomal miR-10a derived from amniotic fluid stem cells preserves ovarian follicles after chemotherapy. Sci. Rep. 6, 23120 (2016).

69. G. Carraro, A. El-Hashash, D. Guidolin, C. Tiozzo, G. Turcatel, B. M. Young, S. P. De Langhe, S. Bellusci, W. Shi, P. P. Parnigotto, D. Warburton. miR-17 family of microRNAs controls FGF10-mediated embryonic lung epithelial branching morphogenesis through MAPK14 and STAT3 regulation of E-Cadherin distribution. Dev. Biol. 333, 238-250 (2009).

70. P. Silveyra, Z. C. Chroneos, S. L. DiAngelo, N. J. Thomas, G. T. Noutsios, N. Tsotakos, J. A. Howrylak, T. M. Umstead, J. Floros. Knockdown of Drosha in human alveolar type II cells alters expression of SP-A in culture: a pilot study. Exp. Lung Res. 40, 354-366 (2014).

71. P. Dravet-Gounot, P. Dravet-Gounot, C. Morin, S. Jacques, F. Dumont, F. Ely-Marius, D. Vaiman, P. H. Jarreau, C. Méhats, E. Zana-Taïeb. Lung microRNA deregulation 
associated with impaired alveolarization in rats after intrauterine growth restriction. PLoS One 12, e0190445 (2017).

72. S. Mujahid, T. Logvinenko, M. V. Volpe, H. C. Nielsen. miRNA regulated pathways in late stage murine lung development. BMC Dev. Biol. 13, 13 (2013).

73. V. V. Sherstyuk, S. P. Medvedev, E. A. Elisaphenko, E. A. Vaskova, M. T. Ri, Y. V. Vyatkin, O. V. Saik, D. N. Shtokalo, E. A. Pokushalov, S. M. Zakian. Genome-wide profiling and differential expression of microRNA in rat pluripotent stem cells. Sci. Rep. 7, 2787 (2017).

74. N. Khoshgoo, R. Visser, L. Falk, C. A. Day, D. Ameis, B. M. Iwasiow, F. Zhu, A. Öztürk, S. Basu, M. Pind, A. Fresnosa, M. Jackson, V. K. Siragam, G. Stelmack, G. G. Hicks, A. J. Halayko, R. Keijzer. MicroRNA-200b regulates distal airway development by maintaining epithelial integrity. Sci. Rep. 7, 6382 (2017).

75. N. Khoshgoo, R. Kholdebarin, P. Pereira-Terra, T. H. Mahood, L. Falk, C. A. Day, B. M. Iwasiow, F. Zhu, D. Mulhall, C. Fraser, J. Correia-Pinto, R. Keijzer. Prenatal microRNA miR-200b therapy improves nitrofen-induced pulmonary hypoplasia associated with congenital diaphragmatic hernia. Ann. Surg. (2017).

76. M. P. Eastwood, J. Deprest, F. M. Russo, H. Wang, D. Mulhall, B. Iwasiow, T. H. Mahood, R. Keijzer. MicroRNA 200b is upregulated in the lungs of fetal rabbits with surgically induced diaphragmatic hernia. Prenat. Diagn. 38, 645-653 (2018).

77. S. E. Wert, C. R. Dey, P. A. Blair, S. Kimura, J. A. Whitsett. Increased expression of thyroid transcription factor-1 (TTF-1) in respiratory epithelial cells inhibits alveolarization and causes pulmonary inflammation. Dev. Biol. 242, 75-87 (2002). 
78. C. Missero, M. T. Pirro, S. Simeone, M. Pischetola, R. Di Lauro. The DNA glycosylase T:G mismatch-specific thymine DNA glycosylase represses thyroid transcription factor1-activated transcription. J. Biol. Chem. 276, 33569-33575 (2001).

79. K. C. Wade, S. H. Guttentag, L. W. Gonzales, K. L. Maschhoff, J. Gonzales, V. Kolla, S. Singhal, P. L. Ballard. Gene induction during differentiation of human pulmonary type II cells in vitro. Am. J. Respir. Cell Mol. Biol. 34, 727-737 (2006).

80. N. Lopez Jimenez, S. Gerber, V. Popovici, S. Mirza, K. Copren, L. Ta, G. M. Shaw, B. Trueb, A. M. Slavotinek. Examination of FGFRL1 as a candidate gene for diaphragmatic defects at chromosome 4p16.3 shows that Fgfrl1 null mice have reduced expression of Tpm3, sarcomere genes and Lrtm1 in the diaphragm. Hum. Genet. 127, 325-336 (2010).

81. S. Perveen, K. Ayasolla, N. Zagloul, H. Patel, K. Ochani, D. Orner, H. Benveniste, M. Salerno, P. Vaska, Z. Zuo, Y. Alabed, M. Nasim, E. J. Miller, M. Ahmed. MIF inhibition enhances pulmonary angiogenesis and lung development in congenital diaphragmatic hernia. Pediatr. Res. 85, 711-718 (2019).

82. F. Friedmacher, T. Doi, J.-H. Gosemann, N. Fujiwara, B. Kutasy, P. Puri. Upregulation of fibroblast growth factor receptor 2 and 3 in the late stages of fetal lung development in the nitrofen rat model. Pediatr. Surg. Int. 28, 195-199 (2012).

83. M. A. Martorell, M. C. Calabuig, A. Llombart-Bosch, J. Esquerdo. Primary omental tumor with ultrastructural features of cellular schwannoma and absence of S-100 antigen reactivity. Pathol. Res. Pract. 185, 480-487 (1989). 
84. H. Glatt, W. Meinl. Use of genetically manipulated Salmonella typhimurium strains to evaluate the role of sulfotransferases and acetyltransferases in nitrofen mutagenicity. Carcinogenesis. 25, 779-786 (2004).

85. J. Wang, J.-Y. Zhou, D. Kho, J. J. J. Reiners, G. S. Wu. Role for DUSP1 (dual-specificity protein phosphatase 1) in the regulation of autophagy. Autophagy. 12, 1791-1803 (2016).

86. B. Yeganeh, J. Lee, L. Ermini, I. Lok, C. Ackerley, M. Post. Autophagy is required for lung development and morphogenesis. J. Clin. Invest. 129, 2904-2919 (2019).

87. I. Tanida, S. Waguri. Measurement of autophagy in cells and tissues. Methods Mol. Biol. 648, 193-214 (2010).

88. W. Hou, Y. Xie, X. Song, X. Sun, M. T. Lotze, H. J. 3rd Zeh, R. Kang, D. Tang. Autophagy promotes ferroptosis by degradation of ferritin. Autophagy. 12, 1425-1428 (2016).

89. K. Kokame, K. L. Agarwala, H. Kato, T. Miyata. Herp, a new ubiquitin-like membrane protein induced by endoplasmic reticulum stress. J. Biol. Chem. 275, 32846-32853 (2000).

90. R. B. van Loenhout, I. Tseu, E. K. Fox, Z. Huang, D. Tibboel, M. Post, R. Keijzer. The pulmonary mesenchymal tissue layer is defective in an in vitro recombinant model of nitrofen-induced lung hypoplasia. Am. J. Pathol. 180, 48-60 (2012).

91. D. R. Dorscheid, K. R. Wojcik, K. Yule, S. R. White. Role of cell surface glycosylation in mediating repair of human airway epithelial cell monolayers. Am. J. Physiol. Lung Cell. Mol. Physiol. 281, L982-92 (2001). 
92. Z. Qian, D. Okuhara, M. K. Abe, M. R. Rosner. Molecular cloning and characterization of a mitogen-activated protein kinase-associated intracellular chloride channel. J. Biol. Chem. 274, 1621-1627 (1999).

93. Y.-T. Chang, A. Ringman Uggla, C. Osterholm, P.-K. Tran, A.-C. Eklof, M. Lengquist, U. Hedin, K. Tran-Lundmark, B. Frenckner. Antenatal imatinib treatment reduces pulmonary vascular remodeling in a rat model of congenital diaphragmatic hernia. Am. J. Physiol. Lung Cell. Mol. Physiol. 302, L1159-66 (2012).

94. L. A. Laviolette, J. Mermoud, I. A. Calvo, N. Olson, M. Boukhali, O. K. Steinlein, E. Roider, E. C. Sattler, D. Huang, B. T. Teh, M. Motamedi, W. Haas, O. Iliopoulos. Negative regulation of EGFR signalling by the human folliculin tumour suppressor protein. Nat. Commun. 8, 15866 (2017).

95. M. R. Chinoy, X. Chi, R. E. Cilley. Down-regulation of regulatory proteins for differentiation and proliferation in murine fetal hypoplastic lungs: altered mesenchymalepithelial interactions. Pediatr. Pulmonol. 32, 129-141 (2001).

96. M. Adams, R. J. Simms, Z. Abdelhamed, H. R. Dawe, K. Szymanska, C. V Logan, G. Wheway, E. Pitt, K. Gull, M. A. Knowles, E. Blair, S. H. Cross, J. A. Sayer, C. A. Johnson. A meckelin-filamin A interaction mediates ciliogenesis. Hum. Mol. Genet. 21, $1272-1286(2012)$.

97. P. Spagnolo, A. Bush. Interstitial Lung Disease in Children Younger Than 2 Years. Pediatrics. 137. (2016). 
98. H. Cheng, T. Chen, M. Tor, D. Park, Q. Zhou, J. B. Huang, N. Khatib, L. Rong, G. Zhou. A High-Throughput Screening Platform Targeting PDLIM5 for Pulmonary Hypertension. J. Biomol. Screen. 21, 333-341 (2016).

99. X. Huang, L. Li, R. Ammar, Y. Zhang, Y. Wang, K. Ravi, J. Thompson, G. Jarai. Molecular characterization of a precision-cut rat lung slice model for the evaluation of antifibrotic drugs. Am. J. Physiol. Lung Cell. Mol. Physiol. 316, L348-L357 (2019).

100. K. Brown, A. Filuta, M.-G. Ludwig, K. Seuwen, J. Jaros, S. Vidal, K. Arora, A. P. Naren, K. Kandasamy, K. Parthasarathi, S. Offermanns, R. J. Mason, W. E. Miller, J. A. Whitsett, J. P. Bridges. Epithelial Gpr116 regulates pulmonary alveolar homeostasis via Gq/11 signaling. JCI Insight 2 (2017).

101. K. C. Liu, R. E. Cheney. Myosins in cell junctions. Bioarchitecture 2, 158-170 (2012).

102. S. Averaimo, R. H. Milton, M. R. Duchen, M. Mazzanti. Chloride intracellular channel 1 (CLIC1): Sensor and effector during oxidative stress. FEBS Lett. 584, 2076$2084(2010)$.

103. R. Fernandez-Valdivia, Y. Zhang, S. Pai, M. L. Metzker, A. Schumacher. 17Rn6 encodes a novel protein required for clara cell function in mouse lung development. Genetics. 172, 389-399 (2006).

104. K. E. Driscoll, D. G. Hassenbein, B. W. Howard, R. J. Isfort, D. Cody, M. H. Tindal, M. Suchanek, J. M. Carter. Cloning, expression, and functional characterization of rat MIP-2: a neutrophil chemoattractant and epithelial cell mitogen. J. Leukoc. Biol. 58, 359-364 (1995). 
Acknowledgments: We thank Reta Aram, Alyssa Belfiore, George Biouss, Jennifer Guadagno, Kasra Khalaj, Yuhki Koike, Sasha Korogodski, Kimberly Lau, Carol Lee, Dorothy Lee, Qi Ma, Karim Maghraby, Ornella Pellerito, Gabriele Raffler, Mark Stasiewicz, Adrienne Sulistyo, Yanting Wang, and Kyoko Yuki. The authors are indebted to Drs. Christian Smith and James Rutka (Brain Tumour Research Centre), the Lab Animal Services, and Nanoscale Biomedical Imaging Facility at SickKids.

Funding: A.Z. was supported by SickKids start-up funds, Canadian Institutes of Health Research (CIHR) - SickKids Foundation New Investigator Research Grant (NI181270R), SickKids Congenital Diaphragmatic Hernia Fund (R00DH00000). L.S. was supported by the Foundation for the Support of Teaching, Research and Service of the University Hospital (FAEPA), the Coordination for the Improvement of Higher Education Personnel (CAPES \#1813259), and the National Council for Scientific and Technological Development (CNPq \#302433-2017-17). M.D.W. was supported by an Early Researcher Award (Ontario Ministry of Research and Innovation) and Tier 2 Canada Research Chairs (CIHR). C.C. was supported by SickKids Restracomp Fellowship and NSERC grant RGPIN-2019-07041. H.H. and Kyoko Yuki were supported by a Genome Canada Genomics Technology Platform grant to The Centre for Applied Genomics (SickKids).

Author contributions: L.A., V.D.C., L.S., M.D.W., J.R., and A.Z. designed the study. L.A., V.D.C., L.M., B.D.L., A.C.M., A.T., B.L., R.L.F., K.M.C., and L.S. performed in vitro and in vivo experiments, collected and analyzed data. A.P.W. supervised organoid studies. R.M., A.L.D., K.P., and P.D.C. isolated and characterized hAFSCs. L.A., H.H., 
C.C., M.D.W., and A.Z. analyzed bioinformatics data. L.A. and A.Z. wrote the manuscript. P.D.C., A.P.W., M.D.W., J.R. provided critical reading of the manuscript. All authors approved the final manuscript.

Competing interests: The authors declare no competing interests.

Data and materials availability: Proteomics differential analysis with rAFSC-EV and rMSCEV cargos is in Supporting Data File S1. We submitted all EV data to EV-TRACK knowledgebase (\#EV190001). RNA-sequencing data for rAFSC-EVs, rMSC-EVs, and primary lung epithelial cells are available on ArrayExpress database (\#E-MTAB-8921). 


\section{Figure Legends}

Fig. 1. Administration of rAFSC-EVs promotes growth, branching morphogenesis, and maturation in fetal hypoplastic lungs. (A) Representative light microscopy photos of lung explants harvested at E14.5 (0 h) and grown for $72 \mathrm{~h}$ in conditions indicated in columns. Scale bar $=750 \mu \mathrm{m}$. (B and $\mathbf{C})$ quantification of total terminal bud count and total lung surface area measured at 72 h. $* * * * \mathrm{P}<0.0001, * * \mathrm{P}<0.01, \mathrm{~ns}=\mathrm{P}>0.05$. Data are quantified blindly by two investigators for the following number of biological replicates: Control $(n=16)$, Nitrofen $(n=17)$, Nitrofen+rAFSC-CM (n=12), Nitrofen+rAFSC-EVs $(n=12)$, Nitrofen+EV-depleted rAFSC-CM $(n=5)$, Nitrofen+rMSC-EVs $(n=8)$. (D) Gene expression changes in lung maturation markers fibroblast growth factor $10(F g f 10)$ and vascular endothelial growth factor $(V e g f a)$, and its receptors $(F l t 1$ and $K d r)$ in lung explants measured at 72 h. $* \mathrm{P}<0.05$, $* * * \mathrm{P}<0.001$. Expression values of at least $n=9$ technical replicates are shown ( $\mathbf{E}$ to $\mathbf{G}$ ) Immunofluorescence co-stain experiment of proliferating cells and distal lung epithelium progenitor cells of lung explants (SOX9, green; EdU, pink, DAPI nuclear stain, blue; scale bar $=100 \mu \mathrm{m}$ ), quantified through number of EdU ${ }^{+}$cell per DAPI and SOX9 fluorescence intensity (AU = arbitrary units). N=4 biological replicates were used with a total of 50x50 $\mu \mathrm{m}$ fields covering entire lung sections as indicated: Control ( $n=157)$, Nitrofen $(n=222)$, Nitrofen+rAFSC-EVs $(n=128)$. (H and I) Western blot analysis of SOX9 and SPC expression in lung explants grown for $72 \mathrm{~h}$, quantified by signal intensity normalized to GAPDH in at least $n=3$ biological replicates from each condition. ( $\mathbf{J}$ and K) Immunofluorescence experiment of surfactant protein C (SPC) expressing cells in lung explants (SPC, green; DAPI nuclear stain, blue; scale bar $=100 \mu \mathrm{m}$ ), quantified by fluorescence intensity: Control ( $n=6)$, Nitrofen ( $n=4)$, Nitrofen+rAFSC-EVs ( $n=4)$. (L) Quantification of SPC protein expression by signal intensity normalized to GAPDH in $n=3$ biological replicates from 
each condition. (M and $\mathbf{N}$ ) TUNEL immunofluorescence experiments on lung explants grown for $72 \mathrm{~h}$, quantified by TUNEL ${ }^{+}$cells per DAPI in $\mathrm{n}=4$ biological replicates with a total of $50 \times 50$ $\mu \mathrm{m}$ fields covering entire lung sections as indicated: Control $(\mathrm{n}=311)$, Nitrofen $(\mathrm{n}=240)$, Nitrofen+rAFSC-EVs ( $\mathrm{n}=107)$. Groups were compared using Kruskal-Wallis (post-hoc Dunn's nonparametric comparison) test for Fig. 1 B, C, F, G, I, K, L, N, and with one-way ANOVA (Tukey post-test) for Fig. $1 \mathrm{D}$, according to Gaussian distribution assessed by D'Agostino Pearson omnibus normality test. 
Fig. 2. rAFSC-EVs maintain homeostasis and stimulate differentiation of the epithelium from hypoplastic fetal lungs. (A) Proliferation rate of primary lung epithelial cells from control and nitrofen-injured hypoplastic lungs treated with rAFSC-CM, rAFSC-EVs, EV-depleted rAFSC-CM [5'EdU labeling, Control $(n=7)$, Nitrofen $(n=5)$, Nitrofen+rAFSC-CM $(n=3)$, Nitrofen+rAFSC-EVs $(\mathrm{n}=5)$, Nitrofen+EV-depleted rAFSC-CM $(\mathrm{n}=3)] . * * * * \mathrm{P}<0.0001, \mathrm{~ns}=$ $P>0.05$. (B) Cell death rate of primary lung epithelial cells from control and nitrofen-injured hypoplastic lungs treated as in (A) [live/dead cytotoxicity assay, Control n=5, Nitrofen ( $\mathrm{n}=5)$, Nitrofen+rAFSC-CM ( $\mathrm{n}=6)$, Nitrofen+rAFSC-EVs $(\mathrm{n}=5)$, Nitrofen+EV-depleted rAFSC-CM $(\mathrm{n}=4)] .{ }^{*} \mathrm{P}<0.05, * * * \mathrm{P}<0.001$. (C) Light microscopy photos of fetal rat lung organoids derived from control lungs and nitrofen-injured hypoplastic lungs either treated with medium alone (Nitrofen) or medium supplemented with rAFSC-EVs (Nitrofen+rAFSC-EVs). Scale bar $=100$ $\mu \mathrm{m}$. Representative photo of Control $(n=108)$, Nitrofen $(n=63)$, Nitrofen+rAFSC-EVs $(n=94)$. (D) Proliferation of cells in organoids evaluated with immunofluorescence (Ki67 staining, green; scale bar $=50 \mu \mathrm{m}$ ) and quantified as percentage of $\mathrm{Ki}^{+} 7^{+}$cells per total number of DAPI (blue) stained nuclei in Control $(n=8)$, Nitrofen $(n=7)$, Nitrofen+rAFSC-EVs $(n=9)$. (E) SPC staining in organoids (green; DAPI nuclear stain, blue; scale bar $=50 \mu \mathrm{m}$ ) quantified with fluorescence intensity calculated from total corrected cellular fluorescence from Control $(n=30)$, Nitrofen $(\mathrm{n}=31)$, Nitrofen + rAFSC-EVs $(\mathrm{n}=25)\left(\mathrm{AU}=\right.$ arbitrary units). $(\mathbf{F}) \mathrm{CC} 10^{+}$cells in organoids (green; DAPI nuclear stain, blue; scale bar $=50 \mu \mathrm{m})$ quantified with fluorescence intensity calculated from total corrected cellular fluorescence Control $(n=30)$, Nitrofen $(n=30)$, Nitrofen+rAFSC-EVs $(\mathrm{n}=30)$. Groups were compared using Kruskal-Wallis (post-hoc Dunn's nonparametric comparison) test for Fig. 2 A, B, D, E, F according to Gaussian distribution assessed by D’Agostino Pearson omnibus normality test. 
Fig. 3. The role of RNA cargo released by rAFSC-EVs. (A and B) Fluorescently labeled rAFSC-EV protein (green) and RNA (red) cargo entered primary lung epithelial cells (DAPI nuclear stain, blue; scale bar $=100 \mu \mathrm{m})$. Cells were outlined based on light microscopy images to highlight the border. To confirm this, cells were washed twice with PBS and fixed in 4\% PFA and re-imaged after live cell imaging (shown in Movie S2 and Movie S3). (C) Bioanalyzer traces of RNase pre-treated rAFSC-EVs. (D to I) Representative photos of gold immunolabeling experiments of RNase-treated rAFSC-EVs in far field (D) and near field (E to $\mathbf{H}$ ) or rAFSC-EVs in near field (I), using transmission electron microscopy, with TSG101 (10 nm), and RNase (25 $\mathrm{nm})$, scale bar $=100 \mathrm{~nm}$. Controls include single stains $(\mathbf{F}$ and $\mathbf{G})$, secondary only antibodies (H), and co-stains in untreated rAFSC-EVs (I). Photos are representative of four biological replicates of rAFSC-EV-RNase and rAFSC-EVs ( $\mathbf{J}$ to $\mathbf{M})$ Effects of RNase pre-treated rAFSCEVs on lung growth parameters (bud count, $(\mathbf{J})$; and surface area, $(\mathbf{K})$, from Control $(\mathrm{n}=16)$, Nitrofen $(n=17)$, Nitrofen+rAFSC-EVs $(n=12)$, and Nitrofen+rAFSC-EV-RNase $(n=4)$, and on pulmonary epithelial cells (proliferation, $(\mathbf{L})$; and cell death rate $(\mathbf{M})$ from Control $(\mathrm{n}=7)$, Nitrofen $\quad(n=5), \quad$ Nitrofen+rAFSC-EVs $\quad(n=5), \quad$ and Nitrofen+rAFSC-EV-RNase $\quad(n=4)$, $* * * * \mathrm{P}<0.0001, * * * \mathrm{P}<0.001, * * \mathrm{P}<0.01, \mathrm{~ns}=\mathrm{P}>0.05$. (N) Small RNA-sequencing analysis of rAFSC-EVs and rMSC-EVs separated by type of RNA species. Solid bar represents proportion of significantly different species per type of RNA. (O) Heat map of miRNAs detected in rAFSCEVs $(n=3)$ and rMSC-EVs $(n=2)$, ranked based on fold change and significant difference between the two populations. The two inlets report the miRNAs involved in lung development (see table S2). Right inlet: miRNAs significantly enriched in rAFSC-EVs detected within the top 50 miRNAs. Left inlet: miRNAs equally abundant in rAFSC-EVs and rMSC-EVs detected within the top 50 miRNAs. Groups were compared using Kruskal-Wallis (post-hoc Dunn's 
nonparametric comparison) test for Fig. $3 \mathrm{~J}, \mathrm{~K}, \mathrm{~L}, \mathrm{M}$ according to Gaussian distribution assessed by D'Agostino Pearson omnibus normality test. 
Fig. 4. Effects of rAFSC-EVs exerted on primary lung epithelial cells. (A) Heat map of mRNA expression of genes from lung epithelial cells of nitrofen-injured lungs treated with rAFSC-EVs from $\mathrm{n}=6$ biological replicates each, FDR $<0.1$. Color represents row-scaled, normalized read counts (RPKM). (B) GSEA enrichment plot of epithelial cell differentiation generated with genes ranked by fold change between NA vs. N. "Leading edge" genes are shown on the side. (C) Interaction network of rAFSC-EV miRNAs and down regulated genes in nitrofen-injured lung epithelial cells treated with rAFSC-EVs. Size of node represents number of connections. Blue nodes represent genes down-regulated (FDR $<0.1)$ in nitrofen-injured lung epithelial cells treated with rAFSC-EVs compared to nitrofen-injured lung epithelial cells. White nodes represent miRNAs that were detected in the rAFSC-EV cargo. Green nodes represent miRNAs that were detected in rAFSC-EV cargo that had higher expression in rAFSC-EV-treated nitrofen-injured lung epithelial cells compared to untreated nitrofen-injured epithelial cells. Triangles represent miRNAs from the miR17 92 family and paralogues. Each miRNA-gene target pair is connected by a gray edge and pairs containing a miRNA from miR17 92 family or its paralogues are connected by a blue edge. 
Fig. 5. Towards the clinical translation of AFSC-EVs as treatment for fetal lung regeneration. (A) Schematic of experimental groups from the rabbit model of $\mathrm{CDH}$. (B) Representative histology images (hematoxylin/eosin) of fetal lungs from control rabbits and from rabbits that underwent surgical $\mathrm{CDH}$ creation and were either untreated $(\mathrm{CDH})$, or subjected to tracheal occlusion $(\mathrm{CDH}+\mathrm{TO})$, or were administered rAFSC-EVs prior to tracheal occlusion $(\mathrm{CDH}+\mathrm{TO}+\mathrm{rAFSC}-\mathrm{EVs})$. Each condition included fetal lungs from $\mathrm{n}=9$ experiments. Scale bar $=$ $500 \mu \mathrm{m}$. (C and D) Differences in number of alveoli (radial alveolar count) were quantified in at least 12 counts per fetal lung in 2 different sections of the lung, and thickness of the alveolar wall (mean wall transection length) was measured in 10 different areas of each lung. $* * \mathrm{P}<0.01$, ${ }^{*} \mathrm{P}<0.05$. ( $\mathbf{E}$ and $\left.\mathbf{F}\right)$ Gene expression changes in alveolar lipofibroblasts (PLIN2), BMP (bone morphogenetic protein) signaling (BMP2, BMP4, Id1) in $\mathrm{n}=9$ biological replicates of each condition. ${ }^{* * *} \mathrm{P}<0.001$ ( $\mathbf{G}$ and $\left.\mathbf{J}\right)$ Effects of good manufacturing practice-grade hAFSC-EVs on proliferation rate and viability rate on nitrofen-injured human A549 cells ( $\mathbf{G}$ and $\mathbf{H}$ ), and human pulmonary alveolar epithelial cells (I and $\mathbf{J})$ ( $\mathrm{n}>30$ technical replicates). ( $\mathbf{K}$ and $\mathbf{L}$ ) Uptake of hAFSC-EVs fluorescently labeled with PKH26 by A549 cells or human pulmonary alveolar epithelial cells. Scale bar $=25 \mu \mathrm{m}$. Groups were compared using Kruskal-Wallis (post-hoc Dunn's nonparametric comparison) test for Fig. 5 C, D, E, F, H, I, and J, and with one-way ANOVA (Tukey post-test) for Fig. $5 \mathrm{G}$ according to Gaussian distribution assessed by D’Agostino Pearson omnibus normality test. 
Fig. 6. Schematic of changes that occur with AFSC-EV administration to hypoplastic fetal lungs. (A) Untreated hypoplastic lungs with few lung buds, small total surface area, and dysregulated homeostasis (low cell proliferation, high cell death, undifferentiated epithelial and fibroblast cells). (B) Administration of AFSC-EVs to hypoplastic lungs improves terminal branching and results in increased number of lung buds, higher surface area, and restored cellular homeostasis (improved cell proliferation, reduced cell death, more differentiated epithelial and fibroblast cells). 


\section{Fetal lung underdevelopment is rescued}

\section{by amniotic fluid stem cell extracellular vesicles}

Lina Antounians ${ }^{1,2}$, Vincenzo D. Catania ${ }^{1,2}$, Louise Montalva ${ }^{1,2}$, Benjamin D. Liu ${ }^{1,2}$, Huayun $\mathrm{Hou}^{3,4}$, Cadia Chan ${ }^{3,4}$, Andreea C. Matei ${ }^{1,2}$, Areti Tzanetakis ${ }^{1,2}$, Bo Li $i^{2,5}$, Rebeca L. Figueira ${ }^{6}$, Karina M. da Costa ${ }^{6}$, Amy P. Wong ${ }^{1}$, Robert Mitchell ${ }^{7}$, Anna L. David ${ }^{8,9}$, Ketan Patel ${ }^{7,10}$, Paolo De Coppi $^{11,12}$, Lourenço Sbragia ${ }^{6}$, Michael D. Wilson ${ }^{3,4}$, Janet Rossant ${ }^{1,4}$, Augusto Zani ${ }^{1,2, *}$

${ }^{1}$ Developmental and Stem Cell Biology Program, Peter Gilgan Centre for Research and Learning, The Hospital for Sick Children, Toronto, M5G 0A4, Canada.

${ }^{2}$ Division of General and Thoracic Surgery, The Hospital for Sick Children, Toronto, M5G 1X8, Canada.

${ }^{3}$ Genetics and Genome Biology Program, Peter Gilgan Centre for Research and Learning, The Hospital for Sick Children, Toronto, M5G 0A4, Canada.

${ }^{4}$ Department of Molecular Genetics, University of Toronto, Toronto, M5S 1A8, Canada.

${ }^{5}$ Translational Medicine Program, Peter Gilgan Centre for Research and Learning, The Hospital for Sick Children, Toronto, M5G 0A4, Canada.

${ }^{6}$ Laboratory of Experimental Fetal and Neonatal Surgery, Division of Pediatric Surgery, Ribeirão Preto Medical School, University of São Paulo, Ribeirão Preto, São Paolo, 14049-900, Brazil.

${ }^{7}$ School of Biological Sciences, University of Reading, Reading, RG6 6AS, UK.

${ }^{8}$ Institute for Women's Health, University College London, London, WC1E 6HU, UK.

${ }^{9}$ NIHR University College London Hospitals Biomedical Research Centre, London, W1T 7HA, UK

${ }^{10}$ FRIAS Freiburg Institute for Advanced Studies, University of Freiburg, Freiburg, 79104, Germany.

${ }^{11}$ Stem Cell and Regenerative Medicine Section, Great Ormond Street Institute of Child Health, University College of London, London, WC1N 1EH, UK.

${ }^{12}$ NIHR Biomedical Research Centre and Specialist Neonatal and Paediatric Unit, Great Ormond Street Hospital, London, WC1N 1EH, UK.

*To whom correspondence should be addressed: augusto.zani@sickkids.ca

One Sentence Summary: Fetal lung regeneration via administration of extracellular vesicles derived from amniotic fluid stem cells 


\section{Extended Materials and Methods}

Cells

Rat amniotic fluid stem cells (rAFSCs) were isolated from amniotic fluid of E12 SpragueDawley rat fetuses as described (66), and grown in alpha-Minimal Essential Media ( $\alpha$ MEM, Gibco, ThermoFisher, Waltham, MA) supplemented with 20\% Chang supplements (Irvine Scientific, Santa Ana, CA), 15\% fetal bovine serum (FBS, ThermoFisher Scientific, Waltham, MA), and $0.5 \%$ Penicillin/Streptomycin (ThermoFisher Scientific, Waltham, MA). Human AFSCs (hAFSCs) were obtained under good manufacturing practice guidelines as described (UCL/UCLH REC Reference: 08/0304) (22). Sprague-Dawley rat bone-marrow derived mesenchymal stem cells (MSCs) were purchased (CellBiologics, Chicago, IL) and grown in supplier recommended medium until 90\% confluence. Human adenocarcinomic alveolar basal epithelial cells (A549) were purchased (Sigma Aldrich, Missouri, MO) and grown in Dulbecco's Modified Eagle Medium, (DMEM) with Nutrient Mixture F-12 media (Gibco, ThermoFisher, Waltham, MA) supplemented with 10\% FBS and 0.5\% Penicillin/Streptomycin. All cells were used within 6 passages. Human pulmonary alveolar epithelial cells (HPAEpiC) were obtained from the lungs of a healthy fetus at 21 weeks of gestation (ScienCell, Carlsbad, CA), grown in supplier recommended medium, and used immediately for proliferation and viability assays. Human bone marrow-derived MSCs were obtained from a healthy donor (ATCC, Manassas, Virginia) and grown in supplier recommended medium. Human MSCs were used within three passages.

Extracellular vesicles (EVS)

EVs from rat and human AFSCs and from MSCs were isolated by ultracentrifugation from cells that were treated with exosome-depleted FBS (ThermoFisher, Waltham, MA) for $18 \mathrm{~h}$, as 
described (29). Based on previous studies and confirmed in this study, we established that $4 \times 10^{6}$ AFSCs cultured under these conditions secrete approximately $3 \times 10^{9} \pm 1 \times 10^{7} \mathrm{EVs}$, as quantified by nanoparticle tracking analysis (29). For all in vitro, ex vivo, and in vivo experiments herein described, we administered $50 \mu \mathrm{L}$ of the EV preparation that corresponds to $0.5 \%$ of the conditioned medium $\left(50 \mu \mathrm{L} \mathrm{EV}\right.$ volume of $10 \mathrm{~mL} \mathrm{CM}$ volume, v/v) and $1.5 \times 10^{8} \pm 5 \times 10^{5} \mathrm{EVs}$. For in vitro organoid experiments, the dose was $3.6 \times 10^{8} \pm 1.2 \times 10^{6} \mathrm{EVs}$.

EVs used in this study were characterized for size by nanoparticle tracking analysis, morphology by transmission electron microscopy, and expression of canonical EV-related markers by Western blot (fig. S1), as described (29) and recommended by the International Society for Extracellular Vesicles. Small EVs had a mean size of $140 \pm 5 \mathrm{~nm}$ and mode size $104 \pm 11 \mathrm{~nm}$. To isolate medium/large EVs $(\mathrm{m} / \mathrm{lEVs},>200 \mathrm{~nm})$, sucrose gradient ultracentrifugation was used with six layers ranging from $10 \%$ to $90 \%$ sucrose in phosphate-buffered saline (PBS). rAFSC$\mathrm{CM}$ was spun through this gradient at $100,000 \mathrm{~g}$ for $14 \mathrm{~h}$. Fractionated layers were isolated and nanoparticle tracking analysis was used to confirm the presence of large vesicles $(\mathrm{m} / \mathrm{lEVs}$ mean size of $363 \pm 17 \mathrm{~nm}$, mode size $217 \pm 32 \mathrm{~nm}$ ).

Ex vivo model of pulmonary hypoplasia

In fetal rats, pulmonary hypoplasia was induced as described $(30,40)$ with the administration of nitrofen (Sigma Aldrich, Missouri, MO) to pregnant Sprague-Dawley rats (100 mg in $1 \mathrm{~mL}$ olive oil; protocol \#39168, \#49892). At E14.5, the dam was euthanized, and fetal lungs were harvested. Lungs were washed in PBS, grown on $0.8 \mu \mathrm{m}$ nanofilter membranes, and incubated for $72 \mathrm{~h}$ in culture medium alone (DMEM), rAFSC-CM, or medium supplemented with rAFSCEVs or rMSC-EVs $(0.5 \% \mathrm{v} / \mathrm{v})$. For AFSC co-culture experiments, five thousand rAFSCs were seeded onto the bottom of the plate, and lung explants on nanofilter membranes were added on 
top of the cells and allowed to float for $72 \mathrm{~h}$. Fetal lungs from dams that received olive oil (no nitrofen) at E9.5 served as control.

In vitro model of pulmonary hypoplasia

At E14.5, a single cell suspension was obtained from pooled lungs of control or nitrofen-injured rat fetuses by trypsinization ( $0.25 \%$ Trypsin-EDTA, ThermoFisher, Waltham, MA) for 20 minutes. Cells were spun down by centrifugation ( 5 minutes, $800 \mathrm{~g}$ ) and the pellet was resuspended in DMEM supplemented with 10\% FBS and subjected to three serial depletions of fibroblasts by incubation for $1 \mathrm{~h}$ each following an established protocol (40, 62). Cells were used to test epithelial homeostasis and to generate fetal lung organoids for assessment of epithelial cell differentiation. For epithelial homeostasis experiments, cells were grown for 5 days in Bronchial Epithelial Cell Growth Medium (BEGM; Lonza, Basel Switzerland). Cells were checked daily for proper epithelial morphology using a light microscope. On the fifth day, cells were confirmed to be positive for SPC and negative for vimentin via immunofluorescence staining assays. Epithelial homeostasis was investigated by assessing cell proliferation and cell death as described (40) on cells from nitrofen-injured lungs that either had their medium replaced with BEGM, or BEGM supplemented with $500 \mu \mathrm{L}$ of rAFSC-CM, $500 \mu \mathrm{L}$ of EV-depleted rAFSCCM, rAFSC-EVs, or rMSC-EVs $(0.5 \% \mathrm{v} / \mathrm{v})$. For AFSC co-culture experiments, rAFSCs were seeded in the top compartment of a transwell $(0.4 \mu \mathrm{m})$ and primary lung epithelial cells were seeded in the bottom compartment (in a ratio of 1:10, rAFSC to primary lung epithelial cells), as described (40).

For epithelial differentiation experiments, cells were seeded in a ratio of 60:40 semi-solid Matrigel (Corning, Corning, NY) to medium ratio, to generate organoids as described (63). Cells from nitrofen-injured fetuses were cultured for 10 days with medium alone or with medium 
supplemented with $1.2 \% \mathrm{v} / \mathrm{v}$ rAFSC-EVs or rMSC-EVs. Lung organoids from untreated fetuses served as control. Medium was replaced every other day.

Human A549 cells were injured for $24 \mathrm{~h}$ with nitrofen $(40 \mu \mathrm{M})$, and subsequently administered medium alone, hAFSC-EVs or hMSC-EVs $(0.5 \% \mathrm{v} / \mathrm{v})$. Untreated and uninjured A549 cells served as control. Following $24 \mathrm{~h}$ incubation, proliferation and cell death rates were determined by EdU incorporation kit (Click-IT®, ThermoFisher Scientific, Waltham, MA), and Live/Dead cell viability assay (ThermoFisher Scientific, Waltham, MA), as described (40). Experiments were repeated for control $(n=4)$, medium only $(n=4)$, hAFSC-EVs $(n=4)$, hMSC-EVs $(n=4)$, and included $>30$ technical replicates.

HPAEpiC from a fetus at 21 weeks of gestation contained both alveolar type I and type II cells, which were selected with cytokeratin-18 and cytokeratin-19 by the supplier. Cells were grown in supplier recommended medium and used in the first passage after reaching $\sim 70 \%$ confluence. HPAEpiC were stressed with nitrofen exposure at $400 \mu \mathrm{m}$ (dosage at $40 \mu \mathrm{m}$ was not optimal in inducing impairment in cell proliferation or viability). Experiments were repeated for control $(\mathrm{n}=6)$, medium only $(\mathrm{n}=6)$, hAFSC-EVs $(\mathrm{n}=4)$, hMSC-EVs $(\mathrm{n}=4)$, and included $>100$ technical replicates.

In vivo model of pulmonary hypoplasia

In fetal rabbits, pulmonary hypoplasia was induced secondary to surgical creation of a diaphragmatic hernia at embryonic day E25 in New Zealand rabbits, following ethical approval (protocol \#191/2018,\#40/2020), as described (41). Two days later at E27, tracheal ligation was performed either alone or in conjunction with EV administration [rAFSC-EVs (n=9), rMSC-EVs $(\mathrm{n}=8)$, or hAFSC-EVs $(\mathrm{n}=5)]$. EVs $(50 \mu \mathrm{L})$ were injected intra-tracheally prior to ligation of the trachea as shown in Movie S4. Lungs were harvested at E31 and immediately frozen for RNA 
extractions or were fixed in $4 \%$ paraformaldehyde and embedded in paraffin. Fetal rabbits with intact diaphragms and that did not receive tracheal occlusion served as control.

\section{Lung morphometry}

In fetal rats, lung explants from different conditions were compared for terminal bud density and surface area using ImageJ independently by two blinded researchers, as described (27). Terminal branching was measured by counting the number of terminal buds defined as the number of single acini separated by distinct septae at the periphery of the explant (27). Differential interference contrast photos were taken on a light microscope (Leica DMI6000B, Wetzlar, Germany) at 2.5X magnification. Experiments were repeated as many times as indicated: control $(n=16)$, medium only $(n=17)$, rAFSC-CM $(n=12)$, medium supplemented with $0.5 \% \mathrm{v} / \mathrm{v}$ rAFSCEVs $(n=12)$, EV-depleted rAFSC-CM (n=5), RNase-treated rAFSC-EVs $(n=4)$, rMSC-EVs $(\mathrm{n}=8)$, medium supplemented with $0.25 \%$ v/v rAFSC-EVs AFSC-EVs $(\mathrm{n}=5)$, medium supplemented with $0.05 \%$ v/v rAFSC-EVs $(n=5)$, rAFSC-m/1EVs $(n=4)$, and co-cultured rAFSCs $(n=7)$.

Rabbit fetal lungs were blindly evaluated with histology (hematoxylin and eosin stain staining) to assess the number of alveoli and the thickness of the alveolar wall, as measures of the degree of lung alveolarization. For the number of alveoli, the radial alveolar count (RAC), a wellestablished index of alveolar number within the acinus (64), was determined in at least 12 counts per fetal lung in 2 different sections of the lung. For the thickness of the alveolar wall, the mean wall transection length was measured in 10 different areas of each lung, as described (65).

RNA expression 
Lung explants from fetal rats and freshly harvested lungs of fetal rabbits were frozen at $-20{ }^{\circ} \mathrm{C}$. Total RNA was isolated using Trizol reagent (ThermoFisher Scientific, Waltham, MA), following supplier recommended protocols. Purified RNA was quantified using a NanoDrop ${ }^{\mathrm{TM}}$ spectrophotometer (ThermoFisher Scientific, Waltham, MA) and cDNA synthesis was performed with $200 \mathrm{ng}$ for rat and $1 \mu \mathrm{g}$ for rabbit quantified RNA (superscript VILO cDNA synthesis kit, ThermoFisher Scientific, Waltham, MA). qPCR experiments were conducted with SYBR $^{\mathrm{TM}}$ Green Master Mix (Wisent, Saint-Jean-Baptiste, QC) for 40 cycles (denaturation: 95 ${ }^{\circ} \mathrm{C}$, annealing: $58{ }^{\circ} \mathrm{C}$, extension: $72{ }^{\circ} \mathrm{C}$ ) using the primer sequences reported in table S6. Melt curve plots were used to determine target specificity of the primers. $\Delta \Delta \mathrm{CT}$ method was used to determine normalized relative gene expression.

To determine the expression of specific miRNAs in EVs and parent cells, RNA was extracted from approximately 4 million cells of rAFSCs and $\mathrm{rMSCs}$ ( $\mathrm{n}=3$ replicates each) using the Nucleospin miRNA kit (Macherey-Nagel, Düren, Germany), following supplier recommended protocols. EV RNA was isolated using the same procedure, from $\mathrm{CM}$ of the corresponding parent cells ( $\mathrm{n}=3$ replicates each). cDNA was synthesized using miRCURY LNA RT kit (Qiagen, Hilden, Germany) and UniSp6 RNA Spike-in controls were used. Expression of miR17-5p (YP02119304), miR-18a-5p (YP00204207), miR-19b-3p (YP00204450), miR-20a-5p (YP00204292), and controls Rnu5g (YP00203908) was assessed with miRCURY LNA SYBR ${ }^{\circledR}$ Green PCR Kit (Qiagen, Hilden, Germany), following supplier recommended protocols. 40cycle $\mathrm{qPCR}$ was conducted as described above, and $\triangle \Delta \mathrm{CT}$ method was used to determine normalized relative miRNA expression of rAFSC-EVs and rAFSCs to rMSCs and rMSC-EVs.

\section{Immunofluorescence}


Rat lung explants were fixed using $4 \%$ paraformaldehyde for $18 \mathrm{~h}$, washed in PBS, and incubated in 30\% sucrose for at least $18 \mathrm{~h}$. Optimal cutting temperature compound (Electron Microscopy Sciences, Hatfield, PA) embedded lungs were cryosectioned in coronal orientation and stained with primary antibodies reported in table S7. Fetal lung organoids were fixed in 4\% paraformaldehyde for 30 minutes, permeabilized in $0.5 \%$ triton X (Sigma Aldrich, Missouri, MO) and $0.05 \%$ Tween-20 (Sigma Aldrich, Missouri, MO) in PBS, pre-blocked in 1\% bovine serum albumin (BSA; Sigma Aldrich, Missouri, MO) with $0.2 \%$ triton-X and $0.05 \%$ Tween-20 in PBS. Organoids were stained with primary antibodies reported in table S7. A Leica SP8 lightning confocal microscope (Wetzlar, Germany) was used to image samples using the same laser power and exposure across conditions. Wherever possible, z-stacks were taken to increase coverage of tissues. Total corrected cellular fluorescence was calculated to compare the fluorescence intensities between conditions, as described (67) using ImageJ 1.51.

\section{Proliferation and apoptosis experiments on lung explants}

Proliferation experiments in explants were conducted with the addition of EdU $(10 \mu \mathrm{M}$ final concentration in medium) to lung explants cultures $3 \mathrm{~h}$ prior to the $72 \mathrm{~h}$ endpoint of experiments. Explants were then fixed and processed for immunofluorescence assays as stated above. The Click-iT ${ }^{\mathrm{TM}}$ protocol was used to label EdU ${ }^{+}$cells (2.4:1000, Alexa Fluor ${ }^{\mathrm{TM}}$ 647) in co-staining experiments with SOX9 (1:1000, Alexa Fluor $\left.{ }^{\mathrm{TM}} 488\right)$, as recommended by the supplier. Lung explants from $\mathrm{n}=4$ biological replicates were used in at least triplicate technical replicates for analysis. Quantification of EdU signal was conducted with HistoQuant in QuantCenter Imaging Software (3D Histech, Budapest, Hungary) and covered $>10050 \times 50 \mu \mathrm{m}$ fields.

Cell apoptosis experiments on lung explants were conducted with the Click-iT ${ }^{\mathrm{TM}}$ TUNEL assay for in situ apoptosis detection, according to manufacturer's protocol. Briefly, cryo-sectioned lung 
explants from $n=4$ biological replicates were used in at least triplicate technical replicates for analysis. Alexa Fluor ${ }^{\mathrm{TM}} 647$ was used in co-staining experiments. Quantification of TUNEL signal was conducted with HistoQuant in QuantCenter Imaging Software (3D Histech, Budapest, Hungary) and covered $>10050 \times 50 \mu \mathrm{m}$ fields.

\section{Protein expression}

Protein from lung explants was isolated by re-suspending explants in cell extraction buffer (ThermoFisher Scientific, Waltham, MA) supplemented with protease inhibitors (Sigma Aldrich, Missouri, MO), and sonicating for 3 cycles of 10 seconds each. Protein was quantified using the Pierce Bradford Assay (ThermoFisher Scientific, Waltham, MA), and $20 \mu \mathrm{g}$ of protein from each sample was processed as described (29) and probed for SPC and SOX9 (table S7; Data file S5). Expression of canonical EV markers CD63, Hsp70, Flo-1, and TSG101 in rAFSC-EVs and rMSC-EVs, and the nuclear marker H3K27me3 that indicates cellular debris, were analyzed as described (29). EV preparations did not have expression of H3K27me3, demonstrating that the preparations are free of cell debris. All details for the antibodies are available in table S7.

\section{EV characterization and staining}

To track EV migration into primary lung epithelial cells and lung explants, EV cargoes were fluorescently labelled for RNA and protein using Exo-Glow ${ }^{\mathrm{TM}}$ (System Biosciences, Palo Alto, CA) and for lipid membrane using PKH26 red fluorescent cell linker (Sigma Aldrich, Missouri, MO) following supplier recommended protocols. For PKH26 staining, EVs isolated using ultracentrifugation were re-suspended in Diluent C, stained with PKH26 for five minutes with periodic mixing, then the reaction was stopped with $1 \%$ BSA in water. Starting samples containing water only were used as negative controls for staining procedures. For live cell tracking, cells were grown on $35 \mathrm{~mm} \mu$-Dish plates for $24 \mathrm{~h}$ to reach $60 \%$ confluence (Ibitreat, 
Fitchburg, WI). DAPI was added in culture medium for 10 minutes ( $2 \%$ in medium), and then 2 $\mu \mathrm{g}$ of EVs stained with ExoGlow RNA or ExoGlow Protein were added and imaged once every two seconds for 10 minutes using a Leica SP8 lightning confocal microscope. After live cell imaging was performed, cells were washed twice with PBS and fixed in 4\% PFA, and re-imaged to visualize the internalization of the stained EVs.

\section{Role of rAFSC-EV RNA Cargo}

To determine the role of RNA in rescuing pulmonary hypoplasia, rAFSC-EVs were treated with RNase-A (ThermoFisher, Waltham, MA) at $2 \mu \mathrm{g} / \mu \mathrm{L}$ for 90 minutes, then with RNase inhibitor (ThermoFisher, Waltham, MA) as described (68). Data shown in viability and proliferation assays are representative of $n=3$ technical replicates, with at least 5 fields per experiment. Bioanalyzer analysis (Agilent Technologies, Santa Clara, CA) was used to test effectiveness of RNA degradation, after total RNA isolation using miRvana miRNA isolation kit as described above. Untreated EVs that were exposed to all temperature changes without the addition of RNase-A were used as control.

To confirm the entry of RNase into rAFSC-EVs, TSG101 and RNase were probed by immunoEM labelling. Samples were prepared for TEM following established protocols (29). Briefly, fixed EV preparations (rAFSC-EVs or RNase-treated rAFSC-EVs) were allowed to absorb onto charged EM grids for $1 \mathrm{~h}$. All reagents were pre-filtered using $0.22 \mu \mathrm{m}$ syringe filters. Samples were washed in PBS, permeabilized in $0.05 \%$ triton-X in PBS for 30 minutes, washed five times in PBS, and then incubated for $2 \mathrm{~h}$ in primary antibody $(1: 100$ in 10\% BSA-c; Aurion, Wageningen, Netherlands) with TSG101, RNase, or both (table S7). Following five washes in PBS, samples were incubated for $1 \mathrm{~h}$ with the corresponding secondary antibodies (1:25 in 10\% BSA-c, table S7), washed an additional five times in PBS, then fixed in $1 \%$ glutaraldehyde for 
10 minutes. Following ten washes in distilled water, grids were contrasted and embedded in uranyl oxalate for 10 minutes, methyl cellulose-uranyl acetate for 10 minutes, and then prepared for EM imaging on a Tecnai 20 (FEI, Hillsboro, OR) from $25 \mathrm{kx}$ to $100 \mathrm{kx}$ magnification. Four biological replicates of rAFSC-EV-RNase and rAFSC-EVs, which included four technical replicates each, were included in these experiments. Experimental groups included single stains, and only secondary antibody stains (incubation with serum alone). Experiments were optimized for incubation time and antibody concentrations. Gold tags were identified and measured manually using the Tecnai 20 Software.

To determine if there was a carry-over effect of the RNase-A treatment on rAFSC-EVs, we performed an additional step and separated the enzymatically treated rAFSC-EVs from the supernatant, which presumably contained the inactivated RNase-A. This supernatant was then administered to the control primary lung epithelial cells, and proliferation rate was determined as described above.

Profiling of rAFSC-EVS and $r M S C-E V S$

$10 \mathrm{~mL}$ of rAFSC-CM or rMSC-CM was centrifuged at $1500 \mathrm{~g}$ for $5 \mathrm{~min}$ to remove residual cells and debris. The supernatant was transferred to a new $50 \mathrm{~mL}$ conical tube for $\mathrm{EV}$ isolation. Isolations were conducted in triplicate. ExoQuick-TC (System Biosciences, Palo Alto, CA) was added to the supernatant at 1:5 ratio (ExoQuick:Supernatant), mixed gently, and allowed to incubate for $18 \mathrm{~h}$ at $4{ }^{\circ} \mathrm{C}$. After $24 \mathrm{~h}$, the admixture was centrifuged at $1500 \mathrm{~g}$ for $30 \mathrm{~min}$ to separate EVs.

Proteomic profiling of EV cargo 
EVs were quantified for protein concentration using Qubit fluorometry (Invitrogen, Carlsbad, CA). $10 \mu \mathrm{g}$ of EV protein was processed by SDS-PAGE using 10\% Bis Tris NuPage mini-gel (Invitrogen, Carlsbad, CA) in the MES buffer system. The migration window (2 cm lane) was excised and in-gel digestion was performed using a ProGest robot (DigiLab, Hopkinton, MA) with the following protocol: 1) Washed with $25 \mathrm{mM}$ ammonium bicarbonate followed by acetonitrile. 2) Reduced with $10 \mathrm{mM}$ dithiothreitol at $60{ }^{\circ} \mathrm{C}$ followed by alkylation with $50 \mathrm{mM}$ iodoacetamide at room temperature. 3) Digested with trypsin (Promega, Madison, WI) at $37{ }^{\circ} \mathrm{C}$ for 4 h. 4) Quenched with formic acid and the supernatant was analyzed directly without further processing.

The digested protein samples were analyzed by nanoscale liquid chromatography coupled to tandem mass spectrometry (MS) with a Waters NanoAcquity High Performance Liquid Chromatography system interfaced to a ThermoFisher Q Exactive. Peptides were loaded on a trapping column and eluted over a $75 \mu \mathrm{m}$ analytical column at $350 \mathrm{~nL} / \mathrm{min}$ using a $2 \mathrm{~h}$ reverse phase gradient; both columns were packed with Luna C18 resin (Phenomenex, Torrance, CA). The mass spectrometer was operated in data-dependent mode, with the Orbitrap operating at 60,000 and 17,500 full width at half maximum for MS and MS/MS respectively. The fifteen most abundant ions were selected for MS/MS. Data were searched using Mascot, and parsed into Scaffold (Proteome Software) for validation, filtering and to create a non-redundant list per sample. Data was filtered using $1 \%$ protein and peptide false discovery rate (FDR) and required at least two unique peptides per protein. A minimum of three spectral count values greater than 0 in at least one of the groups was considered significantly different, and a t-test was performed on these values. For protein pathway enrichment analysis, 222 proteins that were differentially expressed in rAFSC-EVs were used as input for g:Profiler, and R package "ggplot2" was used to 
plot the top significantly enriched pathways for Biological Processes, Cellular Component, and Molecular Functions.

\section{RNA-sequencing of EV cargo}

Total RNA was isolated using the SeraMir Exosome RNA Purification Column kit (System Biosciences, Palo Alto, CA) according to the manufacturer's instructions. For each sample, $1 \mu \mathrm{L}$ of the final RNA eluate was used for measurement of small RNA concentration by Agilent Bioanalyzer Small RNA Assay using Bioanalyzer 2100 Expert instrument (Agilent Technologies, Santa Clara, CA).

Small RNA libraries were constructed with the CleanTag Small RNA Library Preparation Kit (TriLink, San Diego, CA) according to the manufacturer's protocol. The final purified library was quantified with High Sensitivity DNA Reagents (Agilent Technologies, Santa Clara, CA) and High Sensitivity DNA Chips (Agilent Technologies, Santa Clara, CA). The libraries were pooled, and the 140 base pair to 300 base pair region was size selected on an $8 \% \mathrm{TBE}$ gel (Invitrogen, Carlsbad, CA). The size selected library is quantified with High Sensitivity DNA 1000 Screen Tape (Agilent Technologies, Carlsbad, CA), High Sensitivity D1000 reagents (Agilent Technologies, Carlsbad, CA), and the TailorMix HT1 qPCR assay (SeqMatic, Fremont, CA), followed by a NextSeq High Output single-end sequencing run at SR75 using NextSeq 500/550 High Output v2 kit (Illumina, San Diego, CA) according to the manufacturer's instructions.

Following an initial quality assessment with bioinformatics tool FastQC, $\mathrm{n}=3$ biological replicates of rAFSC-EVs and $n=2$ biological replicates of rMSC-EVs were included in the final analysis. Bowtie2 was used to map the spike-in DNA, and the reads were trimmed and filtered to improve the quality of data input for read mapping using open-source tools (FastqMcf, cutadapt, 
PRINSEQ). After trimming, reads were mapped using open-source software (Bedtools/SAMtools). DESeq was used for differential expression analysis with default settings.

\section{Primary Lung Epithelial Cell RNA-sequencing Experiments}

Primary lung epithelial cells from nitrofen-injured lungs and normal control lungs were isolated as described above, grown in PneumaCult ${ }^{\mathrm{TM}}$ Ex Plus Medium, and treated with medium supplemented with rAFSC-EVs or rMSC-EVs $(0.5 \% \mathrm{v} / \mathrm{v})$. Total RNA extraction was conducted on $\mathrm{n}=6$ biological replicates of each condition. RNA was extracted using Nucleospin miRNA kit (Macherey-Nagel, Düren, Germany) following supplier recommended protocols. Purified RNA was quantified using NanoDrop, and Bioanalyzer was used to assess the quality of RNA. Samples with RNA integrity number of $>9$ were used to construct libraries. For library construction, we used an automated NEBNext Ultra II Directional with polyA isolation (New England BioLabs) using the Agilent NGS Workstation (Agilent Technologies) as per manufacturer's protocol. Briefly, $250 \mathrm{ng}$ of total RNA spiked-in with SIRVs (Spike-in RNA Variant Control Mixes, Set3, Lexogen) as per manufacturer's protocol was used to generate complementary DNA (cDNA). cDNA was amplified with 12 PCR cycles. The resulting libraries were quantified with Qubit DNA HS (ThermoFisher). Fragment sizes were analyzed on the Agilent Bioanalyzer using the High Sensitivity DNA assay prior to sequencing. Paired-end sequencing was performed by The Centre for Applied Genomics, The Hospital for Sick Children, Toronto, Canada on a NovaSeq 6000 S2 flowcell (Illumina) with a read length of 100 base pairs. 25-35 million paired end reads were obtained for each library. Sequencing quality was examined using FastQC and qualimap (see data file S2 for detailed QC metrics on sequencing libraries). Reads were aligned to the rat genome (rnor6, obtained from UCSC genome browser database) using a splice aware aligner, STAR (version 2.5.1b) with default 
settings. Reads were assigned to genes using featureCounts (version 1.5.3) with parameters "-p B -s 2 -Q 255". Gene models were obtained from Ensembl (Rnor_6.0.91). Reads from ERCC (External RNA Controls Consortium, Ambion) spike-ins (included in SIRV Set3) were only used for QC purposes. For each sample, a linear model was fitted between $\log 2$ reads per million mapped reads (RPKM) values and $\log 2$ expected RNA amount of the ERCC transcripts to evaluate the accuracy of the RNA-seq measurement. Number of ERCC transcripts detected (transcripts per million $>0$ ) and the corresponding $\mathrm{R}^{2}$ values from the linear models are listed in data file S2. Normalized gene counts (RPKM) were calculated with R package "edgeR" (version 3.26.5) with "calcNormFactors" and "rpkm" functions. Only genes with RPKM $>1$ in at least 12 samples were used for downstream analyses. All samples were used in the model fitting and dispersion estimation steps. The Quasi-likelihood F-test method was then used to identify the differentially expressed genes between pairs of conditions of interest (FDR $<0.1)$. Heatmaps were generated with $\mathrm{R}$ package "pheatmap with colors representing row-scaled RPKM values. $\mathrm{R}$ package 'fgsea' was used for GSEA analysis. For each pair-wise comparison, genes are ranked based on their fold changes (NA vs. N or NM vs. N). GMT files for "C2: curated gene sets" and "C5: GO gene sets" were obtained from the MSigDB collections and used separately in the analysis.

\section{Small RNA-sequencing on epithelial cells}

To study changes in miRNA expression patterns in the same target cells, we further analyzed the Nitrofen and Nitrofen+rAFSC-EVs treated cells using small RNA-sequencing. Total RNA isolated from $\mathrm{n}=4$ matched samples of Nitrofen and Nitrofen+rAFSC-EVs was used to prepare small RNA libraries (NEBNext small RNA kit) and subjected to miRNA-sequencing. Sequencing libraries were quantified and size selected as described above, and sequenced on a 
single-end 50-base pair rapid run flowcell. FastQC was used to examine the quality of approximately 1.4 million mapped reads per sample. BBDuk (BBMap suite v37.90) was used to trim adaptor sequences from reads with reference adapter sequences provided by BBMap suite and settings "hdist=1 mink=11" for small RNA-seq reads. For miRNA size specificity, only reads less than 23 nucleotides in length were retained. Following trimming, FastQC was used to examine the quality of trimmed sequenced reads. miRDeep2 (v2.0.0) mapper.pl was used with default parameters to map reads of at least 18 nucleotides in length to rat genome (rnor6). Known and novel miRNAs were identified using miRDeep2 main algorithm (miRDeep2.pl) with default parameters and known mature miRNAs for rat which were obtained from miRBase (v22.1). Only known and novel miRNAs with reported miRDeep score $\geq 2$ were retained for downstream analyses.

\section{Counts processing and differential miRNA expression analysis}

Prior to differential miRNA expression analysis, read counts were scaled to sample library sizes and read counts per million (CPM) were calculated using R (v3.6.0) edgeR functions "cpm" and "calcNormFactors" (v3.26.5). Only miRNAs with CPM $\geq 1$ in at least 3 samples within each condition were retained for downstream analysis. Differentially expressed miRNAs were identified using edgeR. Quasi-likelihood F-test method was used to test for differential expression (FDR < 0.1) for rAFSC-EV-treated and nitrofen-injured lung epithelial cells (NA) compared to nitrofen-injured cells $(\mathrm{N})$.

miRNA-mRNA gene target correlation

Rat orthologs of miRNA-mRNA gene targets were determined from TargetScan (v7.2) and miRTarBase (release v8.0). Only TargetScan gene targets with weighted context score percentile $\geq 50$ were retained. Spearman's correlation was calculated using $\log C P M$ miRNA expression 
and $\operatorname{logRPKM}$ gene expression for a given pair. miRNA-gene pairs with Spearman's correlation coefficient (rho) $<0$ and $\mathrm{p}$-value $\leq 0.05$ were considered negatively correlated.

\section{Cargo-seq miRNA-mRNA interaction network}

miRNAs with a detected expression value $\geq 2$ in rAFSC-EVs were considered in this analysis. miRNA-gene target pairs were determined as outlined above and shown as an interaction network generated using Cytoscape. Target genes that are differentially expressed (FDR $<0.1$ ) and have lower expression in rAFSC-EV-treated samples $(\log 2 \mathrm{FC}<0)$ are shown in the interaction network (blue nodes). miRNAs detected in rAFSC-EVs with higher median logCPM expression in rAFSC-EV-treated and nitrofen-injured primary cells compared to nitrofen-injured untreated cells are considered "miRNA up in primary cells" (green nodes). "miRNA in rAFSCEV cargo" (white nodes) represent miRNAs detected in rAFSC-EV cargo and are not detected in rAFSC-EV-treated nitrofen-injured primary cells or these miRNAs have lower median logCPM expression in rAFSC-EV-treated nitrofen-injured primary cells compared to nitrofen-injured untreated primary cells. 
A
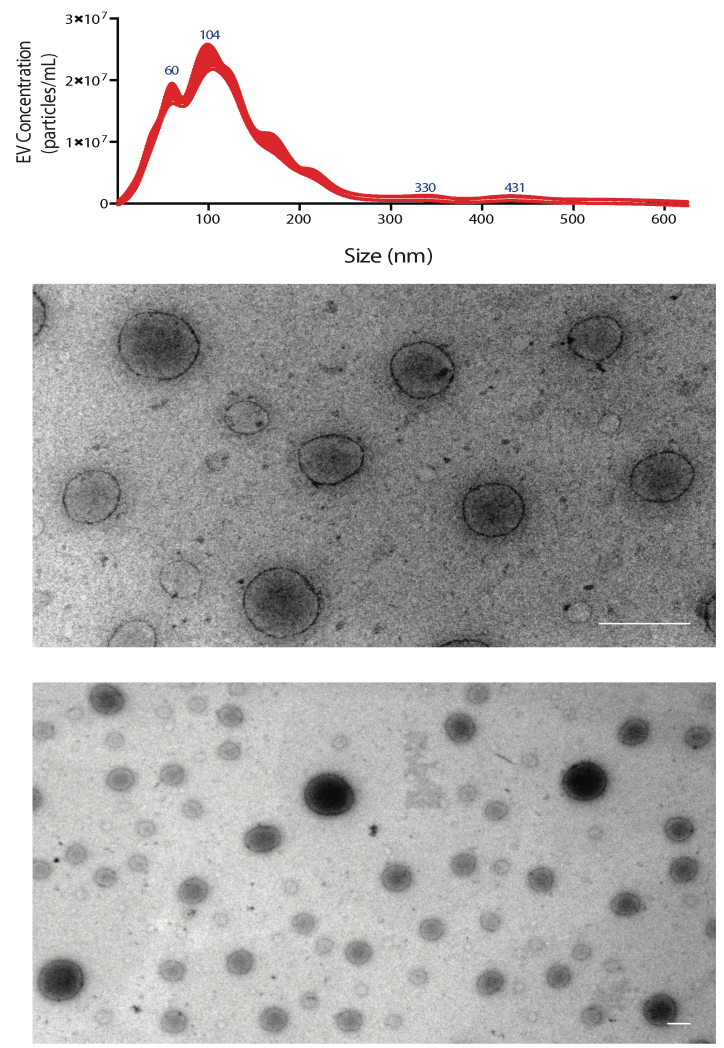

C

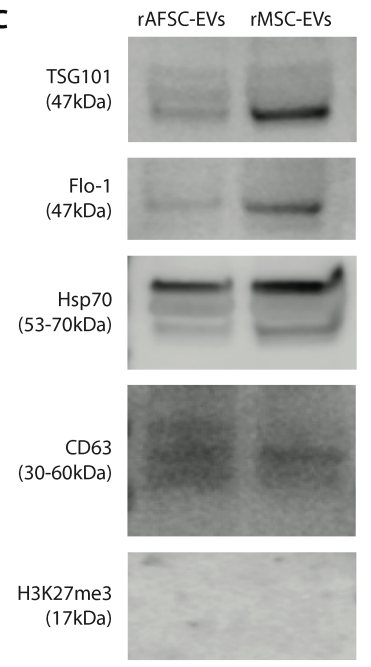

B
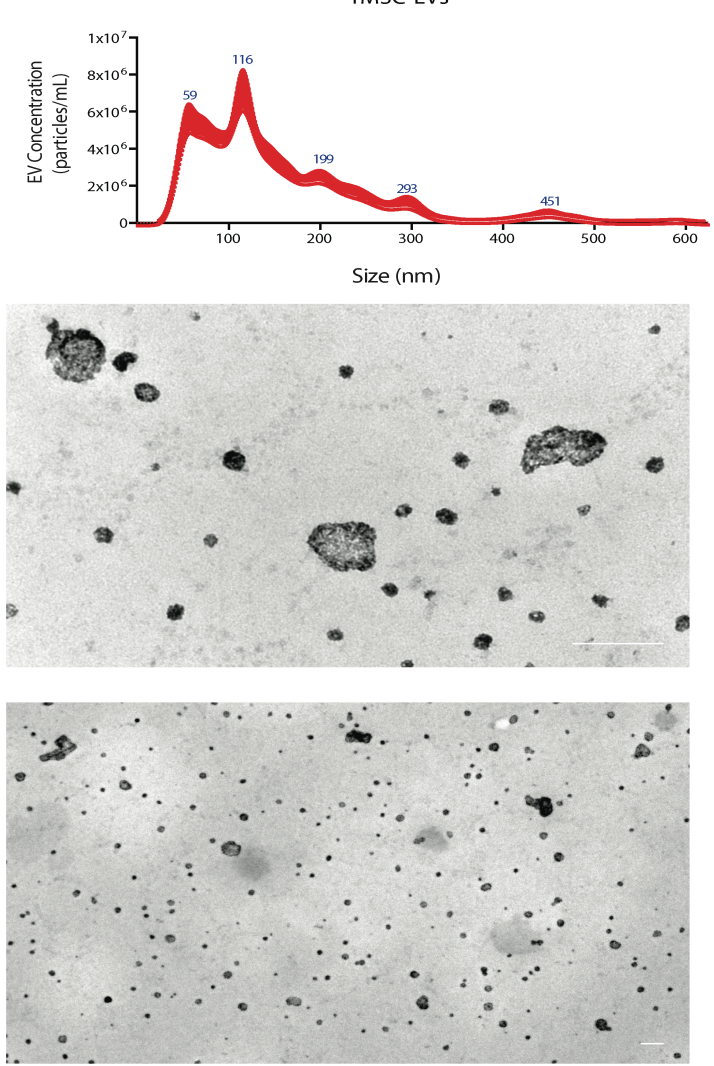

E

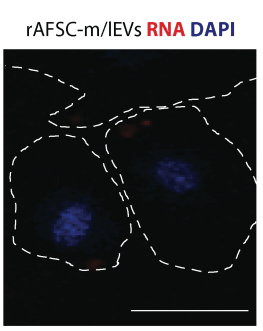

G

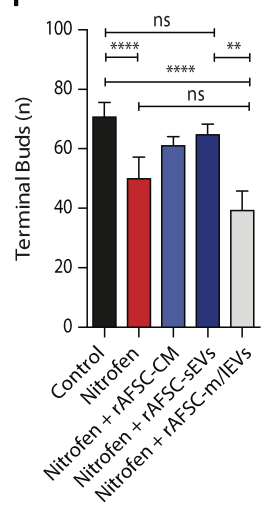

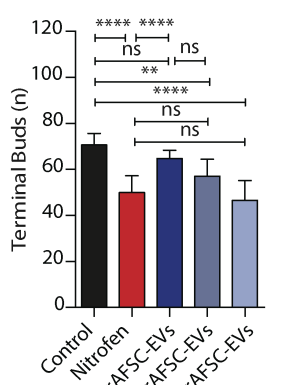

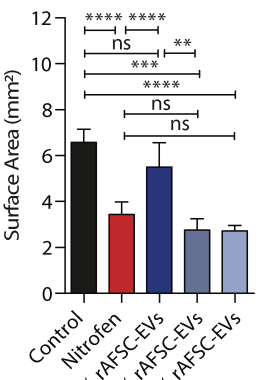

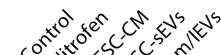

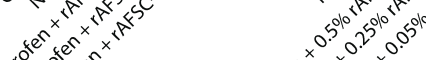


Fig. S1. Characterization of rAFSC-EVs and rMSC-EVs and effects on lung explants based on size and concentration. (A) Representative plot of the average size distribution of rAFSCEVs and rMSC-EVs visualized using nanoparticle tracking analysis. Data are representative of five 40 -second videos of each EV preparation. X-axis = size distribution $(\mathrm{nm}), \mathrm{y}$-axis = concentration (particles/mL). (B) Representative transmission electron microscopy photos of rAFSC-EVs and rMSC-EVs; two different magnifications highlight the morphology of individual EVs at near fields (top) and far fields (bottom). Scale bar $=200 \mathrm{~nm}$. (C) Expression of canonical EV markers TSG101, Flo-1, Hsp70, and CD63 obtained by Western blot analysis for rAFSC-EVs and rMSC-EVs in $n=3$ technical replicates. EV preparations do not express histone marker H3K27me3. (D) Representative plot of the average size distribution of medium/large rAFSC-EVs. Data are representative of five 40-second videos of each EV preparation. X-axis = size distribution $(\mathrm{nm}), \mathrm{y}$-axis $=$ concentration $($ particles $/ \mathrm{mL})$. $(\mathbf{E})$ Live cell tracking of RNA in medium/large rAFSC-EVs (m/1 rAFSC-EVs), DAPI, blue. Scale bar $=100 \mu \mathrm{m}$. Cells were outlined based on light microscopy images to highlight the cell border. (F) Effects of EV size (small EVs, rAFSC-sEVs; medium/large, m/1 rAFSC-EVs) on lung explant terminal bud count and mean surface area in Control $(n=16)$, Nitrofen $(n=17)$, Nitrofen+rAFSC-CM $(n=12)$, Nitrofen+rAFSC-sEVs $(n=12)$, and Nitrofen+rAFSC-m/lEVs $(n=4)$. (G) Effects of decreasing doses of rAFSC-EVs $(0.5 \%, 0.25 \%, 0.05 \% \mathrm{v} / \mathrm{v})$ on lung explant terminal bud count and mean surface area in Control $(n=16)$, Nitrofen $(n=17)$, Nitrofen $+0.5 \%$ v/v rAFSC-EVs $(n=12)$, Nitrofen $+0.25 \%$ v/v rAFSC-EVs $(n=5)$, Nitrofen $+0.05 \%$ v/v rAFSC-EVs $(n=5)$. Groups were compared using Kruskal-Wallis (post-hoc Dunn's nonparametric comparison) test for fig. S1 F and G, according to Gaussian distribution assessed by D'Agostino Pearson omnibus normality test. 
A

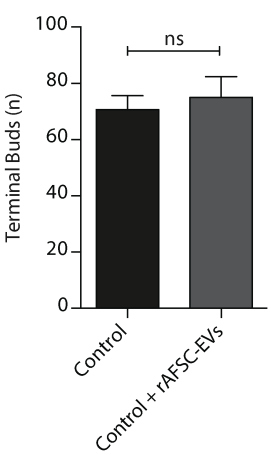

C

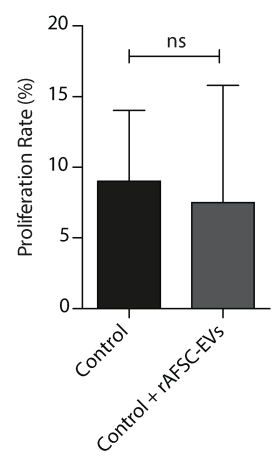

B

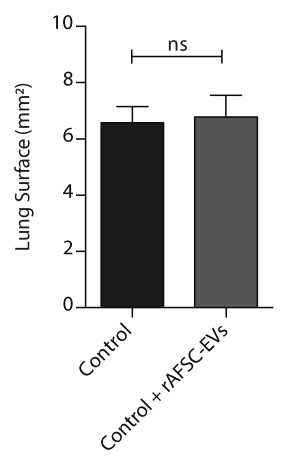

D

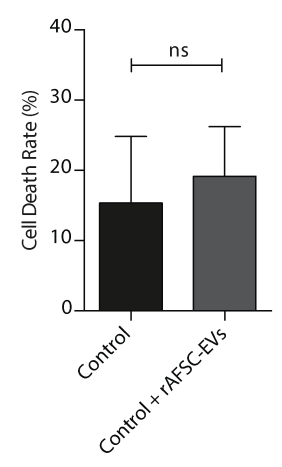


Fig. S2. Effects of rAFSC-EVs on control lung explants and primary lung epithelial cells. (A and B) Addition of rAFSC-EVs on control lung explants quantified for terminal bud count, (A) and lung surface area, (B), in Control $(n=16)$ and Control+rAFSC-EVs $(n=4)$. Effects on control primary lung epithelial cells proliferation $(\mathbf{C})$, and cell death rates $(\mathbf{D})$ in Control $(\mathrm{n}=4)$ and Control+rAFSC-EVs $(\mathrm{n}=3), \mathrm{ns}=\mathrm{P}>0.05$. Groups were compared using Mann-Whitney test for fig. S2 A-D, according to Gaussian distribution assessed by D'Agostino Pearson omnibus normality test. 
A

Nitrofen + rMSC-EVs

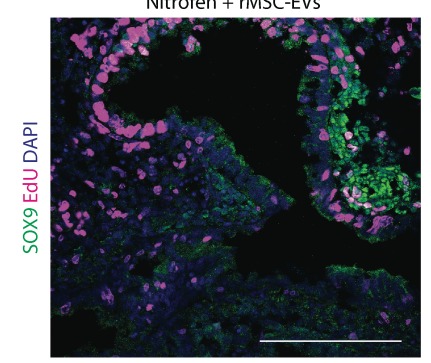

B

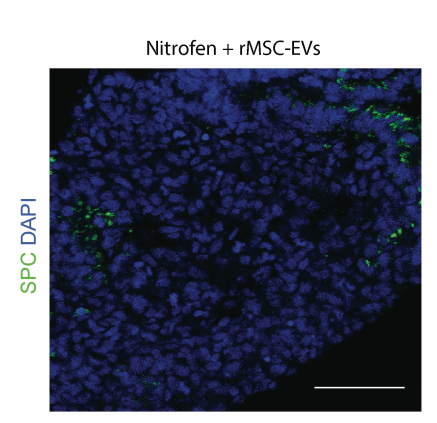

D

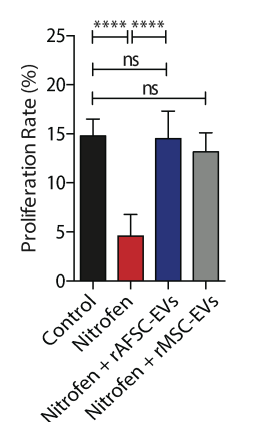

F

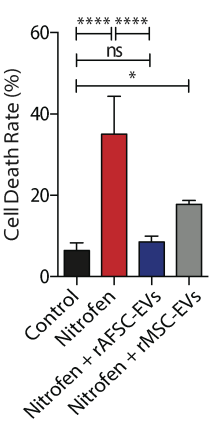

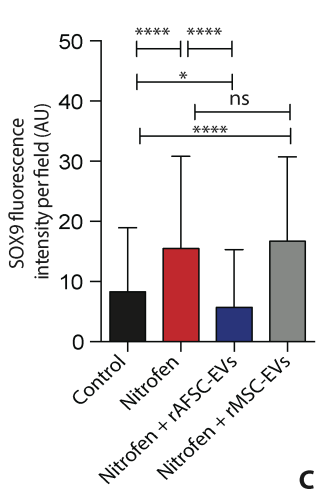
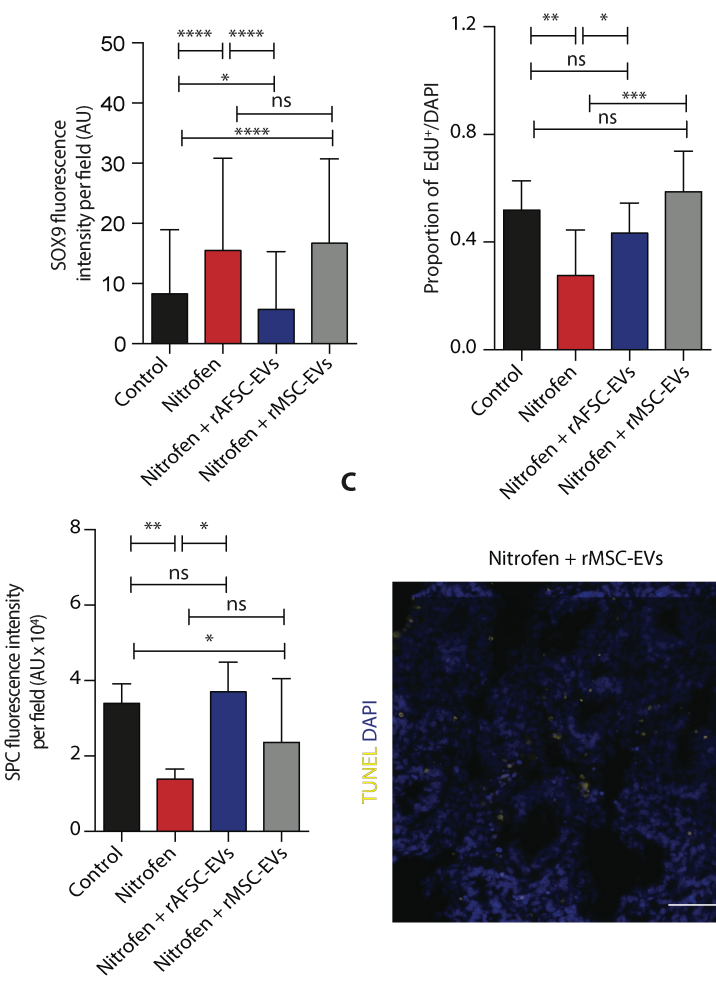

G
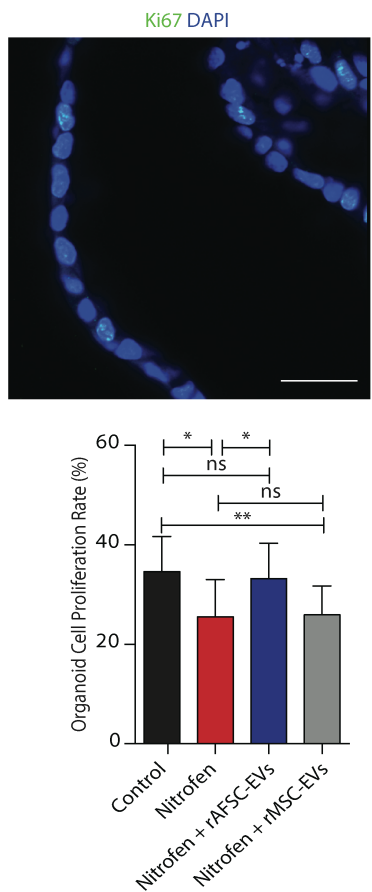

Nitrofen + rMSC-EVs
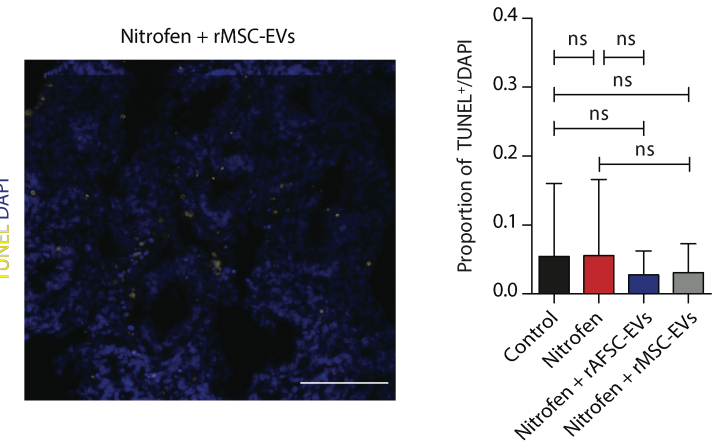

I
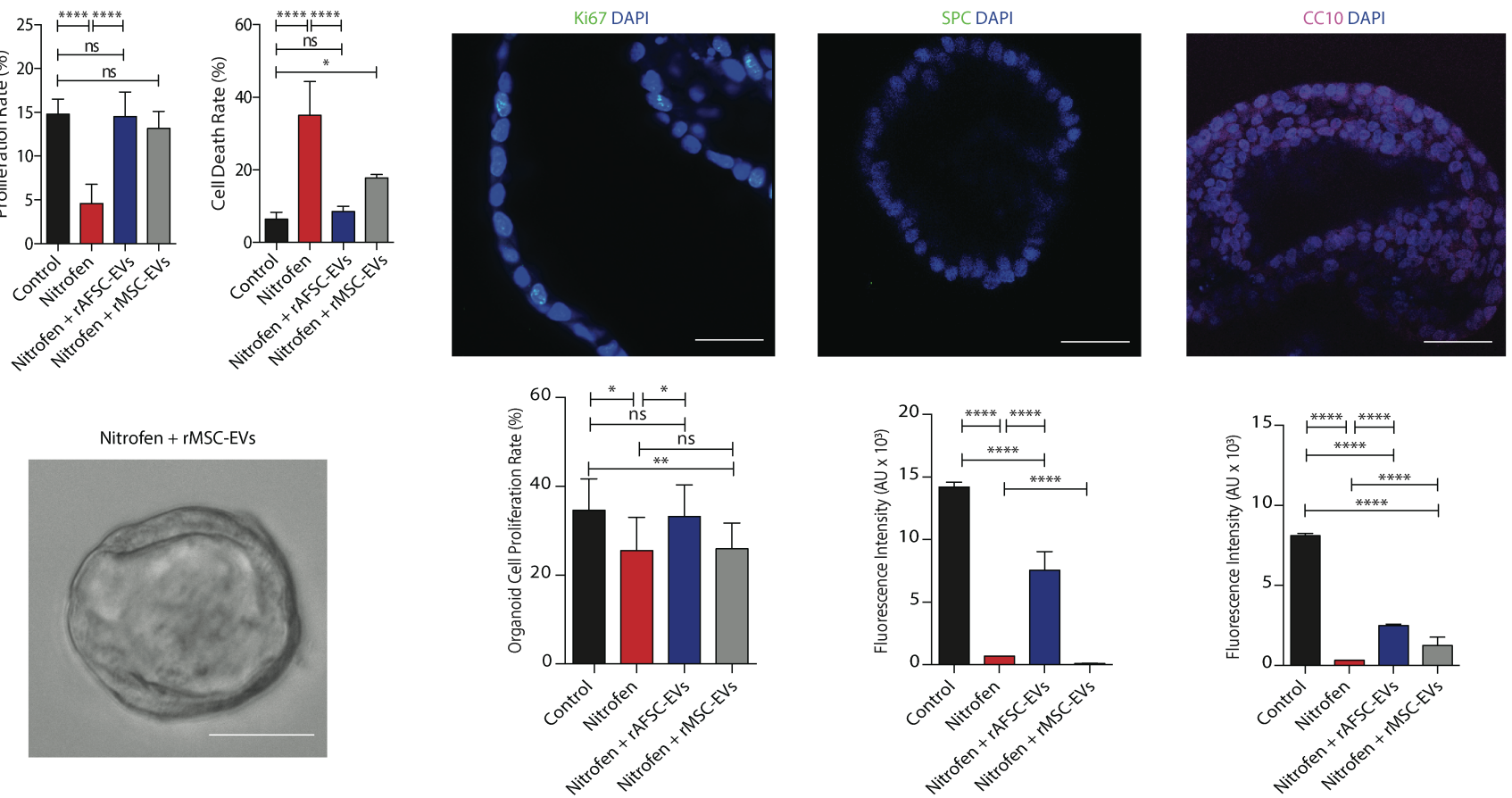


\section{Fig. S3. Effects of rMSC-EV administration on in vitro and ex vivo models of pulmonary}

hypoplasia. (A) Immunofluorescence co-stain experiment of proliferating cells and distal lung epithelium progenitor cells of lung explants (SOX9, green; EdU, pink, DAPI nuclear stain, blue; scale bar $=100 \mu \mathrm{m})$, quantified through number of EdU ${ }^{+}$cell per DAPI and SOX9 fluorescence intensity ( $\mathrm{AU}=$ arbitrary units) in $\mathrm{n}=4$ biological replicates with a total of $50 \times 50 \mu \mathrm{m}$ fields covering entire lung sections as indicated: Control $(n=157)$, Nitrofen $(n=222)$, Nitrofen+rAFSCEVs (n=128), Nitrofen+rMSC-EVs (n=122). (B) Immunofluorescence experiment of surfactant protein C (SPC) expressing cells in lung explants (SPC, green; DAPI nuclear stain, blue; scale bar=100 $\mu \mathrm{m})$, quantified by fluorescence intensity: Control $(n=6)$, Nitrofen $(n=4)$, Nitrofen+rAFSC-EVs ( $\mathrm{n}=4)$, Nitrofen+rMSC-EVs $(\mathrm{n}=4)$. (C) TUNEL immunofluorescence experiments on lung explants grown for $72 \mathrm{~h}$, quantified by $\mathrm{TUNEL}^{+}$cells per DAPI in $\mathrm{n}=4$ biological replicates with a total of $50 \times 50 \mu \mathrm{m}$ fields covering entire lung sections as indicated: Control $(n=311)$, Nitrofen $(n=240)$, Nitrofen+rAFSC-EVs $(n=107), \quad$ Nitrofen+rMSC-EVs $(n=191)$. (D) Proliferation rate of primary lung epithelial cells from control and nitrofen-injured hypoplastic lungs treated with medium only, rAFSC-EVs, or rMSC-EVs [5'EdU labeling Control $(n=7)$, Nitrofen $(n=5)$, Nitrofen+rAFSC-EVs $(n=5)$, Nitrofen+rMSC-EVs $(n=4)]$. (E) Cell death rate of primary lung epithelial cells from control and nitrofen-injured hypoplastic lungs treated as in (D) (live/dead cytotoxicity assay in Control $n=5$, Nitrofen ( $n=5$ ), Nitrofen+rAFSC-EVs $(n=5)$, Nitrofen+rMSC-EVs $(n=4)$. (F) Light microscopy photos of fetal rat lung organoids derived from nitrofen-injured hypoplastic lungs treated with rMSC-EVs. Scale bar $=100 \mu \mathrm{m}$. Representative photo of $n=104$ organoids imaged. (G) Proliferation of cells in organoids evaluated with immunofluorescence (Ki67 staining, green; scale bar $=50 \mu \mathrm{m}$ ) and quantified as percentage of $\mathrm{Ki}^{+} 7^{+}$cells per total number of DAPI (blue) stained nuclei in Control 
$(\mathrm{n}=8)$, Nitrofen $(\mathrm{n}=7)$, Nitrofen+rAFSC-EVs $(\mathrm{n}=9)$, Nitrofen+rMSC-EVs $(\mathrm{n}=14)$. (H) SPC staining in organoids (green; DAPI nuclear stain, blue; scale bar $=50 \mu \mathrm{m}$ ) quantified with fluorescence intensity calculated from total corrected cellular fluorescence in Control $(n=30)$, Nitrofen $(\mathrm{n}=31)$, Nitrofen+rAFSC-EVs $(\mathrm{n}=25)$, Nitrofen+rMSC-EVs $(\mathrm{n}=5)$. (I) $\mathrm{CC} 10^{+}$cells in organoids (green; DAPI nuclear stain, blue; scale bar $=50 \mu \mathrm{m}$ ) quantified with fluorescence intensity calculated from total corrected cellular fluorescence in Control $(n=30)$, Nitrofen $(n=30)$, Nitrofen+rAFSC-EVs $(\mathrm{n}=30)$, Nitrofen+rMSC-EVs $(\mathrm{n}=25)$. Groups were compared using Kruskal-Wallis (post-hoc Dunn's nonparametric comparison) test for fig. S3 A-E, G-I, according to Gaussian distribution assessed by D'Agostino Pearson omnibus normality test. 
A

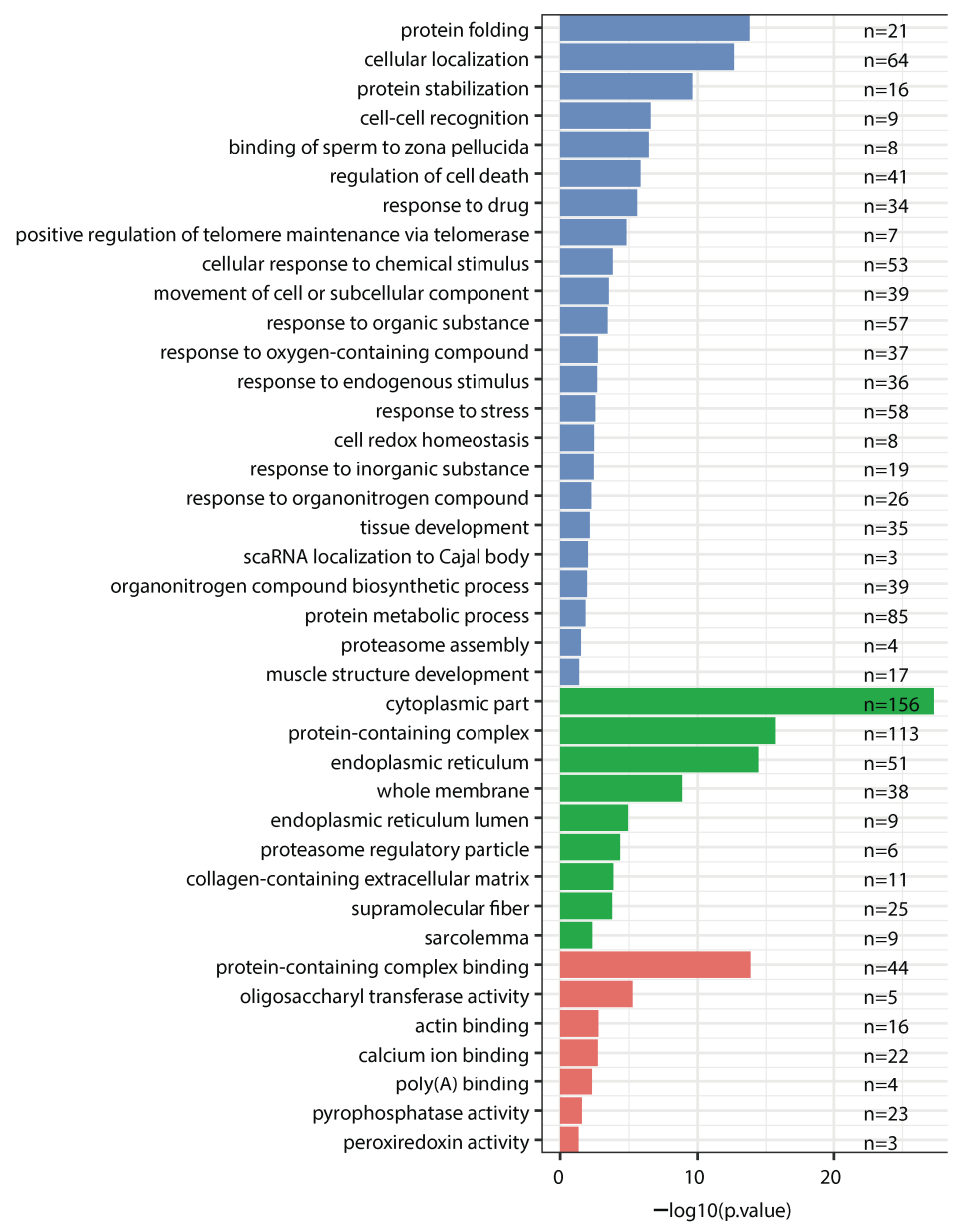

B

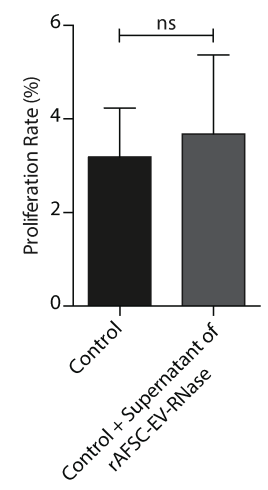

C

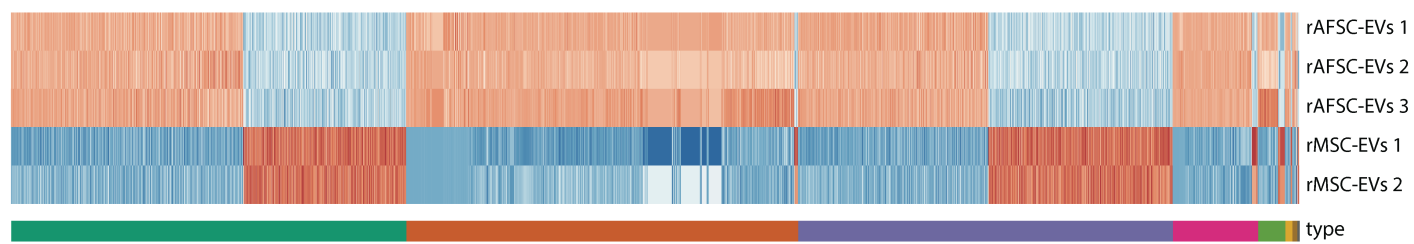

$\begin{array}{lll}1.5 & \text { type } \\ 1 & \begin{array}{l}\text { RefSeq } \\ \text { rfam } \\ 0.5\end{array} & \begin{array}{l}\text { RefSeq_antisense } \\ \text { miRNA } \\ \text { tRNA } \\ 0\end{array} \\ -0.5 & \begin{array}{l}\text { other_ncRNA } \\ \text { piRNA } \\ \text { other_ncRNA_antisense }\end{array} \\ -1 & \\ -1.5 & \end{array}$

D

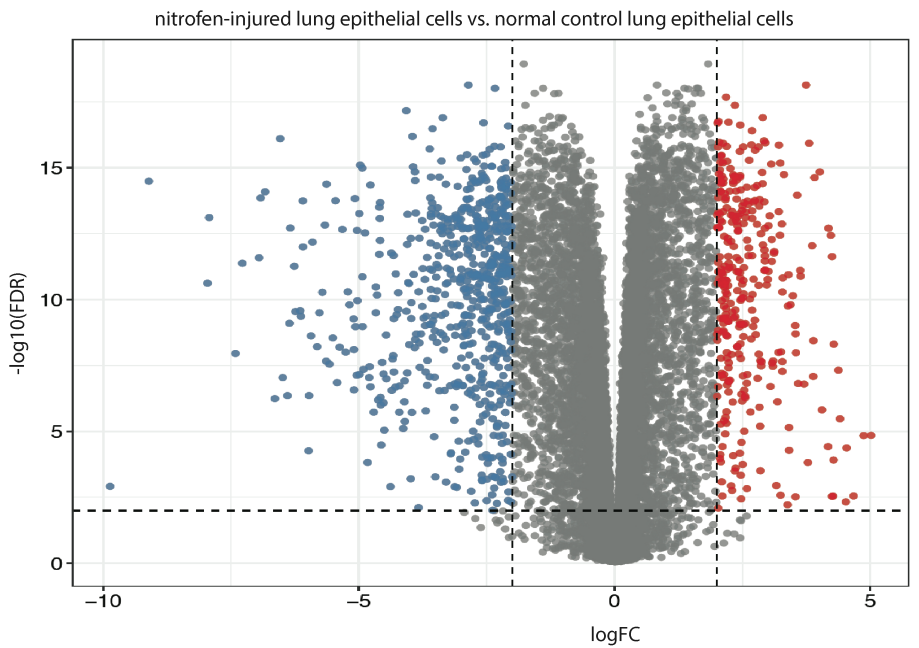


Fig. S4. Analysis of protein and RNA cargo of rAFSC-EV and rMSC-EV. (A) Pathway enrichment analysis of rAFSC-EV enriched protein cargo in GO terms Biology Processes, Cellular Component, and Molecular Functions. (B) Effect of potential carry-over of RNase in rAFSC-EV-RNase experiments on control cell proliferation ( $\mathrm{n}=17$ technical replicates). The enzymatically treated rAFSC-EVs were separated from the supernatant, which was then administered to control lung epithelial cells ( $n=43$ technical replicates). Groups were compared using unpaired t-test, according to Gaussian distribution assessed by D'Agostino Pearson omnibus normality test. (C) Heatmap showing expression levels of significantly different species of RNA (FDR $<0.01$ ) separated by type for cargo from rAFSC-EV ( $\mathrm{n}=3$ ) and rMSC-EV (n=2) samples. Rows and columns are displayed using hierarchical clustering (Ward's method; row distance measure: Pearson correlation; column distance measure: Euclidean). Color scale represents rows scaled (scaled across samples for each gene), $\log 2$ transformed normalized counts. (D) Volcano plot of genes differentially expressed between nitrofen-injured lung epithelial cells and control (non-nitrofen exposed) lung epithelial cells. Each dot represents a gene with $\log 2$ fold change $<-2$ (lower expression in Nitrofen vs. Control, $n=322$ red nodes) or $>2$ (higher expression in Nitrofen vs. Control, $n=661$ blue nodes). 
A

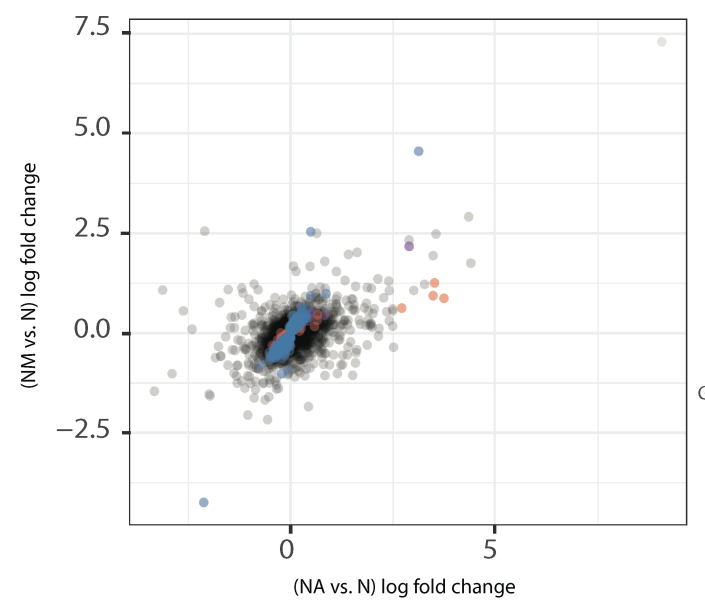

- significant in both $(n=55)$

- significant only in rAFSC-EVs $(n=24)$

significant only in rMSC-EVs $(n=550)$

C

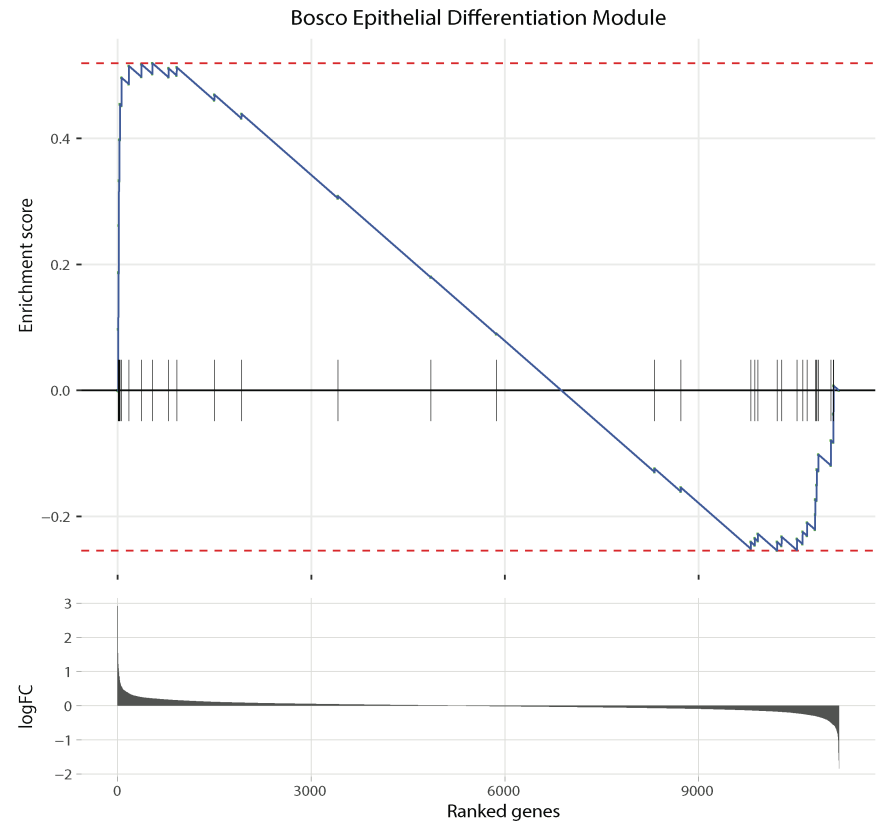

GO_EPIDERMAL_CELL_DIFFERENTIATION GO_EPIDERMIS_DEVELOPMENT GO_EPITHELIAL_CELL_DIFFERENTIATION GO_MULTICELLULAR_ORGANISMAL_HOMEOSTASIS

GO_ROUGH_ENDOPLASMIC_RETICULUM GO_CYTOSKELETAL_PART GO_STRUCTURAL_CONSTITUENT_OF_CYTOSKELETON GO_STRUCTURAL_MOLECULE_ACTIVITY GO_CHROMOSOME_SEPARATION GO_METAPHASE_ANAPHASE_TRANSITION_OF_CELL_CYCLE GO_DNA_REPLICATION_INDEPENDENT_NUCLEOSOME_ORGANIZ GO_NEGATIVE_REGULATION_OF_CHROMOSOME_SEGREGATION GO_CHROMOSOMAL_REGION GO_CONDENSED_NUCLEAR_CHROMOSOME GO_SPINDLE_MICROTUBULE GO_CONDENSED_NUCLEAR_CHROMOSOME_KINETOCHORE GO_MICROTUBULE_BINDING GO_CYTOSKELETAL_PROTEIN_BINDING

GO Biological Process

$\begin{array}{llllllllll}0.0 & 0.5 & 1.0 & 1.5 & 2.0 & 0.0 & 0.5 & 1.0 & 1.5 & 2.0\end{array}$

Normalized Enrichment Score

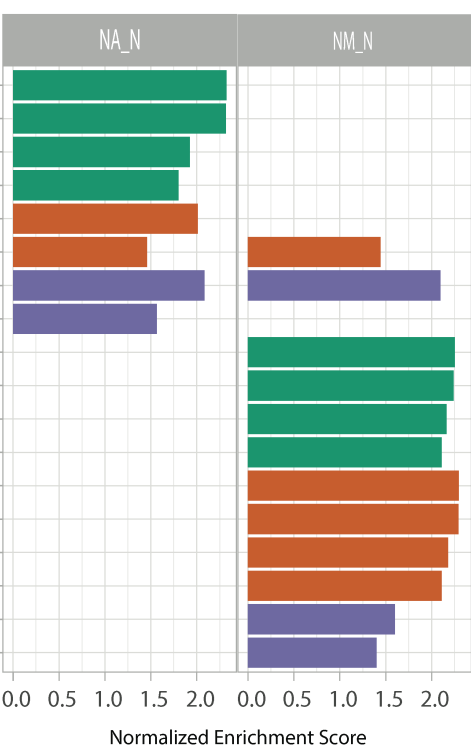

GO Cellular Compartment

GO Molecular Function

D

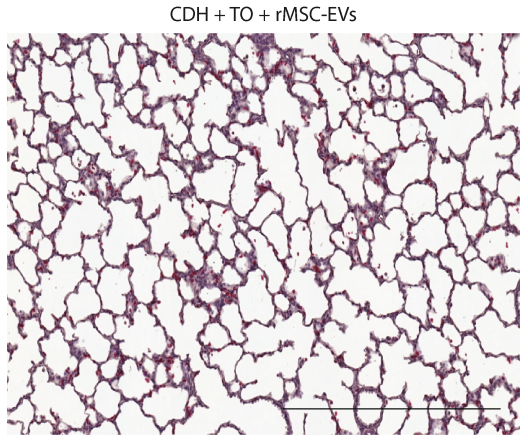

E

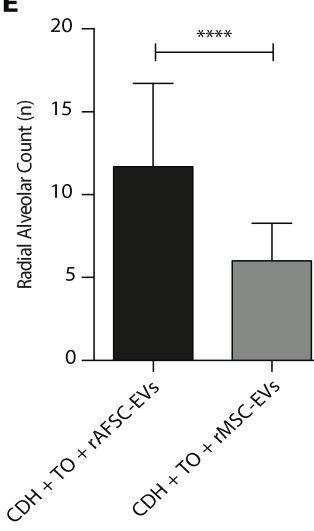

$\mathbf{F}$

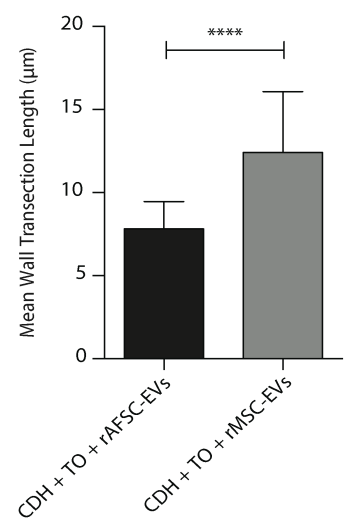


Fig. S5. Enrichment plots for RNA-seq analysis of rMSC-EV treated primary lung epithelial cells and effects on in vivo model of pulmonary hypoplasia. (A) Scatterplot of log fold changes between Nitrofen+rAFSC-EVs (NA) vs. Nitrofen (N) and Nitrofen+rMSC-EVs $(\mathrm{NM})$ vs. N. Pearson correlation $=0.54(\mathrm{p}<2.2 \mathrm{e}-16,95 \% \mathrm{CI}[0.53,0.55])$. Each dot represents a gene with its log fold change between NA vs. N shown on the X-axis and log fold change between NM vs. N shown on the Y-axis. Dots are colored based on if the gene is identified as significantly differentially expressed (FDR $<0.1$ ) only in NA vs. N (red), in NM vs. N (blue), or in both comparisons (purple). See supplementary data file S3 for the full lists of differentially expressed genes. (B) Selected pathways identified with gene set enrichment analysis of NA vs. N and NM vs. $\mathrm{N}$ primary lung epithelial cells for GO pathways Biological Process, Cellular Component, and Molecular Function. See supplementary data file S4 for full lists of GSEA results. (C) GSEA enrichment plot of epithelial cell differentiation generated with all genes ranked by fold changes between Nitrofen vs. Nitrofen+rMSC-EV-treated. (D) Representative histology images (hematoxylin/eosin) of fetal lungs from fetal rabbits that underwent surgical $\mathrm{CDH}$ creation and were subjected to administration of rMSC-EVs prior to tracheal occlusion $(\mathrm{CDH}+\mathrm{TO}+\mathrm{rMSC}-\mathrm{EVs})$. Scale bar $=500 \mu \mathrm{m} .(\mathbf{E}$ and $\mathbf{F})$ Differences in number of alveoli (radial alveolar count, E) and thickness of the alveolar wall (mean wall transection length, F) between $\mathrm{CDH}+\mathrm{TO}+\mathrm{rAFSC}-\mathrm{EVs}(\mathrm{n}=9)$ and $\mathrm{CDH}+\mathrm{TO}+\mathrm{rMSC}-\mathrm{EVs}(\mathrm{n}=8)$. Groups were compared using Mann-Whitney test for fig. S5 E and F, according to Gaussian distribution assessed by D’Agostino Pearson omnibus normality test. 


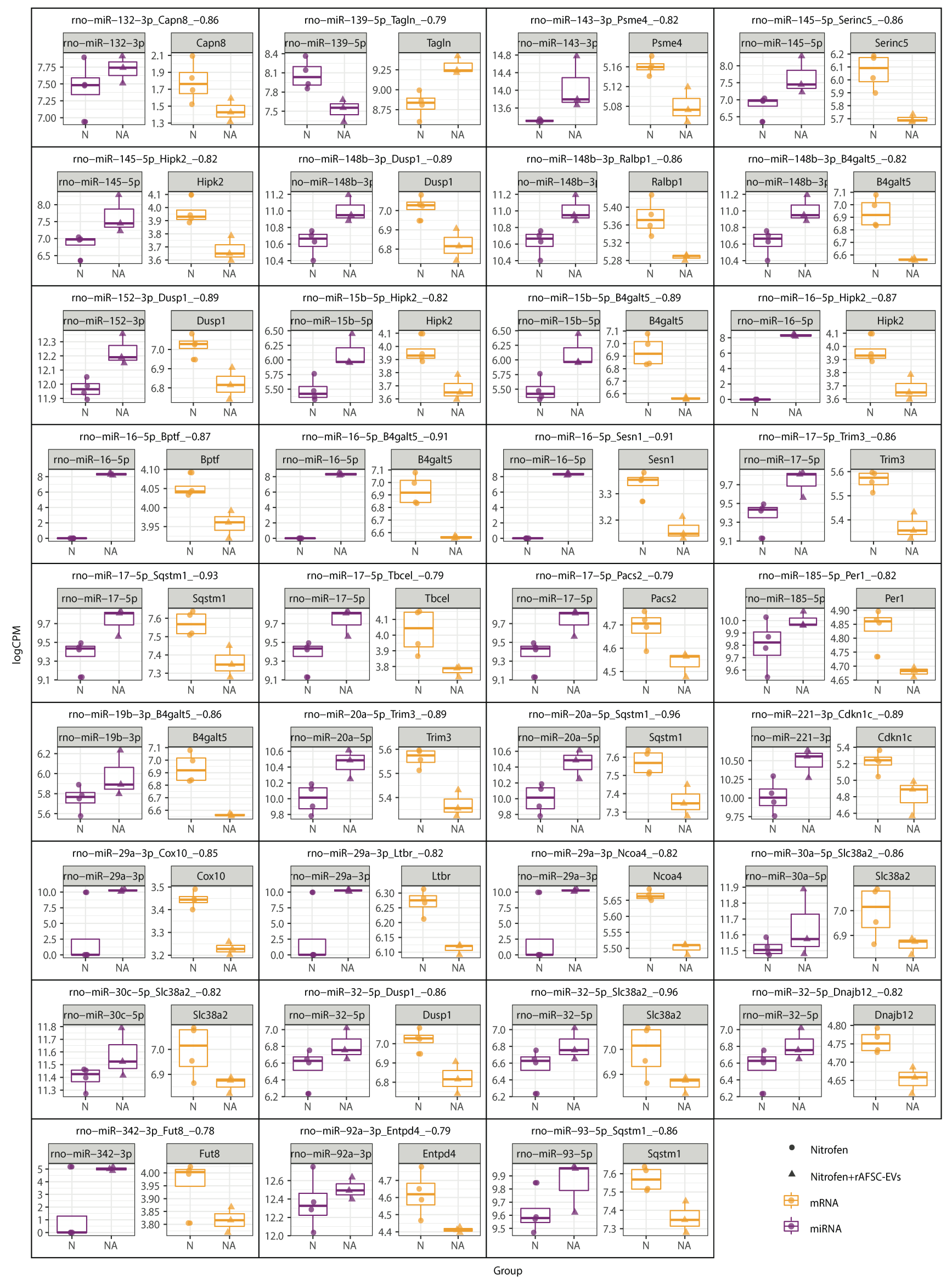


Fig. S6. Correlation analysis of miRNA-mRNA sequencing in primary lung epithelial cells. Negatively correlated miRNA-mRNA pairs in primary lung epithelial cells are graphed by log of counts per million mapped reads (CPM) of miRNA (purple) and mRNA (orange) for primary lung epithelial cells from Nitrofen $(\mathrm{N})$ and Nitrofen+rAFSC-EVs (NA) conditions. For a given negatively correlated pair ( $\mathrm{n}=3-4$ replicates), $\log \mathrm{CPM}$ expression is shown for miRNA (purple) and gene (orange). Expression is shown for nitrofen-injured lung epithelial cells (Nitrofen, N, circles) and rAFSC-EV-treated nitrofen-injured epithelial cells (Nitrofen+rAFSC-EVs, NA, triangles). Spearman's correlation coefficient (rho) is shown next to the miRNA-mRNA pair label. 
A
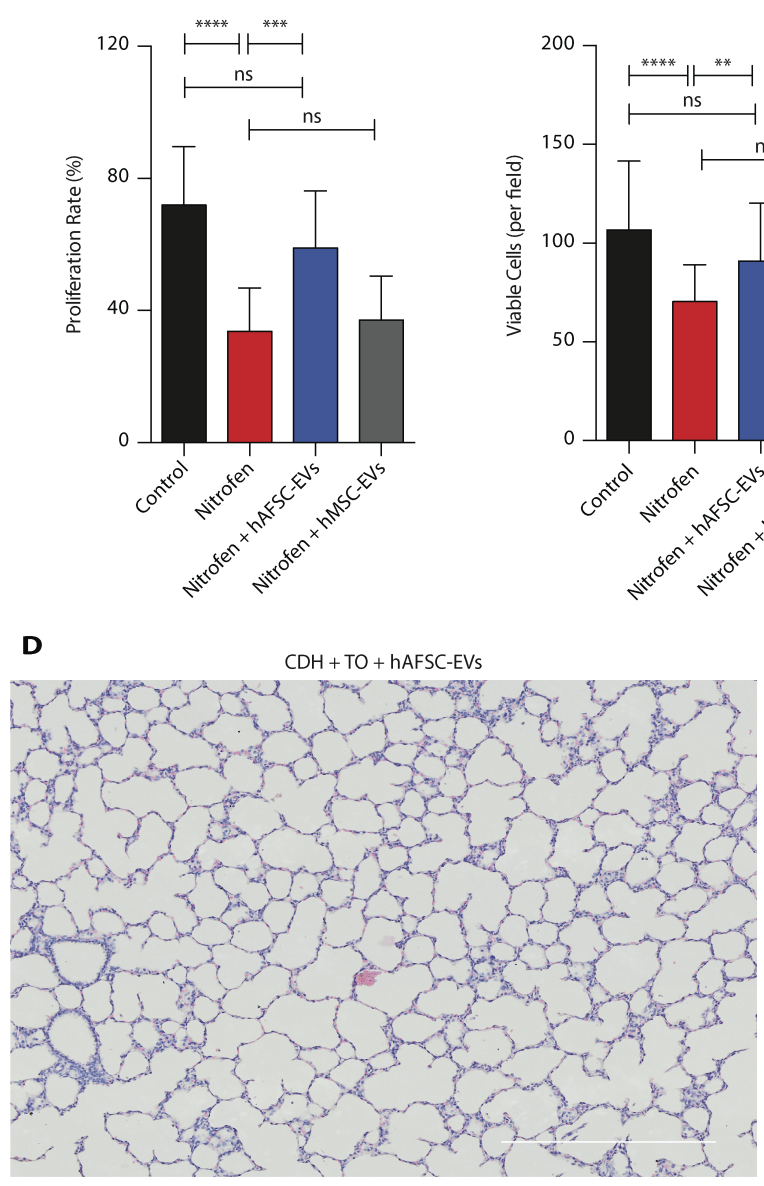

B

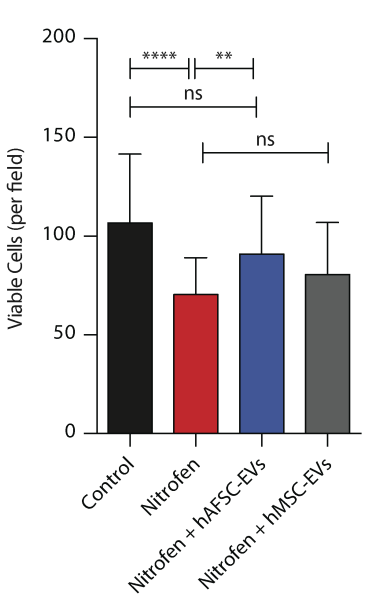

C

PKH26+hMSC-EVs DAPI Calcein-AM

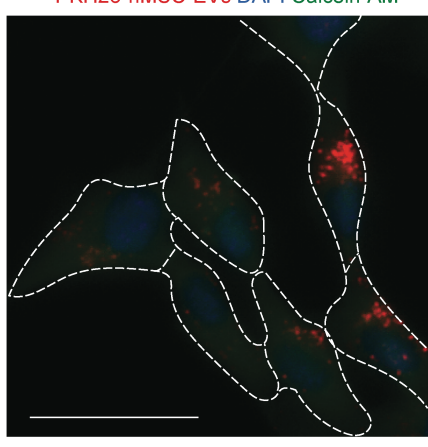

E

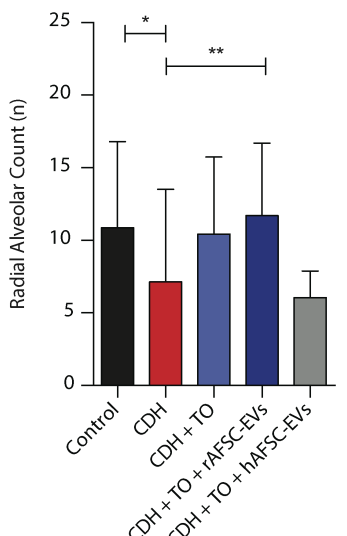

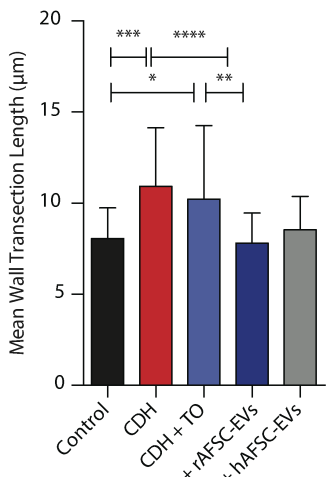

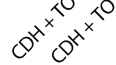


Fig. S7. Effects of hAFSC-EVs and hMSC-EVs on human fetal lung epithelial cells and in the in vivo model of pulmonary hypoplasia. (A) Proliferation rate of primary human pulmonary alveolar epithelial cells (HPAEpiC) from a fetus at 21 weeks of gestation, injured with $400 \mu \mathrm{M}$ of nitrofen exposure for $24 \mathrm{~h}$, and then treated with medium only, or medium supplemented with $0.5 \% \mathrm{v} / \mathrm{v}$ GMP-grade hAFSC-EVs or hMSC-EVs. Replicates were conducted in $n=4$ technical replicates. (B) Number of viable cells per field for the same conditions as in (A). (C) hMSC-EVs labeled with PKH26 (red signal) entering HPAEpiC (live cells labeled with Calcein-AM, green, nucleus labeled with DAPI, blue). Scale bar $=25 \mu \mathrm{m}$. (D) Representative histology image (hematoxylin/eosin) of fetal lungs of rabbits that underwent surgical CDH creation and were administered hAFSC-EVs prior to tracheal occlusion (CDH+TO+hAFSCEVs). Scale bar $=500 \mu \mathrm{m}$. Samples are representative of Control $(n=9), \mathrm{CDH}(n=9), \mathrm{CDH}+\mathrm{TO}$ $(\mathrm{n}=9), \mathrm{CDH}+\mathrm{TO}+\mathrm{rAFSC}-\mathrm{EVs}(\mathrm{n}=9)$, and CDH+TO+hAFSC-EVs $(\mathrm{n}=5) .(\mathbf{E}$ and $\mathbf{F})$ Differences in number of alveoli (radial alveolar count, E) and thickness of the alveolar wall (mean wall transection length, F). Groups were compared using Kruskal-Wallis (post-hoc Dunn's nonparametric comparison) test for fig. S7 E, F, according to Gaussian distribution assessed by D’Agostino Pearson omnibus normality test. 
A

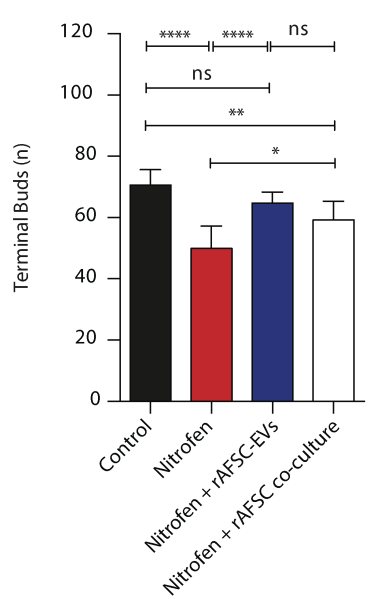

B

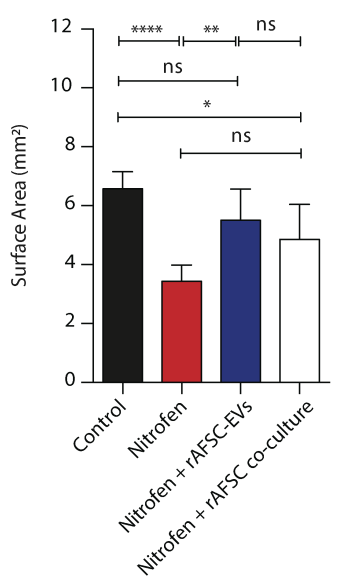

E

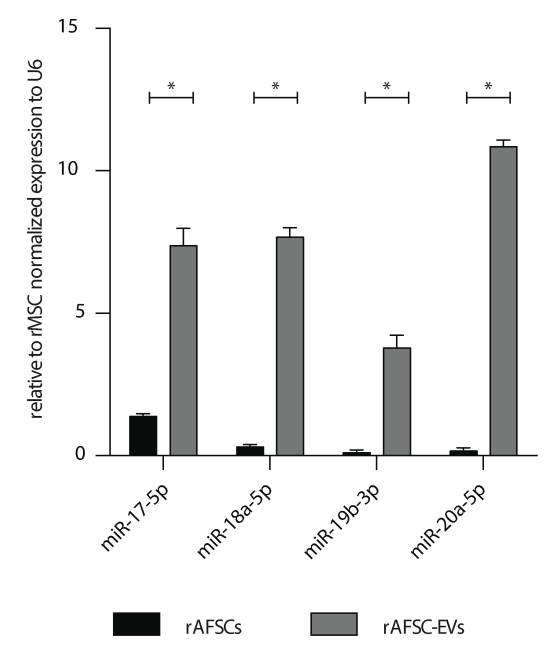

C

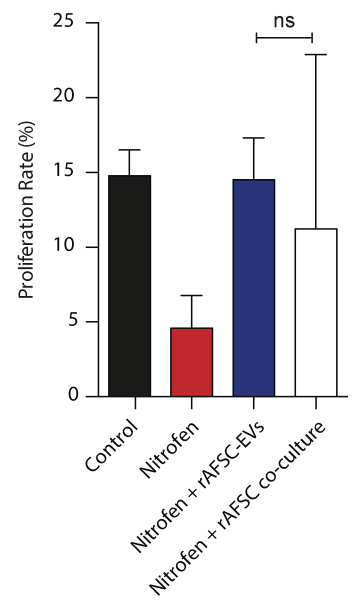

D

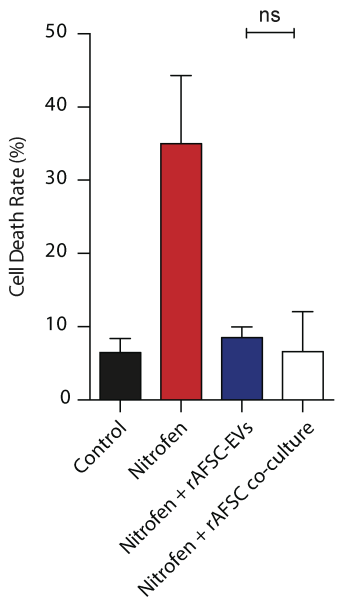

F
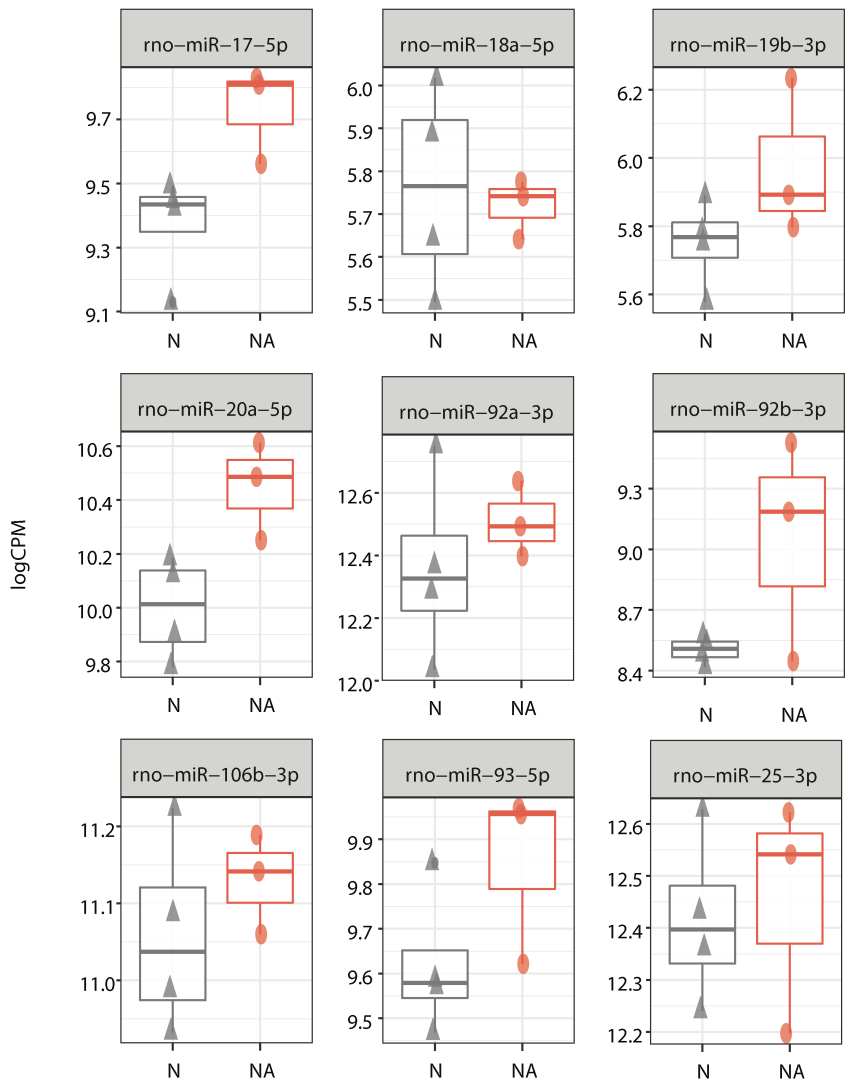
Fig. S8. Influence of rAFSCs in co-culture with ex vivo and in vitro models of pulmonary hypoplasia and effects on rAFSC-EV miRNA cargo. (A and B) Effects on terminal bud count (A) and mean surface area (B) of nitrofen-injured fetal lung explants co-cultured with rAFSCs at $72 \mathrm{~h}$ ( $\mathrm{n}=7$ biological replicates). (C and D) Proliferation rate $(\mathbf{C})$ and cell death rate (D) of primary lung epithelial cells treated in co-culture with rAFSCs in transwells for $24 \mathrm{~h}(\mathrm{n}=3$ biological replicates). (E) miRNA expression of rAFSCs compared with rAFSC-EVs through miRCURY LNA SYBR qPCR. Data are shown as normalized relative expression to rMSCs and rMSC-EVs for four members of the miR17 92 family $(\mathrm{n}=3$ matched replicates per each condition). (F) Log of counts per million mapped reads (CPM) for the expression of miR17 92 family members and paralogues in primary lung epithelial cells exposed to Nitrofen $(N, n=4$, grey triangles) and Nitrofen+rAFSC-EVs (NA, n=3, pink circles) identified through small RNAsequencing analysis. Groups were compared using Kruskal-Wallis (post-hoc Dunn's nonparametric comparison) test for fig. S8 A and B, and with Mann-Whitney test for fig. S8 C and D, according to Gaussian distribution assessed by D'Agostino Pearson omnibus normality test. Groups in fig. S8 E were compared using Holm-Sidak method with alpha=5\%, each target was analyzed individually, without assuming a consistent SD. 
Table S1: Highlighted proteins expressed in rAFSC-EVs and rMSC-EVs.

\begin{tabular}{|l|l|l|l|l|}
\hline $\begin{array}{l}\text { Identified } \\
\text { proteins }\end{array}$ & $\begin{array}{l}\text { Molecular weight } \\
\mathbf{( k D a})\end{array}$ & $\begin{array}{l}\text { Average NSAF } \\
\text { rMSC }\end{array}$ & $\begin{array}{l}\text { Average NSAF } \\
\text { rAFSC }\end{array}$ & $\begin{array}{l}\text { p-value for fold change } \\
\text { rAFSC / rMSC }\end{array}$ \\
\hline Anxa1 & 39 & 0.000 & 0.017 & 0.000 \\
\hline Anxa11 & 54 & 0.000 & 0.001 & 0.122 \\
\hline Anxa2 & 39 & 0.012 & 0.019 & 0.232 \\
\hline Anxa3 & 36 & 0.000 & 0.001 & 0.374 \\
\hline Anxa4 & 36 & 0.000 & 0.003 & 0.011 \\
\hline Anxa5 & 36 & 0.000 & 0.012 & 0.000 \\
\hline Anxa6 & 76 & 0.000 & 0.012 & 0.000 \\
\hline Anxa7 & 50 & 0.000 & 0.002 & 0.000 \\
\hline Cd63 & 26 & 0.000 & 0.001 & 0.001 \\
\hline Celf1 & 52 & 0.000 & 0.000 & 0.374 \\
\hline Hnrnpa1 & 34 & 0.000 & 0.001 & 0.157 \\
\hline Hnrnpa2b1 & 32 & 0.000 & 0.001 & 0.118 \\
\hline Hnrnpc & 33 & 0.000 & 0.000 & 0.374 \\
\hline Hnrnpf & 46 & 0.000 & 0.001 & 0.001 \\
\hline Hnrnph1 & 49 & 0.000 & 0.002 & 0.000 \\
\hline Hnrnpk & 51 & 0.000 & 0.001 & 0.028 \\
\hline Hnrnp1 & 68 & 0.000 & 0.001 & 0.165 \\
\hline Hnrnpm & 74 & 0.000 & 0.001 & 0.036 \\
\hline Hnrnpu & 88 & 0.000 & 0.002 & 0.017 \\
\hline Hnrnpul2 & 85 & 0.000 & 0.000 & 0.001 \\
\hline Hspa1a & 70 & 0.000 & 0.003 & 0.000 \\
\hline Hspa2 & 70 & 0.000 & 0.001 & 0.374 \\
\hline Hspa4 & 94 & 0.000 & 0.000 & 0.374 \\
\hline Hspa5 & 72 & 0.011 & 0.010 & 0.032 \\
\hline Hspa8 & 71 & 0.000 & 0.012 & 0.575 \\
\hline Hspa9 & 74 & 0.002 & 0.000 \\
\hline Da: & & \\
\hline
\end{tabular}

$\mathrm{kDa}$ : kilodaltons

NSAF: normalized spectral abundance factor

rAFSCs: rat amniotic fluid stem cells

rMSCs: rat mesenchymal stromal cells 
Table S2: miRNAs related to lung development that are differentially expressed in rAFSC-EVs over rMSC-EVs.

\begin{tabular}{|c|c|c|c|c|c|c|c|c|c|c|}
\hline miRNA & miR ID & chr & start & end & type & rMSCs & rAFSCs & $\begin{array}{l}\log _{2} \text { Fold } \\
\text { Change }\end{array}$ & $\begin{array}{l}\text { adjusted } \\
\text { p-value }\end{array}$ & Relevance \\
\hline miR-17 & $\begin{array}{l}\text { rno-miR-17-5p } \\
\text { rno-mir-17-2 } \\
\text { rno-mir-17-1 } \\
\text { rno-miR-17-1-3p }\end{array}$ & $\begin{array}{l}\operatorname{chr} 15 \\
\operatorname{chrX} \\
\operatorname{chr} 15 \\
\operatorname{chr} 15\end{array}$ & $\begin{array}{r}103640915 \\
140167738 \\
103640902 \\
103640952\end{array}$ & $\begin{array}{l}103640937 \\
140167815 \\
103640985 \\
103640973\end{array}$ & $\begin{array}{l}+ \\
- \\
+ \\
+\end{array}$ & $\begin{array}{l}59.87 \\
59.87 \\
65.28 \\
0.71\end{array}$ & $\begin{array}{l}22473.82 \\
22473.82 \\
22863.5 \\
177.19\end{array}$ & $\begin{array}{l}8.5522 \\
8.5522 \\
8.4522 \\
7.958\end{array}$ & $\begin{array}{l}0 \\
0\end{array}$ & \multirow{3}{*}{$\begin{array}{l}\text { - control FGF10- } \\
\text { mediated embryonic } \\
\text { lung epithelial } \\
\text { branching } \\
\text { morphogenesis (69); } \\
\text { - control lung } \\
\text { progenitor cell } \\
\text { proliferation and } \\
\text { differentiation (59, } \\
69 \text {. }\end{array}$} \\
\hline miR-18 & $\begin{array}{l}\text { rno-miR-18a-5p } \\
\text { rno-mir-18a } \\
\text { rno-miR-18a-3p }\end{array}$ & $\begin{array}{l}\operatorname{chr} 15 \\
\operatorname{chr} 15 \\
\operatorname{chr} 15\end{array}$ & $\begin{array}{r}103641054 \\
103641038 \\
103641095\end{array}$ & $\begin{array}{l}103641076 \\
103641133 \\
103641115\end{array}$ & $\begin{array}{l}+ \\
+ \\
+\end{array}$ & $\begin{array}{l}3.07 \\
5.28 \\
2.2\end{array}$ & $\begin{array}{l}953.84 \\
1034.37 \\
81.58\end{array}$ & $\begin{array}{l}8.2779 \\
7.6146 \\
5.2098\end{array}$ & 0 & \\
\hline miR-19 & $\begin{array}{l}\text { rno-miR-19a-5p } \\
\text { rno-miR-19b-1-5p } \\
\text { rno-mir-19a } \\
\text { rno-miR-19a-3p } \\
\text { rno-mir-19b-2 } \\
\text { rno-miR-19b-3p } \\
\text { rno-mir-19b-1 }\end{array}$ & $\begin{array}{l}\text { chr15 } \\
\text { chr15 } \\
\text { chr15 } \\
\text { chr15 } \\
\text { chrX } \\
\text { chr15 } \\
\text { chr15 }\end{array}$ & $\begin{array}{l}103641197 \\
103641502 \\
103641185 \\
103641233 \\
140167226 \\
103641540 \\
103641487\end{array}$ & $\begin{array}{l}103641216 \\
103641523 \\
103641266 \\
103641255 \\
140167321 \\
103641562 \\
103641573\end{array}$ & $\begin{array}{l}+ \\
+ \\
+ \\
+ \\
+ \\
+ \\
+ \\
+\end{array}$ & $\begin{array}{l}0 \\
0 \\
2.71 \\
2.71 \\
16.7 \\
16.7 \\
16.7\end{array}$ & $\begin{array}{l}1.08 \\
1.05 \\
1007.59 \\
1006.52 \\
5235.41 \\
5235.41 \\
5231.7\end{array}$ & $\begin{array}{l}\text { Inf } \\
\text { Inf } \\
8.5407 \\
8.5392 \\
8.2922 \\
8.2922 \\
8.2912\end{array}$ & $\begin{array}{l}1 \\
0 \\
0\end{array}$ & \\
\hline miR-20 & $\begin{array}{l}\text { rno-miR-20a-3p } \\
\text { rno-miR-20a-5p } \\
\text { rno-mir-20a } \\
\text { rno-miR-20b-5p } \\
\text { rno-mir-20b }\end{array}$ & $\begin{array}{l}\text { chr15 } \\
\operatorname{chr} 15 \\
\operatorname{chr} 15 \\
\operatorname{chrX} \\
\operatorname{chrX}\end{array}$ & $\begin{array}{l}103641408 \\
103641372 \\
103641357 \\
140167407 \\
140167365\end{array}$ & $\begin{array}{l}103641428 \\
103641394 \\
103641441 \\
140167429 \\
140167436\end{array}$ & $\begin{array}{l}+ \\
+ \\
+ \\
+ \\
- \\
-\end{array}$ & $\begin{array}{l}0 \\
30.04 \\
30.04 \\
0.51 \\
0.51\end{array}$ & $\begin{array}{l}1.6 \\
19844.96 \\
19844.96 \\
21.61 \\
21.61\end{array}$ & $\begin{array}{l}\text { Inf } \\
9.3677 \\
9.3677 \\
5.3986 \\
5.3986\end{array}$ & $\begin{array}{l}0.8997 \\
0 \\
0 \\
0.0038 \\
0.0038\end{array}$ & \multirow{2}{*}{$\begin{array}{l}\text { - regulate embryonic } \\
\text { growth, apoptosis, } \\
\text { and fetal lung } \\
\text { development (9); } \\
\text { - regulate surfactant } \\
\text { protein C secretion } \\
\text { (miR19b and 92a) } \\
(70) ;\end{array}$} \\
\hline miR-92 & $\begin{array}{l}\text { rno-miR-92b-5p } \\
\text { rno-miR-92a-1-5p } \\
\text { rno-mir-92a-1 } \\
\text { rno-miR-92a-3p } \\
\text { rno-mir-92a-2 } \\
\text { rno-mir-92b } \\
\text { rno-miR-92b-3p }\end{array}$ & $\begin{array}{l}\text { chr2 } \\
\text { chr15 } \\
\text { chr15 } \\
\text { chr15 } \\
\text { chrX } \\
\text { chr2 } \\
\text { chr2 }\end{array}$ & $\begin{array}{l}207955729 \\
103641619 \\
103641609 \\
103641656 \\
140167096 \\
207955680 \\
207955690\end{array}$ & $\begin{array}{l}207955752 \\
103641641 \\
103641686 \\
103641676 \\
140167187 \\
207955762 \\
207955711\end{array}$ & $\begin{array}{l}- \\
+ \\
+ \\
+ \\
+\end{array}$ & $\begin{array}{l}0.2 \\
2.2 \\
1466.75 \\
447.53 \\
447.53 \\
404.68 \\
404.48\end{array}$ & $\begin{array}{l}1.62 \\
15.58 \\
3152.85 \\
519.1 \\
519.1 \\
109.76 \\
108.14\end{array}$ & $\begin{array}{l}3.0149 \\
2.8214 \\
1.104 \\
0.214 \\
0.214 \\
-1.8824 \\
-1.9032\end{array}$ & $\begin{array}{l}1 \\
0.1041 \\
0.0346 \\
1 \\
1 \\
0.1754 \\
0.1696\end{array}$ & \\
\hline miR-106 & $\begin{array}{l}\text { rno-miR-106b-5p } \\
\text { rno-mir-106b } \\
\text { rno-miR-106b-3p }\end{array}$ & $\begin{array}{l}\operatorname{chr} 12 \\
\operatorname{chr} 12 \\
\operatorname{chr} 12\end{array}$ & $\begin{array}{l}21365432 \\
21365382 \\
21365391\end{array}$ & $\begin{array}{l}21365452 \\
21365463 \\
21365412\end{array}$ & - & $\begin{array}{l}12.55 \\
302.19 \\
289.64\end{array}$ & $\begin{array}{l}2451.88 \\
12390.58 \\
9939.25\end{array}$ & $\begin{array}{l}7.6103 \\
5.3576 \\
5.1008\end{array}$ & 0 & \multirow{2}{*}{$\begin{array}{l}\text { - are involved in } \\
\text { alveolarization } \\
\text { processes (mir17) } \\
(71) .\end{array}$} \\
\hline miR-363 & $\begin{array}{l}\text { rno-miR-363-3p } \\
\text { rno-mir-363 }\end{array}$ & $\begin{array}{l}\operatorname{chrX} \\
\operatorname{chrX}\end{array}$ & $\begin{array}{l}140166956 \\
140166945\end{array}$ & $\begin{array}{l}140166976 \\
140167031\end{array}$ & - & $\begin{array}{l}3.21 \\
4.49\end{array}$ & 3.72 & $\begin{array}{l}0.2128 \\
-0.2719\end{array}$ & 1 & \\
\hline
\end{tabular}




\begin{tabular}{|l|lllllllll|}
\multirow{3}{*}{ miR-93 } & rno-miR-93-5p & chr12 & 21365223 & 21365245 & - & 953.63 & 108642.09 & 6.8319 & 0 \\
& rno-mir-93 & chr12 & 21365173 & 21365259 & - & 955.42 & 108717.23 & 6.8302 & 0 \\
& rno-miR-93-3p & chr12 & 21365185 & 21365207 & - & 1.79 & 75.15 & 5.3896 & 0 \\
\hline \multirow{2}{*}{ miR-25 } & rno-miR-25-3p & chr12 & 21364981 & 21365002 & - & 5238.63 & 83820.36 & 4 & 0 \\
& rno-mir-25 & chr12 & 21364970 & 21365053 & - & 5262.06 & 83911.87 & 3.9952 & 0 \\
& rno-miR-25-5p & chr12 & 21365019 & 21365040 & - & 23.43 & 90.98 & 1.9574 & 0.0033 \\
\hline
\end{tabular}

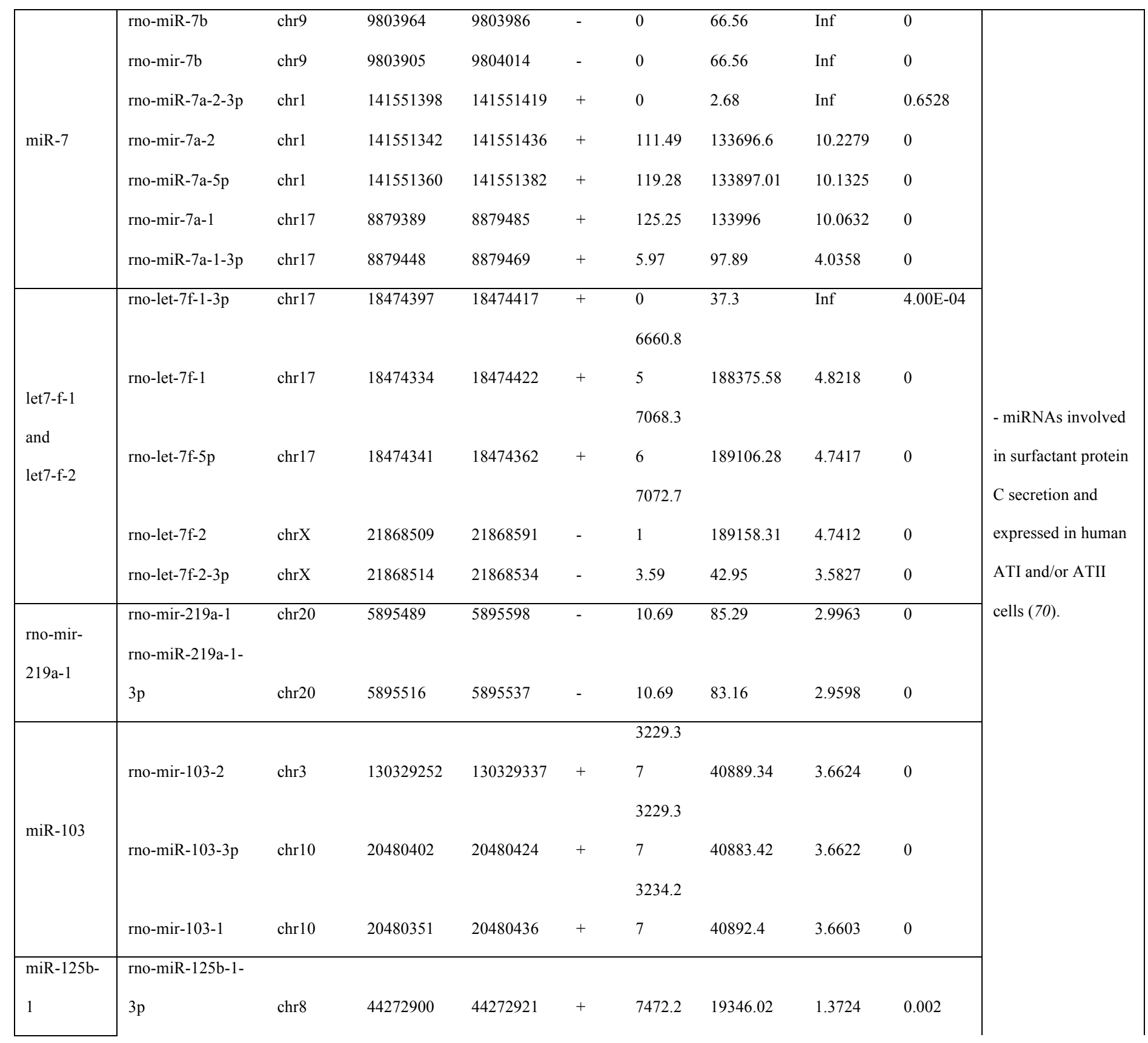




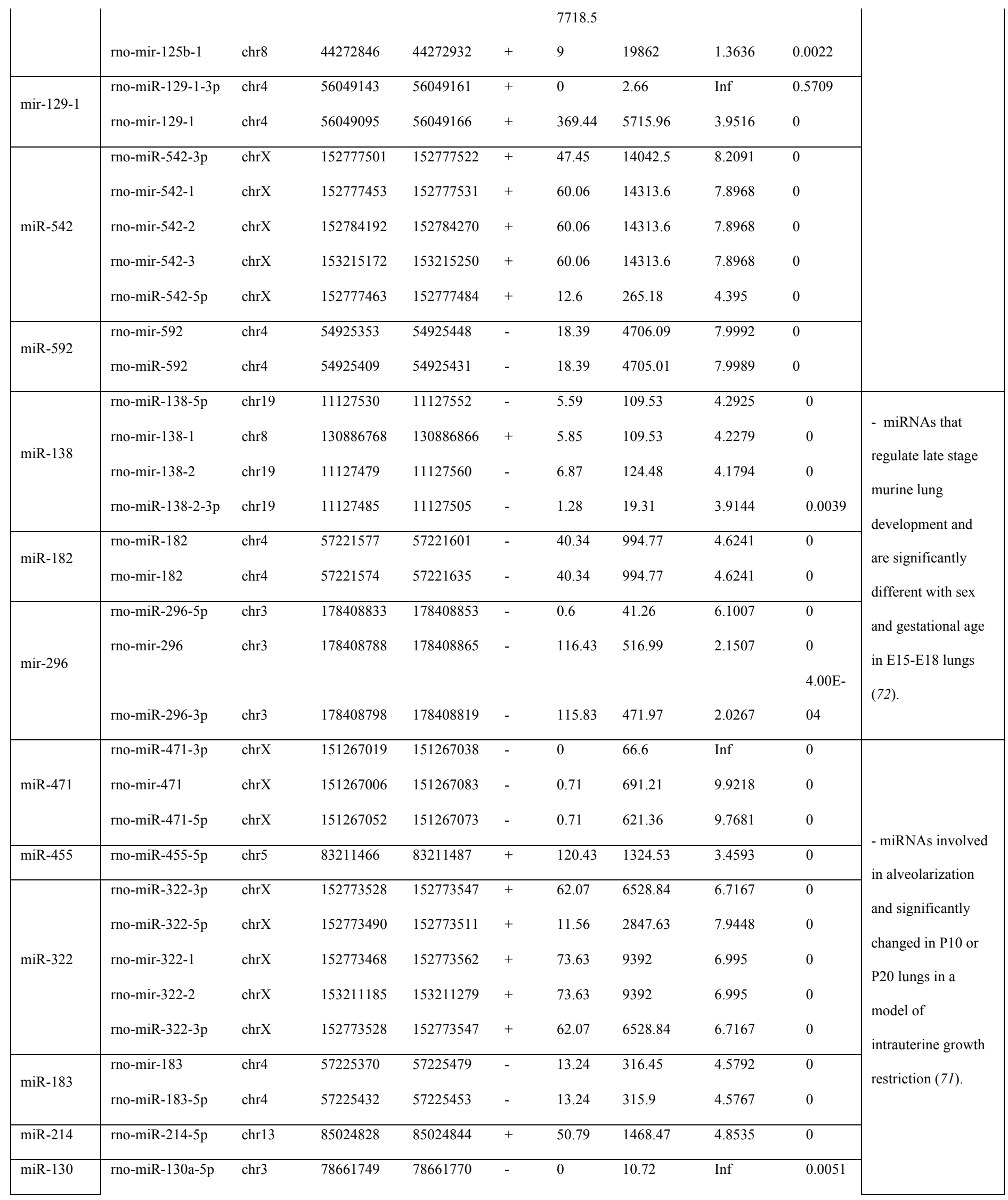




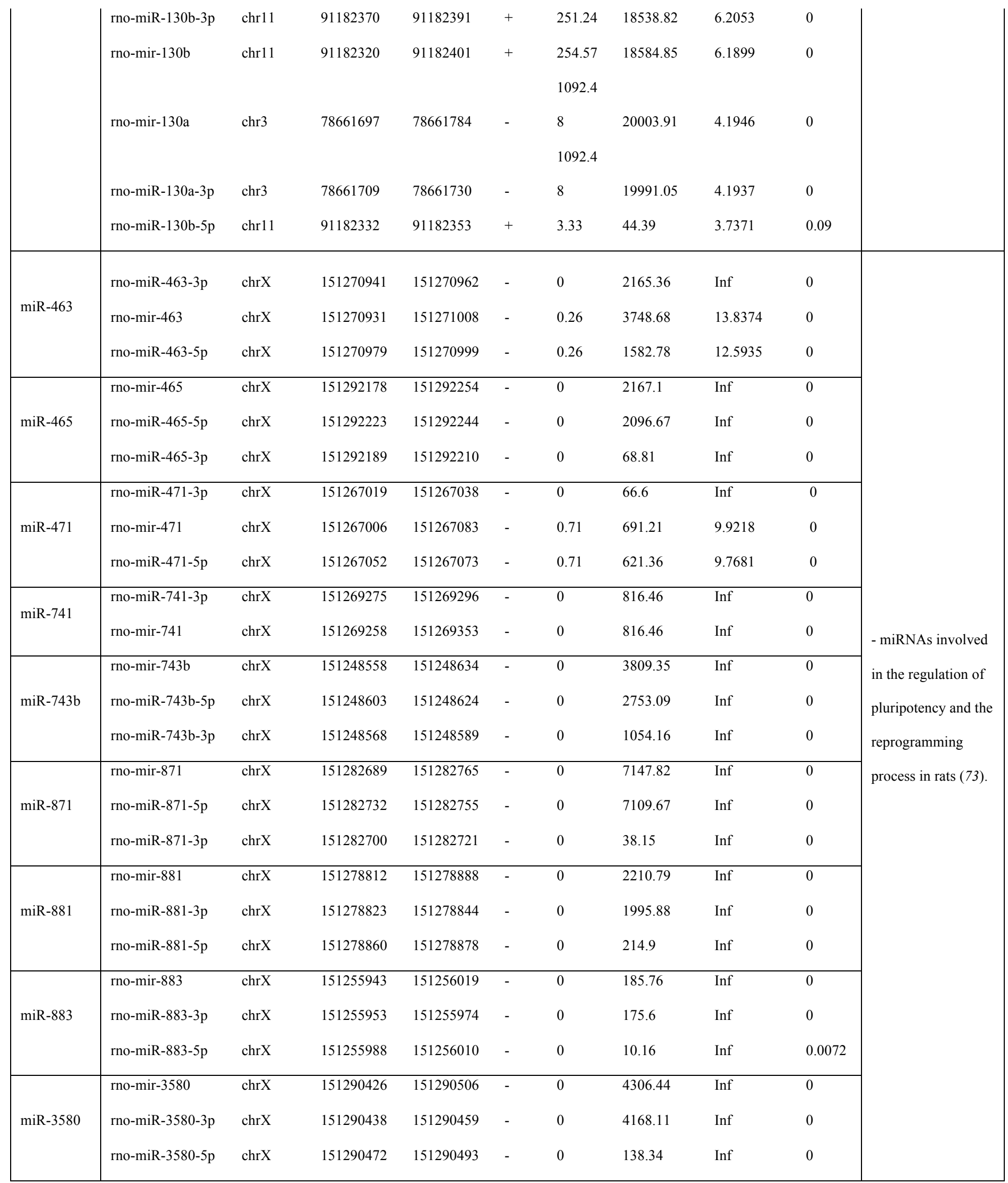


miR: miRNA; rAFSCs: rat amniotic fluid stem cells; rMSCs: rat mesenchymal stem cells; chr: chromosome; inf: infinity; ATI: alveolar type I cells; ATII: alveolar type II cells. 
Table S3: miRNAs known to be involved in pulmonary hypoplasia and present in rAFSC-EVs.

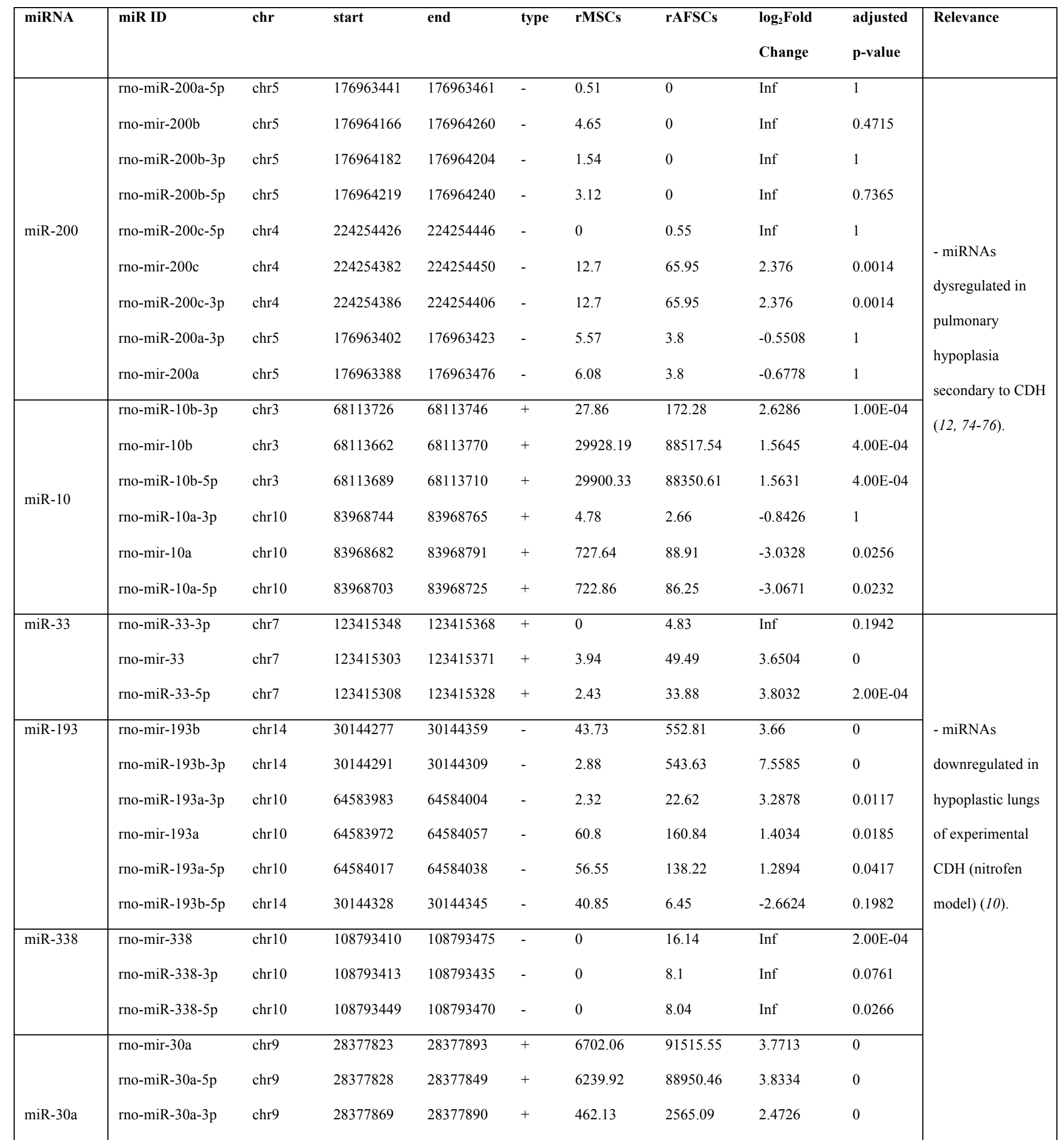




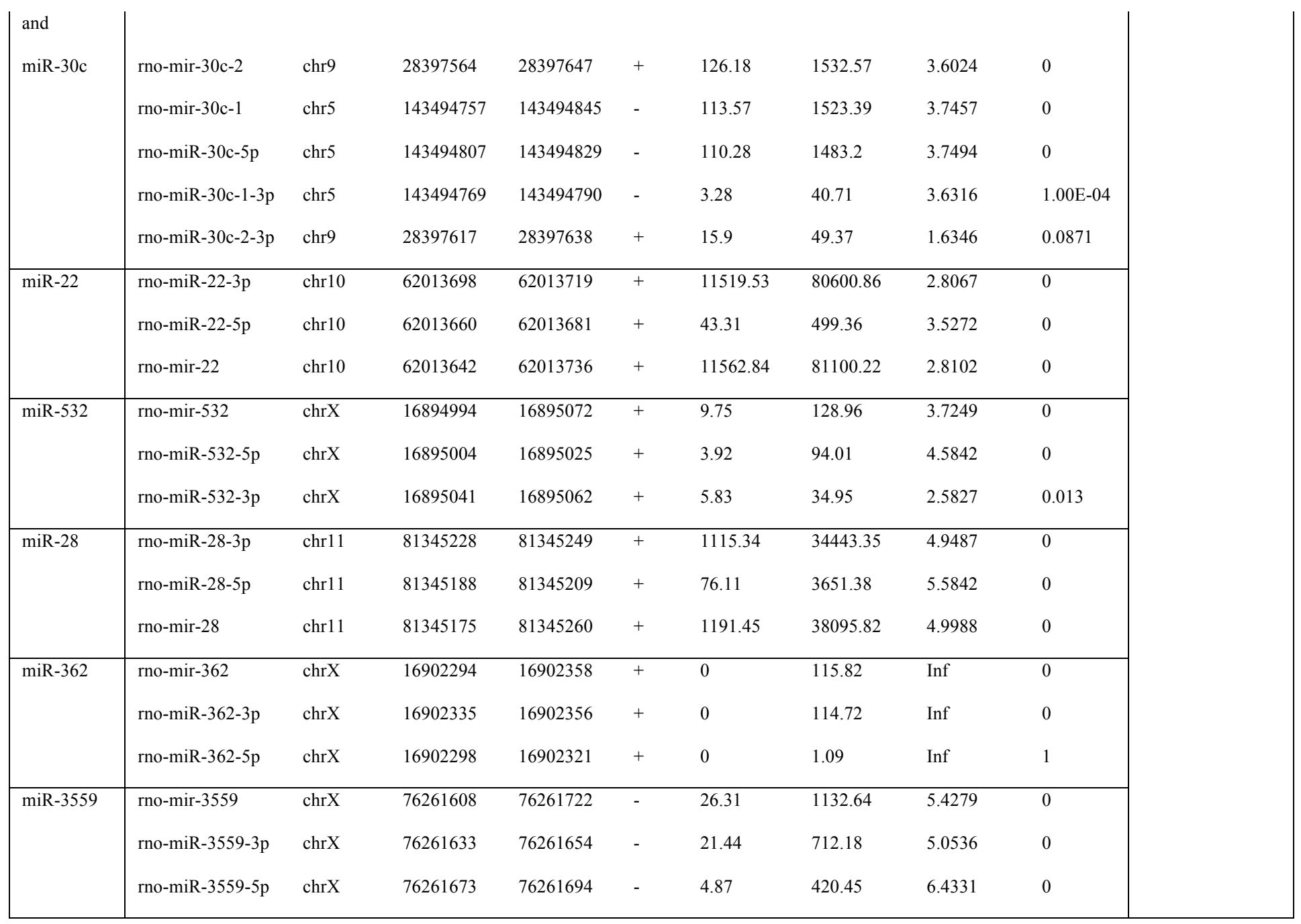

miR: miRNA; rAFSCs: rat amniotic fluid stem cells; rMSCs: rat mesenchymal stem cells; chr: chromosome; inf: infinity. 
Table S4: Genes differentially expressed in nitrofen-injured lung epithelial cells

\begin{tabular}{|c|c|c|c|}
\hline Gene & Name & Link to lung development or epithelial homeostasis & Ref. \\
\hline \multicolumn{4}{|c|}{ Down-regulated } \\
\hline Nkx2.1 & NK2 Homeobox 1 & $\begin{array}{l}\text { Essential regulator of lung development and a marker of } \\
\text { early lung epithelial progenitor }\end{array}$ & $(77)$ \\
\hline Hipk2 & $\begin{array}{l}\text { Homeodomain Interacting } \\
\text { Protein Kinase } 2\end{array}$ & NKX2-1 binding partner & $(78)$ \\
\hline Alcam & $\begin{array}{l}\text { Activated Leukocyte Cell } \\
\text { Adhesion Molecule }\end{array}$ & Marker of type II alveolar epithelial cells & (79) \\
\hline $\mathrm{Mxd} 4$ & $\begin{array}{l}\text { MAX Dimerization } \\
\text { Protein } 4\end{array}$ & $\begin{array}{l}\text { Highly prioritized gene in neonates with pulmonary } \\
\text { hypoplasia /CDH }\end{array}$ & $(80)$ \\
\hline Arg2 & Arginase 2 & $\begin{array}{l}\text { Overexpressed gene in neonates with pulmonary } \\
\text { hypoplasia/CDH }\end{array}$ & $(81)$ \\
\hline Fgfr3 & $\begin{array}{l}\text { Fibroblast Growth Factor } \\
\text { Receptor } 3\end{array}$ & $\begin{array}{l}\text { Upregulation of FGFR3 disrupts alveologenesis in } \\
\text { experimental and human pulmonary hypoplasia/CDH. }\end{array}$ & $(80,82)$ \\
\hline Sult1a1 & $\begin{array}{l}\text { Sulfotransferase Family } \\
\text { 1A Member } 1\end{array}$ & $\begin{array}{l}\text { Upregulated in hypoxic lung injury, and required for } \\
\text { nitrofen activation and mutagenicity }\end{array}$ & $(83,84)$ \\
\hline Dusp1 & $\begin{array}{l}\text { Dual Specificity } \\
\text { Phosphatase } 1\end{array}$ & $\begin{array}{l}\text { Negatively regulates autophagy, a process required for } \\
\text { fetal lung branching morphogenesis }\end{array}$ & $(85,86)$ \\
\hline Sqstm1 & Sequestosome 1 & $\begin{array}{l}\text { Marker of autophagy impairment increased in stressed } \\
\text { conditions }\end{array}$ & $(86,87)$ \\
\hline Ncao4 & $\begin{array}{l}\text { Nuclear Receptor } \\
\text { Coactivator } 4\end{array}$ & Involved in ferritin turnover and autophagy regulation & $(88)$ \\
\hline Herpud1 & $\begin{array}{l}\text { Homocysteine Inducible } \\
\text { ER Protein With Ubiquitin } \\
\text { Like Domain } 1\end{array}$ & $\begin{array}{l}\text { Involved in ER stress response, a critical process for } \\
\text { tissue homeostasis that is dysregulated in pulmonary } \\
\text { hypoplasia }\end{array}$ & $(40,89)$ \\
\hline Cdkn1c & Cyclin Dependent Kinase & Highly expressed in pulmonary hypoplasia & $(90)$ \\
\hline
\end{tabular}




\begin{tabular}{|c|c|c|c|}
\hline & Inhibitor $1 \mathrm{C}$ & & \\
\hline Fuca2 & Alpha-L-Fucosidase 2 & Involved in repair of damaged lung epithelial cells & $(91)$ \\
\hline Clic3 & $\begin{array}{l}\text { Chloride Intracellular } \\
\text { Channel } 3\end{array}$ & $\begin{array}{l}\text { Activator of MAPK signaling, a pathway that is } \\
\text { upregulated in nitrofen-injured lung epithelial cells }\end{array}$ & $(61,92)$ \\
\hline Sesn 1 & Sestrin 1 & $\begin{array}{l}\text { Repressor of PDGFR } \beta \text { signaling, a pathway that is } \\
\text { dysregulated in nitrofen lungs }\end{array}$ & $(93)$ \\
\hline Flcn & Folliculin & $\begin{array}{l}\text { Involved in EGFR signaling, a pathway that is down- } \\
\text { regulated in pulmonary hypoplasia. }\end{array}$ & $(94,95)$ \\
\hline \multicolumn{4}{|c|}{ Up-regulated } \\
\hline Flna & Filamin A & $\begin{array}{l}\text { Actin-binding protein involved in ciliogenesis, FLNA } \\
\text { mutations are associated with severe diffuse lung disease } \\
\text { and alveolar simplification }\end{array}$ & $(96,97)$ \\
\hline Pdlim5 & PDZ And LIM Domain 5 & $\begin{array}{l}\text { Scaffolding protein that is required for TGF- } \beta / \text { Smad } \\
\text { signaling in alveolar epithelial cells, and that prevents } \\
\text { hypoxia-induced pulmonary hypertension }\end{array}$ & $(98)$ \\
\hline Gldn & Gliomedin & $\begin{array}{l}\text { ECM matrix glycoprotein (up-regulated by TGF- } \beta \\
\text { signaling) }\end{array}$ & $(99)$ \\
\hline Igflr & $\begin{array}{l}\text { Insulin Like Growth } \\
\text { Factor } 1 \text { Receptor }\end{array}$ & $\begin{array}{l}\text { Involved in epithelial proliferation and differentiation, } \\
\text { (downregulated in nitrofen) }\end{array}$ & $(32)$ \\
\hline Gnaq & $\begin{array}{l}\text { G Protein Subunit Alpha } \\
\text { Q }\end{array}$ & $\begin{array}{l}\text { Nucleotide-binding protein expressed in alveolar Type II } \\
\text { epithelial cells that controls surfactant homeostasis }\end{array}$ & $(100)$ \\
\hline Myh911 & $\begin{array}{l}\text { Myosin Heavy Chain } 9 \\
\text { non-muscle-like } 1\end{array}$ & $\begin{array}{l}\text { Protein important for epithelial cell tight junction } \\
\text { formation }\end{array}$ & $(101)$ \\
\hline Clic1 & $\begin{array}{l}\text { Chloride Intracellular } \\
\text { Channel } 1\end{array}$ & $\begin{array}{l}\text { Mitochondria and ER chloride channel protein that } \\
\text { regulates redox balance and ER stress }\end{array}$ & $(40,102)$ \\
\hline Hikeshi & Heat Shock Protein & Nuclear transport receptor required for organization and & $(103)$ \\
\hline
\end{tabular}




\begin{tabular}{|l|l|l|l|} 
& $\begin{array}{l}\text { Nuclear Import Factor } \\
\text { Hikeshi }\end{array}$ & function of the secretory apparatus in club cells & \\
\hline Cxcl2 & $\begin{array}{l}\text { C-X-C Motif Chemokine } \\
\text { Ligand 2 }\end{array}$ & $\begin{array}{l}\text { Cytokine that stimulates proliferation in rat alveolar } \\
\text { epithelial cells. }\end{array}$ & $(104)$ \\
& &
\end{tabular}


Table S5: Inter-species conservation of top enriched miRNA in hAFSC-EVs

\begin{tabular}{|c|c|c|}
\hline Human miRNA & Rabbit miRNA orthologue & Sequence \\
\hline hsa-let-7b-5p & ocu-let-7b & 5'-UGAGGUAGUAGGUUGUGUGGUU-3` \\
\hline hsa-miR-23a-3p & ocu-miR-23b-3p & 5'-AUCACAUUGCCAGGGAUUUCC-3’' \\
\hline hsa-miR-24-3p & ocu-miR-24-3p & 5'-UGGCUCAGUUCAGCAGGAACAG-3' \\
\hline hsa-miR-31-5p & ocu-miR-31-5p & 5'AGGCAAGAUGCUGGCAUAGCU-3` \\
\hline hsa-miR-92a-3p & ocu-miR-92a-3p & 5 '-UAUUGCACUUGUCCCGGCCUGU-3' \\
\hline hsa-miR-100-5p & ocu-miR-100-5p & 5’AACCCGUAGAUCCGAACUUGUG-3` \\
\hline hsa-miR-103a-3p & ocu-miR-103a-3p & 5'AGCAGCAUUGUACAGGGCUAUGA-3' \\
\hline hsa-miR-107 & ocu-miR-107-3p & 5'AGCAGCAUUGUACAGGGCUAUCA-3' \\
\hline hsa-miR-221-3p & ocu-miR-221-3p & 5'AGCUACAUUGUCUGCUGGGUUUC-3’ \\
\hline hsa-miR-222-3p & ocu-miR-222-3p & 5'-AGCUACAUCUGGCUACUGGGU-3’' \\
\hline hsa-miR-23b-3p & ocu-miR-23b-3p & $5^{\prime}$-AUCACAUUGCCAGGGAUUACCAC-3' \\
\hline hsa-miR-125b-5p & ocu-miR-125b-5p & 5 '-UCCCUGAGACCCUAACUUGUGA-3’ \\
\hline hsa-miR-145-5p & ocu-miR-145-5p & $5^{`}$-GUCCAGUUUUCCCAGGAAUCCCU-3` \\
\hline hsa-miR-320c & ocu-miR-197-3p & 5’AAAAGCUGGGUUGAGAGGGU-3` \\
\hline hsa-miR-3613-3p & ocu-miR-3613-3p & 5'-ACAAAAAAAAAAGCCCAACCCUUC-3 \\
\hline
\end{tabular}


Table S6: Primer sequences used in this study

\begin{tabular}{|c|c|}
\hline Target & Primer sequence \\
\hline rat Gapdh-F & 5'-GGGTGTGAACCACGAGAAAT-3’ \\
\hline rat Gapdh-R & 5'-ACTGTGGTCATGAGCCCTTC-3’ \\
\hline rat Fgf10-F & 5'-CCACATACATTTGCCTGCCG-3` \\
\hline rat Fgf10-R & 5'-GGGGAAACTCTATGGCTCAAAAG-3` \\
\hline rat Vegfa-F & 5'-AGAAAGCCCATGAAGTGGTGA-3’ \\
\hline rat Vegfa $-\mathrm{R}$ & 5'-TCTCATCGGGGTACTCCTGG-3’ \\
\hline rat Flt1-F & 5'-GTACCTCACCGTGCAAGGAA-3’ \\
\hline rat Flt1-R & 5'-TTCGGAAGAAGACCGCTTCA-3’ \\
\hline rat Kdr-F & 5’-CTGCAGGACCAAGGCAACTA-3’ \\
\hline rat Kdr-R & 5'-CATGCGCTCTAGGATGACGA-3` \\
\hline rabbit RPLP0-F & 5`CTGTGCCAGCTCAGAACACT-3` \\
\hline rabbit RPLP0-R & 5’-TGCACGTCGCTCAGGATTTC-3` \\
\hline rabbit PLIN-2-F & 5'-TGCTGAGCACATCGAGTCAC-3’ \\
\hline rabbit PLIN-2-R & 5'ATGTTGGACAGGAGGCTGTG-3’' \\
\hline rabbit BMP2-F & 5’-GGAAGCTTTGGGAGACGACA-3` \\
\hline rabbit BMP2-R & 5`-TTTCGAGTTGGCTGTTGCAG-3` \\
\hline rabbit BMP4-F & 5'-CTTCCACCACGAAGAACATCTG-3’ \\
\hline rabbit BMP4-R & 5'ATGGCCTCGTTCTCTGGGAT-3` \\
\hline rabbit Id1-F & 5`-TTCTACAACCGTCTCCTGCG-3` \\
\hline rabbit Id1-R & 5'-CTGGCGACCTTCATGGTTCT-3’ \\
\hline
\end{tabular}


Table S7: Details of antibodies used in this study

\begin{tabular}{|c|c|c|c|c|c|c|c|c|}
\hline \multirow[t]{2}{*}{ Target } & \multirow[t]{2}{*}{ Antibody } & \multirow[t]{2}{*}{ Company } & \multicolumn{2}{|c|}{ Lung explants } & \multicolumn{2}{|c|}{ Organoids } & \multicolumn{2}{|c|}{$\begin{array}{c}\text { Primary epithelial } \\
\text { cells }\end{array}$} \\
\hline & & & $1^{\circ}$ & $2^{\circ}$ & $1^{\circ}$ & $2^{\circ}$ & $1^{\circ}$ & $2^{\circ}$ \\
\hline SPC & ab40879 & $\begin{array}{l}\text { Abcam } \\
\text { (Cambridge, } \\
\text { UK) }\end{array}$ & $1: 500$ & $1: 1,000$ & $1: 200$ & $1: 1,000$ & $1: 200$ & $1: 1,000$ \\
\hline SOX9 & HPA001758 & $\begin{array}{l}\text { SigmaAldrich } \\
\text { (St Louis, MO) }\end{array}$ & $1: 500$ & $1: 1,000$ & - & - & - & - \\
\hline Ki67 & ab15580 & $\begin{array}{l}\text { Abcam } \\
\text { (Cambridge, } \\
\text { UK) }\end{array}$ & - & - & $1: 100$ & $1: 1,000$ & - & - \\
\hline $\mathrm{CC} 10$ & sc-365992 & $\begin{array}{l}\text { SantaCruz } \\
\text { Biotechnology } \\
\text { (Dallas, TX) }\end{array}$ & - & - & $1: 50$ & $1: 1,000$ & - & - \\
\hline Vimentin & ab92547 & $\begin{array}{l}\text { Abcam } \\
\text { (Cambridge, } \\
\text { UK) }\end{array}$ & - & - & - & - & $1: 100$ & $1: 1,000$ \\
\hline
\end{tabular}

\begin{tabular}{|l|l|l|c|c|c|c|}
\hline Target & \multicolumn{1}{|c|}{ Antibody } & \multicolumn{1}{c|}{ Company } & \multicolumn{2}{c|}{ Western Blot } & \multicolumn{2}{c|}{ ImmunoEM } \\
\cline { 4 - 6 } & & & $\mathbf{1}^{\circ}$ & $\mathbf{2}^{\circ}$ & $\mathbf{1}^{\circ}$ & $\mathbf{2}^{\circ}$ \\
\hline TSG101 & sc-7964 & $\begin{array}{l}\text { Santa Cruz Biotechnology, } \\
\text { Dallas, TX }\end{array}$ & $1: 500$ & $1: 3,000$ & $1: 100$ & - \\
\hline $\begin{array}{l}\text { Goat-anti- } \\
\text { mouse IgG } \\
\text { (H\&L) }\end{array}$ & $\begin{array}{l}25128 \\
\text { EM-grade 10nm gold } \\
\text { tag }\end{array}$ & $\begin{array}{l}\text { Electron Microscopy } \\
\text { Sciences, Hatfield, PA }\end{array}$ & - & - & - & $1: 25$ \\
\hline RNase & PA578151 & $\begin{array}{l}\text { Thermofisher Scientific, } \\
\text { Waltham, Massachusetts }\end{array}$ & - & - & $1: 100$ & - \\
\hline $\begin{array}{l}\text { Goat-anti- } \\
\text { rabbit IgG } \\
\text { (H\&L) }\end{array}$ & $\begin{array}{l}25116 \\
\text { EM-grade 25nm gold } \\
\text { tag }\end{array}$ & $\begin{array}{l}\text { Electron Microscopy } \\
\text { Sciences, Hatfield, PA }\end{array}$ & - & - & - & $1: 25$ \\
\hline CD63 & EXOAB-KIT-1 & $\begin{array}{l}\text { System Biosciences, Palo } \\
\text { Alto, CA }\end{array}$ & $1: 1,000$ & $1: 10,000$ & - & - \\
\hline Flo-1 & 610820 & $\begin{array}{l}\text { BD Transduction } \\
\text { Laboratories, San Jose, CA }\end{array}$ & $1: 1,000$ & $1: 3,000$ & - & - \\
\hline Hsp70 & EXOAB-KIT-1 & $\begin{array}{l}\text { System Biosciences, Palo } \\
\text { Alto, CA }\end{array}$ & $1: 1,000$ & $1: 10,000$ & - & - \\
\hline
\end{tabular}

SPC: surfactant protein C,

SOX

9: SRY-Box 9,

Ki67: marker of proliferation Ki67,

CC10: Clara Cells 10 KDa Secretory Protein,

TSG101: Tumor susceptibility gene 101, 
Flo-1: Flotillin 1,

Hsp70: Heat Shock Protein 70 